\title{
1 Cryo-EM structures reveal high-resolution mechanism of a DNA polymerase sliding clamp loader
}

\author{
4 Christl Gaubitz ${ }^{a}$, Xingchen Liv ${ }^{a}$, Joshua Pajak ${ }^{a}$, Nicholas P. Stone ${ }^{a}$, Janelle A. Hayes ${ }^{a}$, Gabriel Demo ${ }^{b}$, Brian A \\ Kelch $^{\text {af }}$ \\ $7{ }^{\text {a }}$ Department of Biochemistry and Molecular Pharmacology, University of Massachusetts Chan Medical School, Worcester MA \\ $8{ }^{b}$ RNA Therapeutics Institute, University of Massachusetts Chan Medical School, Worcester MA \& Central European Institute of \\ 9 Technology, Masaryk University, Brno, Czech Republic \\ 10 I Correspondence: brian.kelch@umassmed.edu, address: 364 Plantation St., Worcester MA 01605, phone: 508-856-8322
}

\section{SUMMARY}

12 Sliding clamps are ring-shaped protein complexes that are integral to the DNA replication machinery of all life. Sliding 13 clamps are opened and installed onto DNA by clamp loader AAA+ ATPase complexes. However, how a clamp loader 14 opens and closes the sliding clamp around DNA is still unknown. Here, we describe structures of the S. cerevisiae clamp 15 loader Replication Factor C (RFC) bound to its cognate sliding clamp Proliferating Cell Nuclear Antigen (PCNA) en route 16 to successful loading. RFC first binds to PCNA in a dynamic, closed conformation that blocks both ATPase activity and 17 DNA binding. RFC then opens the PCNA ring through a large-scale 'crab-claw' expansion of both RFC and PCNA that 18 explains how RFC prefers initial binding of PCNA over DNA. Next, the open RFC:PCNA complex binds DNA and 19 interrogates the primer-template junction using a surprising base-flipping mechanism. Our structures indicate that initial 20 PCNA opening and subsequent closure around DNA do not require ATP hydrolysis, but are driven by binding energy. ATP 21 hydrolysis, which is necessary for RFC release, is triggered by interactions with both PCNA and DNA, explaining RFC's 22 switch-like ATPase activity. Our work reveals how a AAA+ machine undergoes dramatic conformational changes for 23 achieving binding preference and substrate remodeling.

24

25 Keywords: sliding clamp, DNA replication, AAA+, ATPase, clamp loader

\section{INTRODUCTION}

27 In all known cellular life, DNA replication is coordinated by ring28 shaped sliding clamp proteins that wrap around DNA to activate DNA 29 polymerases and other factors (Moldovan et al., 2007). Sliding clamps 30 are regulated by their presence on DNA, which in turn is governed by 31 clamp loaders that open the sliding clamp ring and place it onto DNA 32 (Kelch, 2016). The clamp loader of eukaryotes Replication Factor $\underline{C}$ 33 (RFC) installs the sliding clamp Proliferating Cell Nuclear Antigen 34 (PCNA) in a coordinated and stepwise fashion (Kelch, 2016). First, RFC 35 binds ATP, which is a prerequisite for tight binding to PCNA (Sakato et 36 al., 2012). Next, RFC binds to PCNA, and then opens the PCNA ring. 37 This open ternary complex is now competent to bind to primer38 template ( $\mathrm{p} / \mathrm{t}$ ) DNA (double-stranded DNA with a single-stranded 5' 39 overhang). Primer-template binding to the ternary complex triggers 40 ATP hydrolysis in the clamp loader, followed by sliding clamp closure 41 and ultimately release of the clamp loader complex (Chen et al., 2009). 42 Therefore, RFC has two macromolecular substrates, PCNA and p/t-
43 DNA, that must bind sequentially. Yet how clamp loaders achieve this 44 strict sequential order remains unknown.

45 Clamp loaders are members of the ATPases associated with 46 various cellular activities (AAA+) family (Erzberger and Berger, 2006). 47 Most members of this family function as ringed, homohexameric 48 molecular motors that harvest energy from ATP to translocate 49 substrates through their central pore (Jessop et al., 2021). However, 50 clamp loaders are not motors but instead are ATP-dependent 51 remodeling switches (Kelch, 2016). In contrast to typical AAA+ 52 ATPases, clamp loaders are heteropentameric with the five different 53 subunits called A-E (Figures $1 A \& B$ ). Each subunit features a classic 54 AAA+ ATPase module, which holds the ATP sandwiched between the 55 Rossmann fold and Lid domain at the binding interface with the 56 neighboring subunit. The AAA + modules of every subunit are 57 extended by collar domains, which tightly associate together into a 58 flat disk, enabling dynamic interactions between the five AAA+ 59 modules. 
A

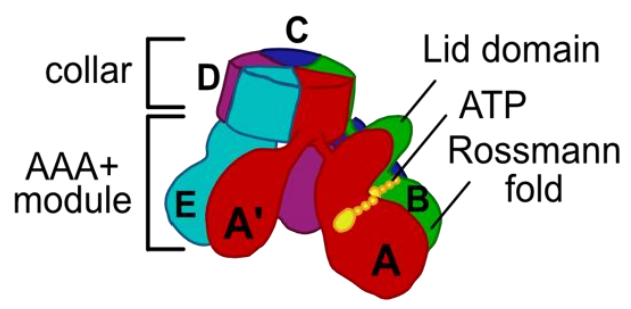

B

\begin{tabular}{|c|c|c|c|c|}
\hline \multicolumn{5}{|c|}{ A (RFC1) } \\
\hline BRC & & ATPase & collar | & \\
\hline B (RFC4) & \multicolumn{4}{|c|}{$\mathrm{D}(\mathrm{RFC2})$} \\
\hline ATPase & collar & & ATPase & collar \\
\hline $\mathrm{C}$ (RFC3) & \multicolumn{4}{|c|}{$E$ (RFC5) } \\
\hline ATPase & collar & & ATPast & collar \\
\hline
\end{tabular}

C

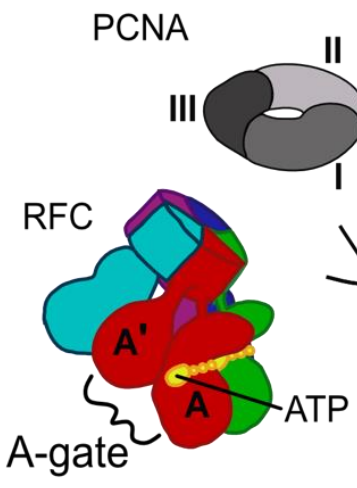

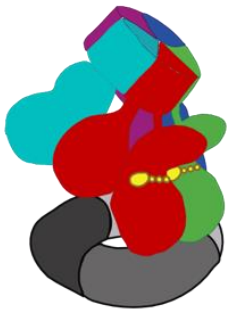

primer/template DNA

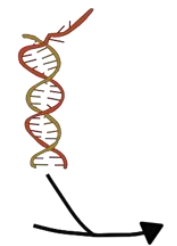

initial RFC:PCNA closed complex human RFC:PCNA, ATP analog (PDB 6VVO) yeast RFC:PCNA, ATP analog (PDB 1SXJ)

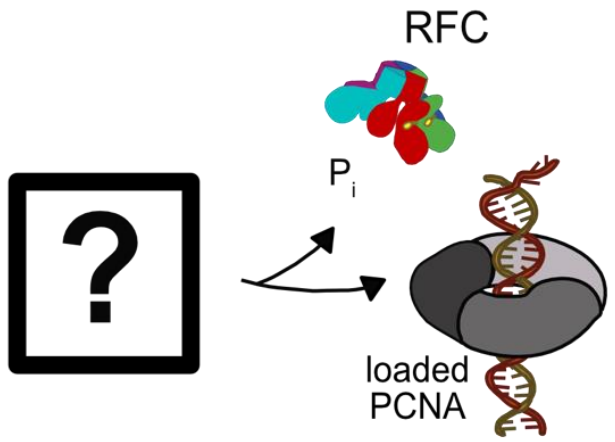

Figure 1. Architecture of the eukaryotic clamp loader (RFC) and clamp (PCNA). (A) RFC is composed of five different subunits (named A to E) that each consist of the AAA+ATPase module and a collar domain. The nucleotide binding site is sandwiched between the $\mathrm{N}$-terminal Rossmann fold domain and the Lid domain of the ATPase module at the subunit interface. The ATPase module and a C-terminal extension of the A subunit called the $A^{\prime}$-domain form the A-gate. (B) Domain organization of RFC subunits. (C) Clamp loading begins with binding of ATP to RFC, followed by PCNA binding. How PCNA is opened and DNA binds to the open RFC:PCNA complex is not known. DNA binding triggers ATP hydrolysis, PCNA closure, and RFC ejection. Structures obtained prior for RFC:PCNA complexes are indicated (Bowman et al. 2004; Gaubitz et al. 2020).

60 In addition to the canonical AAA+ machinery, many clamp loaders 61 contain an $A^{\prime}$ domain that bridges the gap between the $A$ and the $E$ 62 subunit. The space between the $A^{\prime}$ domain and the AAA+ domain of 63 subunit $A$ is the "A-gate", (Figure ${ }_{1 C} C$ ), which serves as the entry site for $64 \mathrm{p} / \mathrm{t}$-DNA binding. It was initially proposed that ATP binding triggers 65 the five AAA+ modules to form a spiral with a symmetrical pitch that 66 matches the geometry of DNA and templates the open clamp 67 (Bowman et al., 2004; Simonetta et al., 05/2009, Table 1). This 68 symmetric, helical arrangement of the subunits results in a cracked 69 interface between the $A$ and $E$ subunits, bridged by the $A^{\prime}$ domain. As 70 the $A^{\prime}$ domain stretches away from the A subunit to maintain contact, 71 the A-gate opens and permits p/t-DNA binding (Kelch et al., 2011). 72 However, structures of the human and yeast RFC:PCNA complexes 73 bound to ATP analog show a closed PCNA ring bound to RFC in an 74 autoinhibited state, where the closed A-gate blocks the DNA binding 75 (Bowman et al. 2004; Gaubitz et al. 2020, Table 1). Additionally, 76 another element called the "E-plug" reaches into RFC's central 77 chamber and sterically occludes DNA binding. This autoinhibited state 78 of RFC bound to closed PCNA is likely the first intermediate in the 79 clamp loading reaction (Gaubitz et al., 2020b; Sakato et al., 02/2012; 80 Thompson et al., 2012).

81 The question remains: How does the clamp loader open the sliding 82 clamp? This is perhaps the most important function of the clamp 83 loader, yet clues as to how this process is achieved remain elusive
84 (Figure $1 \mathrm{C}$ ). The structure of the $\mathrm{T}_{4}$ phage loader bound to DNA and 85 an open clamp indicated that the clamp adopts a right-handed spiral 86 conformation that matches the helical pitch of DNA (Kelch et al., 87 2011). However, this structure represents the state after DNA is bound 88 (Table 1), and does not address how the clamp ring is initially opened. 89 Thus, the structure of a clamp loader bound to an open clamp without 90 DNA has been sought after, as it will illuminate the opening process.

\section{RESULTS}

\section{Structures of RFC:PCNA complexes en route to DNA loading}

93 To understand how RFC opens PCNA and subsequently binds DNA, 94 we used single-particle cryo-EM to determine structures of full-length 95 S. cerevisiae RFC bound to PCNA and the slowly hydrolyzing ATP 96 analog ATPYS in the presence and absence of primer-template $(p / t)$ 97 DNA. We reconstituted the complex from purified RFC and PCNA 98 subcomplexes that were separately expressed in E. coli (Figure 1 99 Supplement $1 \mathrm{~A}$ ). Full-length RFC is functional, as it has the expected 100 ATPase activity profile (McNally et al., 2010) with PCNA and p/t-DNA 101 synergistically activating ATP hydrolysis (Figure 6F).

102 To prevent particle denaturation during sample preparation for cryo103 EM, we cross-linked DNA-free and DNA-bound complexes using the 104 amine-reactive crosslinker bis(sulfosuccinimidyl)suberate (BS3). Mild 105 cross-linking is frequently used to obtain high-resolution cryo-EM 

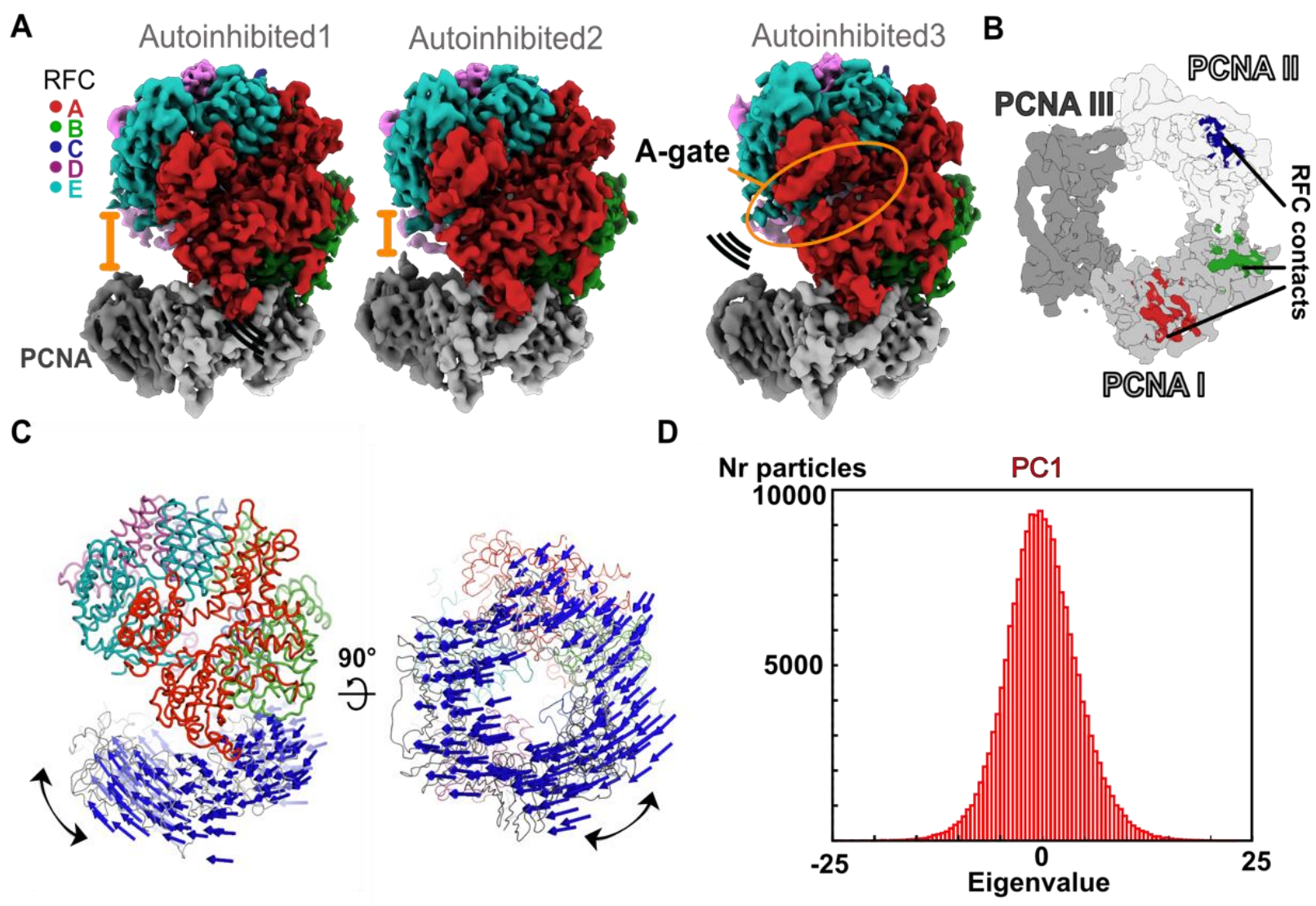

Figure 2. The Autoinhibited state is dynamic. (A) Cryo-EM maps of the three Autoinhibited conformations of the RFC:PCNA complex. PCNA tilts closer relative to RFC in Autoinhibited2. The subunit arrangement of the AAA+ module of Autoinhibitedz is changed slightly, which leads to a crack in the A-gate. (B) Top view on the contact sites of PCNA with RFC in the autoinhibited conformation. (C) Principal Component analysis of all Autoinhibited particles reveals a rocking motion of PCNA relative to RFC. The $C_{\alpha}$ displacement of Principal Component 1 (PC 1 ) is indicated by arrows, scaled down by a factor of 2. (D) Principal Component analysis reveals a range of motions within the initial RFC:PCNA complex. Amplitude histogram of the first principal component $\left(P C_{1}\right)$ reveals a unimodal distribution of particles, suggesting that this state consists of related particles in continuous motion.

106 structures of labile complexes (Gerlach et al. 2018; Yoo et al. 2018; 127

107 Gaubitz et al. 2020). Mass spectrometry of the DNA-free sample 128

108 reveals that most cross-links are intra-molecular and map to the 129

109 unresolved $\mathrm{N}$ - and C-termini of RFC 1 , with only a few detectable inter- 130 The initial complex of RFC:PCNA is dynamic

110 molecular cross-links between RFC subunits (Figure 1 - Supplement 131 Three of the classes from the DNA-free sample are of RFC bound to 111 1B; Table 2). No significant cross-links were observed between RFC 132 closed PCNA in different conformational states (Figure 2). Overall, 112 and PCNA.

133 these structures resemble the previous yeast RFC:PCNA crystal 113 We imaged the RFC:PCNA complex with and without $p / t-D N A$ using 134 structure and our recent cryo-EM structure of human RFC 114 a 300 kV Titan Krios microscope (Figure 1 - Supplements 1C,D, 2A,B, 135 (hRFC):PCNA (Figure 2 - Supplement 1A; Bowman et al. $2004 ;$ Gaubitz $1153 \mathrm{~A}, \mathrm{~B} ;$ Table 3). 3D classification results in four well-defined 136 et al. 2020). The PCNA ring is closed with only the A, B, and C subunits 116 reconstructions from the DNA-free sample, with overall resolutions 137 of RFC contacting PCNA (Figure $2 \mathrm{~B}$ ). The interaction area between 117 ranging between 3.8 and $4.0 \AA$ (Figure1 - Supplement 2D). The 138 clamp loader and clamp averages $\sim 1940 \AA^{2}$ across the three states. 118 dataset of the DNA-containing sample yielded several well defined 139 The nucleotide density in each of the four active sites are most 119 classes, with overall resolutions ranging between 3.3 and $3.5 \AA$ (Figure 140 consistent with the presence of ATP $\mathrm{S}$, although the density for the $\gamma$ 1201 - Supplement ${ }_{3} C$, Table 3). We focused on classes in which all 141 phosphate analog in the $D$ subunit is somewhat ambiguous due to low 121 subunits of RFC and PCNA are visible, although the $\mathrm{N}$ - and C-terminal 142 local resolution throughout this subunit. Nonetheless, the ATPase 122 regions of the $A$ subunit lack clear density. The quality of the cryo-EM 143 sites of the $B, C$, and D subunits are in an inactive state (Figure 2 123 reconstructions readily permitted model building using the crystal 144 Supplement $1 B$ ), with the AAA+ spiral in the overtwisted state 124 structure as a template (Bowman et al., 2004; Figure 1 - Supplement 145 observed in the hRFC structure and the previous yeast RFC crystal 125 1C, 1D; Table 3).

126 146 structure (Figure 2 - Supplement $1 C_{i}$ Bowman et al. 2004; Gaubitz et 147 al. 2020). Therefore, all three of these structures represent 

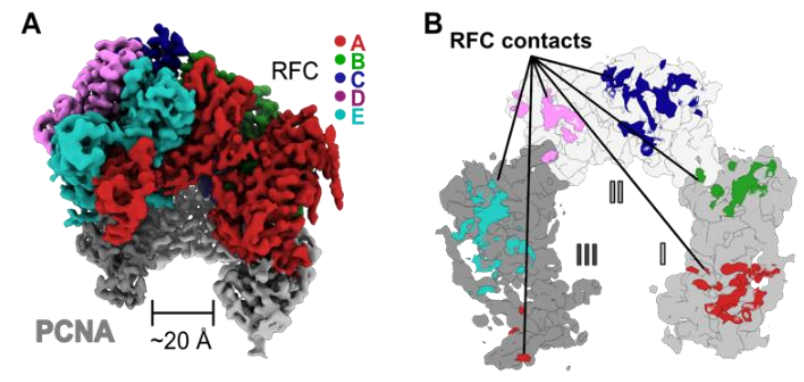

C Autoinhibited1 $\longrightarrow$ Open2

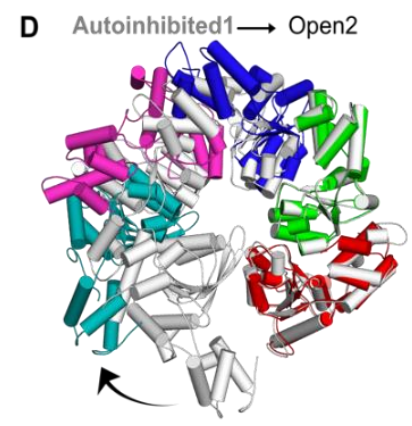

E
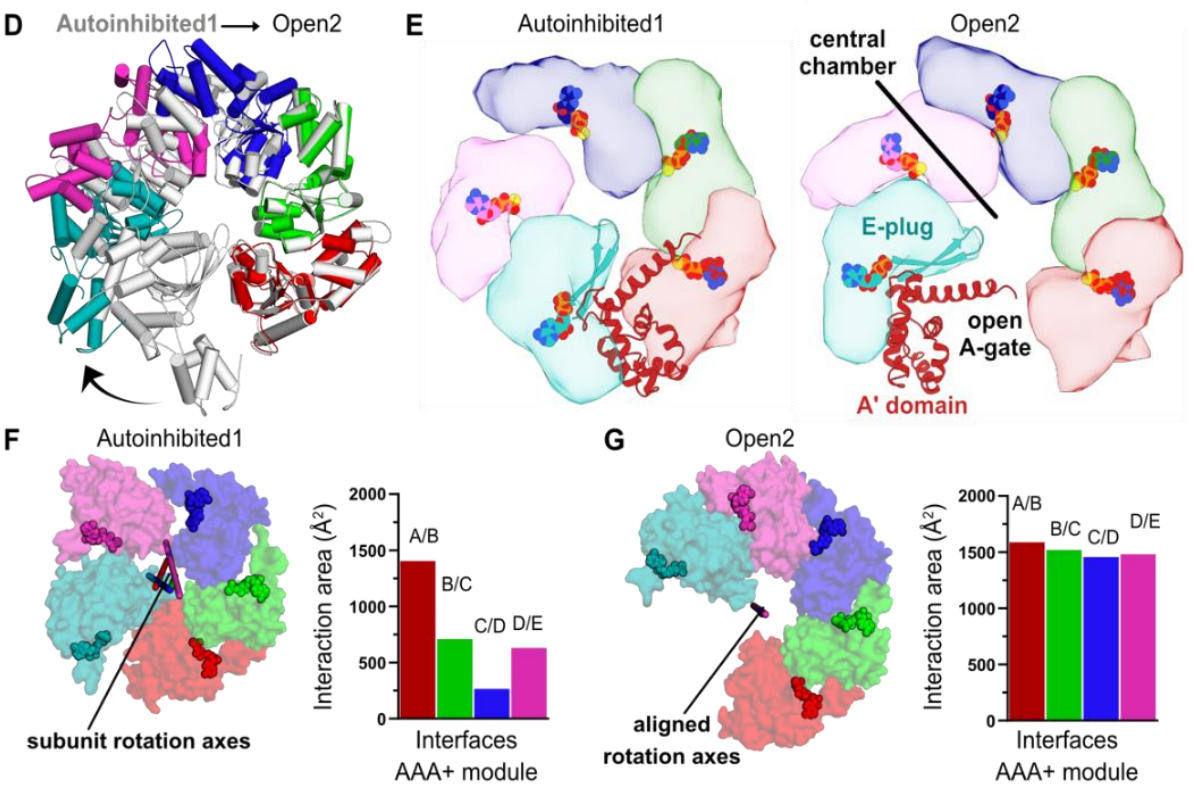

Figure 3: RFC undergoes a large conformational change to open PCNA. (A) Cryo-EM map of RFC bound to an open PCNA ring. (B) PCNA is held open by contacts with all five subunits of RFC. (C) The C $\alpha$ displacement from closed to open PCNA is indicated by arrows, scaled up by a factor of four. (D) The AAA+ modules widen from the Autoinhibited state(gray) to an open spiral conformation. (E) Top view of the AAA+ spiral shows that the E-plug and A-gate block access to RFC's central DNA binding chamber in the Autoinhibited conformation but retract in the open conformation. RFC opens wide enough for DNA to directly enter the central chamber. (F) Top view of the Rossmann fold arrangement in the Autoinhibited conformation. The rotation axes that relate neighboring subunits are shown in different colors and are skewed, indicating asymmetric rotations which lead to gaps between the subunits. (G) The rotation axes overlay in the Open2 state of RFC, indicating a symmetric arrangement of the AAA+ spiral. Symmetrization closes the gaps, and results in an increased interaction area between neighboring subunits.

148 autoinhibited states of RFC (termed Autoinhibited1, Autoinhibited2, 
149 and Autoinhibited3). Because the Autoinhibited1, 2, and 3 states likely 183 different observed cryo-EM class averages do not represent particles 150 represent ATP-saturated configurations, we place these 184 in discrete states, but rather snapshots along a continuum of motion. 151 conformational states early in the clamp loading reaction. 185 Thus, the autoinhibited state of RFC is conformationally 152 The subunits in the AAA+ spiral have a different tilt in each of the 186 heterogeneous, with the dominant motions driving RFC toward PCNA. 153 Autoinhibited states, thereby slightly altering the intersubunit 187 We propose these motions represent an early phase of the transition 154 interactions (Figure 2 - Supplement ${ }_{1} \mathrm{C}$ ). For instance, the 188 toward opening of the PCNA ring.

155 Autoinhibited3 state exhibits a slightly cracked A-gate (but not open

156 enough for DNA to pass through), whereas the A-gate is closed in the 189 PCNA opening is coupled to large-scale expansion of RFC

157 Autoinhibited 1 and 2 states (Figure 2A, Figure 2 - Supplement $2 \mathrm{~A}$ ).

158 Further, the AAA+ modules of subunits C-D change their position into 190 Each of the two cryo-EM datasets revealed a class of RFC bound to 159 a more symmetric alignment with overlapping rotation axes relative to 191 open PCNA with no DNA bound (Figure1-Supplement 2D, 3C). To our 160 Autoinhibited 1 and 2 (Figure 2 - Supplement 1 C). On the other hand, 192 knowledge, these are the first high-resolution structures of a clamp 161 the PCNA ring tilts $\sim 19^{\circ}$ relative to the RFC-D in the Autoinhibited 2193 loader bound to an open clamp prior to DNA binding. Both 162 state relative to the Autoinhibited 1 and 3 states (Figure 2A, Figure $2-194$ reconstructions are highly similar (overall $C_{\alpha}$ RMSD is $0.74 \AA$, map to 163 Supplement 2A).
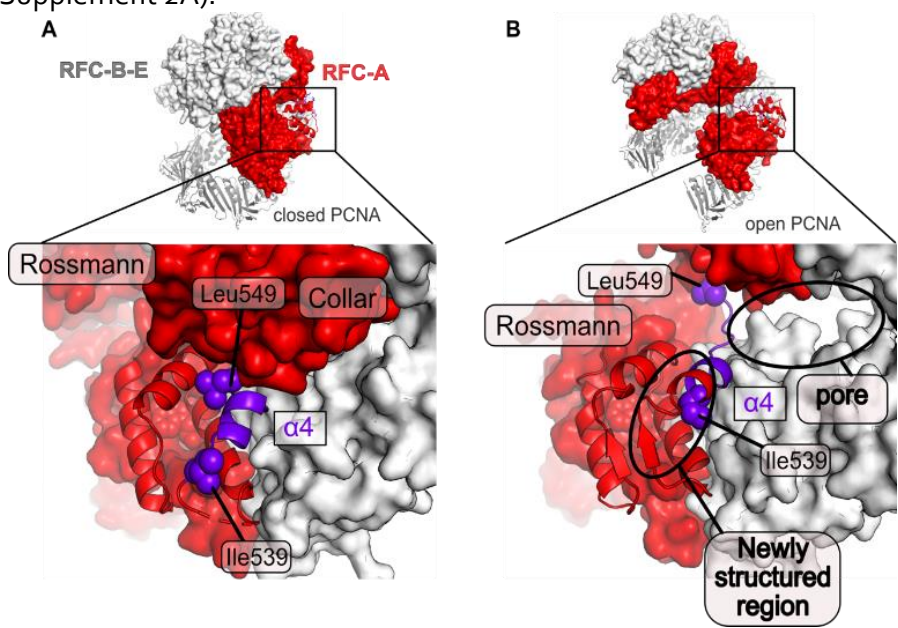
195 map correlation coefficient is $\sim 0.85$ ) and we refer to these structures 196 as Open1 and Open2 (Figure 3 - Supplement 1A-D). PCNA forms a 197 right-handed spiral with a $\sim 20 \AA$ opening that is wide enough for 198 dsDNA to enter (Figures 3A, B). The PCNA ring opens primarily 199 through in-plane rather than out-of-plane motions (in-plane $\sim 19 \AA$ and 200 out-of-plane $\sim 10 \AA$ for Open2, Figure $3 C$ ). Each of the subunits of 201 PCNA twists outward and towards RFC, with the largest distortion in 202 subunit II (Figure 3-Supplement 1F).

203 PCNA opens at the A-gate of RFC, disrupting the interaction 204 between the first and third subunits of the PCNA ring (termed PCNA-I 205 and PCNA-III, hereafter). The open PCNA ring is directly held by all five 206 subunits of RFC, burying $\sim 3800 \AA^{2}$ of surface area, an approximate $207 \sim 1860 \AA^{2}$ increase over that of the Autoinhibited states (Figures $3 B$, 208 Figure 3 - Supplement $2 A, B$ ). The RFC-C subunit shifts downward to 209 interact much more tightly with PCNA-II, while PCNA also forms new 210 interactions with RFC-D, RFC-E, and the $A^{\prime}$ domain of RFC-A (Figure 3 211 - Supplement $2 C, D)$. The overall interface is characterized by an

Figure 4: A fold-switch mechanism for opening a pore in the Open 212 alternating pattern of strong and weak interactions (strong: $R F C$ - $A$, $-C$, state of RFC:PCNA. (A) Helix 4 of the RFC-A subunit in 213 \& - $E_{\text {; }}$ weak: RFC-B, $-D, \& A^{\prime}$ ). The strong interactions are with the main Autoinhibited 1 is shown in purple. (B) In the open conformation, Lid 214 partner binding pocket of PCNA, using a binding region that Helix 4 is displaced and partially unravels, whereby the packing 215 resembles a common motif for PCNA-interacting partners. Of these arrangement of the hydrophobic core of the lid domain in RFC-A 216 strong interfaces, RFC-A is the most substantial and RFC-E weakest; changes. Ile 536 and Leu549 move $\sim 13 \AA$ and $\sim 22 \AA$ from their original 217 RFC-A contains a true PCNA interaction motif, while RFC-C and RFCposition and a pore is formed between the RFC-A and RFC-B 218 E's motifs are increasingly degenerate. It is likely that the stronger subunits.

219 interactions at the "bottom" of the spiral allows the clamp loader to 164 Despite these differences, the three Autoinhibited structures are 220 toggle between the closed and open states of PCNA without releasing 165 very similar, and so we asked if these conformations represent distinct 221 RFC.

166 intermediates or if they are snapshots along a continuum of 222 The AAA+ modules of RFC adopt a right-handed spiral whose 167 conformations. Therefore, we characterized the particles that 223 periodicity matches that of the six contact sites on PCNA. The 168 contribute to the Autoinhibited states using multi-body refinement 224 symmetry of the ATPase spiral can be visualized by the near perfect 169 (Figure 2 - Supplement 2B-I), a computational tool that allows 225 alignment of the rotation axes that relate adjacent AAA+ subunits 170 modeling of macromolecular motion (Nakane et al., 2018). To 226 (Figures 3F-G). The interfaces between adjacent AAA+ modules 171 examine motion between clamp and clamp loader, we defined RFC 227 become tighter, bringing the catalytic arginine finger residue closer to 172 and PCNA as two independent rigid bodies (Figure 2 - Supplement 2228 the neighboring ATPase site and potentiating ATP hydrolysis. This $173 \mathrm{~B}-\mathrm{E})$. This analysis revealed that the dominant motion is rocking of 229 observation explains the modest boost in ATP activity upon PCNA 174 PCNA towards RFC, with the linker between the ATPase and collar 230 binding (Johnson et al., 2006; Figure 6F). However, similar to the 175 domains serving as a hinge (Figure $2 \mathrm{C}$, Video 1 ). Other motions include 231 Autoinhibited structures, all four active sites remain bound to ATP 176 swiveling of the RFC spiral with RFC-D getting closer to PCNA (Figure 232 analog (Figure 3 - Supplement 1 E). Therefore, while opening is 1772 -Supplement $2 \mathrm{E}$, Video 2). These results are not dependent on the 233 necessary to promote ATP hydrolysis by properly positioning the 178 particular mask used, as similar motions are observed using different 234 trans-acting arginine finger residues across the inter-subunit interface, 179 masking strategies (Figure 2 - Supplement $2 \mathrm{~F}-\mathrm{I}$ ). Principal component 235 ATP hydrolysis is not necessary to drive the conformational change 180 analysis of the multi-body conformers revealed a unimodal 236 from Autoinhibited to Open and opening is likely not sufficient to 181 distribution of particles along their eigenvalue (Figure 2D, Figure 2 - 237 stimulate ATP hydrolysis on its own.

182 Supplement $2 \mathrm{D}, \mathrm{H}$ ). This unimodal distribution indicates that the three 
238 In order to rupture the PCNA ring, the AAA+ spiral of RFC widens, 256 Structures of the RFC:PCNA complex bound to primer-template 239 opening the A-gate. RFC opens using a large hinge motion, pivoting 257 DNA

240 around the $B-C$ and $C-D$ subunit interfaces (Figure 3D, 3E; Video 3). 258 To reveal how RFC:PCNA binds and responds to DNA, we analyzed 241 The RFC-E subunit uses its E-plug to bind PCNA, which pulls the $A^{\prime} 259$ two classes that contain DNA-bound RFC:PCNA. One class shows 242 domain and E-plug up to $45 \AA$ away from the AAA+ module. This 260 PCNA in an open lock-washer shape, and the other has PCNA in a 243 reveals a large opening of the A-gate (at its most narrow, the A-gate is 261 closed conformation. Therefore, we term these two states DNA ${ }^{P C N A}$ 244 approximately $20 \AA$ 为 wide) (Figure $3 \mathrm{E}$ ). p/t-DNA can therefore directly $262{ }^{\circ}$ apen and DNA ${ }^{\text {PCNA-closed }}$, respectively (Figures $5 A-5 C$ ). Both classes 245 enter the open RFC:PCNA complex.

263 contain clear density for p/t-DNA: 18 base pairs of duplex DNA are 246 Opening of the A-gate separates the RFC-A Lid and collar domains, 264 bound inside the central chambers of RFC and PCNA, and 6 247 inducing a fold-switching transition in the Lid domain. The majority of 265 nucleotides of the ssDNA template extend through the A-gate, 248 the last helix of the Lid (Helix $\alpha_{4}$; residues 541-546) unravels into a taut 266 preventing its closure. The AAA+ spiral of RFC tracks the minor groove $249 \beta$-strand conformation (Figures 4A, 4B). The remaining residues in 267 of dsDNA using a suite of residues that are conserved across all known 250 helix $\alpha_{4}$ (residues 536-542) shift forward, causing a major change in 268 clamp loaders to match the helical symmetry of DNA (Kelch et al. 251 the core packing of the Lid domain. This "sliding spring" motion leads 269 2011; Simonetta et al., 05/2009).

252 to a $\sim 11 \AA$ helix displacement, whereby some residues, such as Leu 270 The E-plug beta-hairpin slots into the major groove of the duplex 253549 , move up to $22 \AA$ from their original position. The stretching of the 271 region of p/t-DNA (Figure $5 \mathrm{D}$ ). Conserved basic residues at the tip of 254 RFC-A Lid opens a new pore between the A and B subunits (Figure 272 the E-plug interact directly with both the template and primer strands. $2554 \mathrm{~B})$. We discuss the role of this pore in the next section. 273 Therefore, the E-plug provides a mechanism for the RFC AAA+ spiral 274 to recognize both strands of DNA, unlike the clamp loaders from $E$. 275 coli and 44 phage, whose AAA+ spirals only interact with the template 276 strand (Kelch et al., 2011; Simonetta et al., 05/2009). Moreover, this
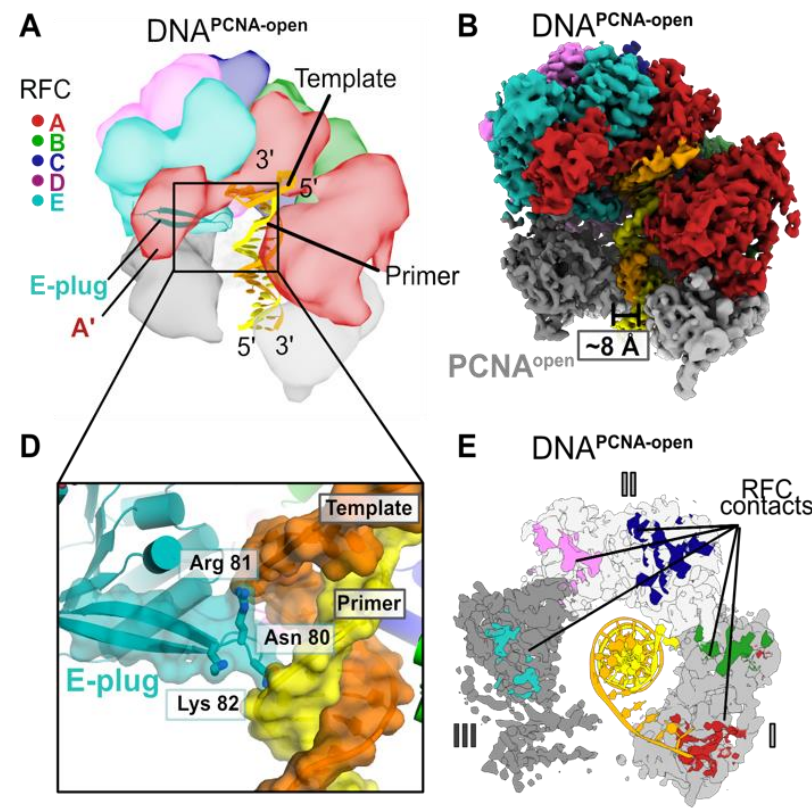

G

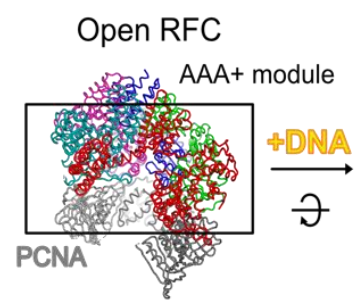

\section{H}
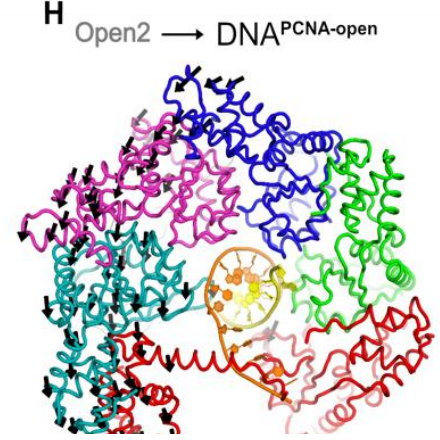

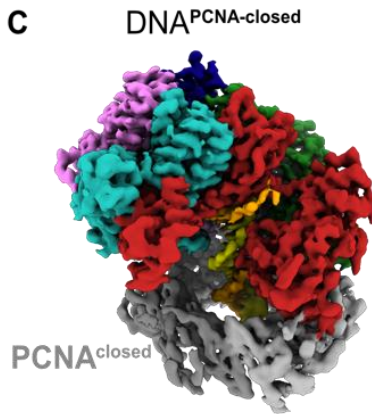

$\mathbf{F}$

$$
\text { DNA PCNA-closed }
$$

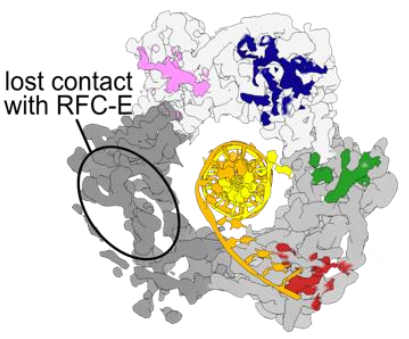

$\mathbf{I}_{\text {DNAPCNA-open }} \longrightarrow$ DNA $^{\text {PCNA-closed }}$

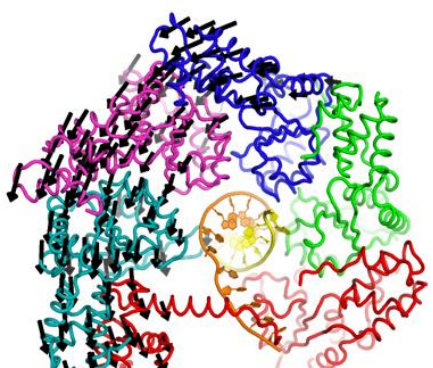

Figure 5: Structures of RFC:PCNA bound to DNA. (A) Schematic representation of the structure of RFC:PCNA bound to primer-template (p/t) DNA. (B) Cryo-EM map of RFC:PCNA bound to $p / t-D N A$ and open PCNA (termed DNA ${ }^{\text {PCNA-open }}$ ). (C) Cryo-EM map of RFC:PCNA bound to p/t-DNA with closed PCNA (termed DNA ${ }^{\text {PCNA-closed }}$ ). (D) The E-plug inserts into the major groove and interacts with both strands of the p/t-DNA. (E) Top view of contact sites of RFC with PCNA. PCNA is held open by contacts with all five subunits in DNA ${ }^{\text {PCNA-open }}$. (F) In DNA ${ }^{\text {PCNA-closed }}$, the interaction between RFC-E and PCNA-III is lost. (G) Overview of structure of Open2. $(\mathrm{H})$ Top view of the AAA+ spiral of DNA ${ }^{\text {PCNA-open }}$. Displacement vectors between Openz and DNA ${ }^{\text {PCNA-open }}$ are indicated by arrows, scaled up by a factor of two. The AAA+ spiral constricts around DNA. (I) The AAA+ spiral of DNA ${ }^{\text {PCNA-closed }}$. Displacement vectors between DNA ${ }^{\text {PCNA-open }}$ and DNA ${ }^{\text {PCNA-closed }}$ indicate that the AAA+ spiral constricts further around DNA, leading to changes in ATPase sites. 
277 structure shows that the E-plug changes its role from blocking DNA 295 similar to that seen for the structure of the T4 phage clamp bound to 278 binding (in the three Autoinhibited states) to one in which it directly 296 clamp loader and p/t-DNA (Kelch et al., 2011).

279 supports DNA binding. This explains the non-intuitive effect on DNA 297 The DNA ${ }^{\text {PCNA-closed }}$ structure has a closed PCNA ring that is distorted 280 binding we observed previously, where hRFC variants with a mutated 298 from planarity. Upon closure, PCNA loses its interaction with the RFC281 E-plug bind DNA with equivalent affinity as WT-hRFC (Gaubitz et al., 299 E subunit, but retains its interfaces with the other four RFC subunits 282 202ob).

300 (Figures $5 \mathrm{E}, 5 \mathrm{~F}$ ). The distortion of the PCNA ring is most prevalent in

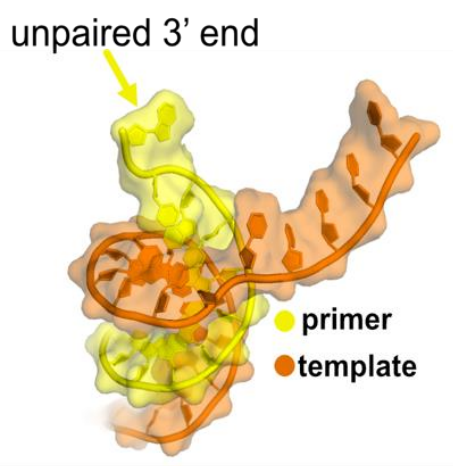

B
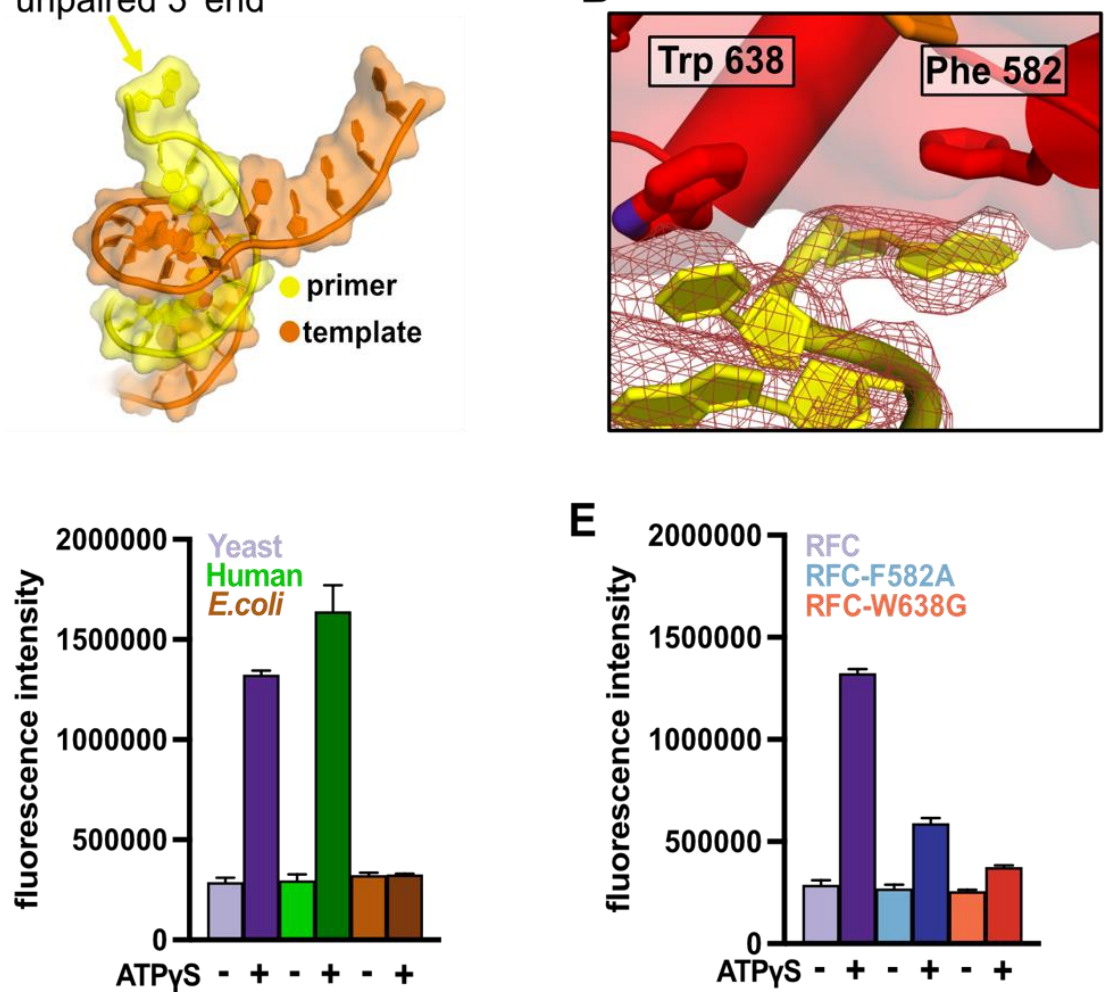

E

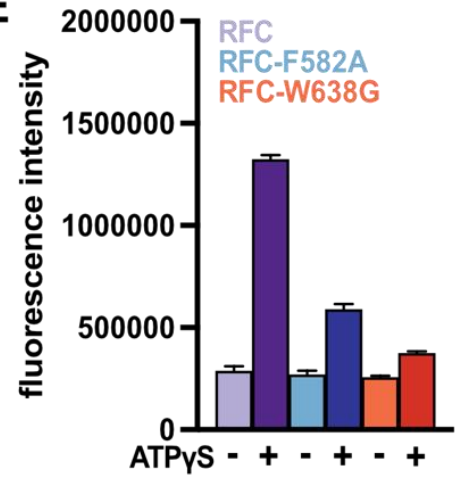

C

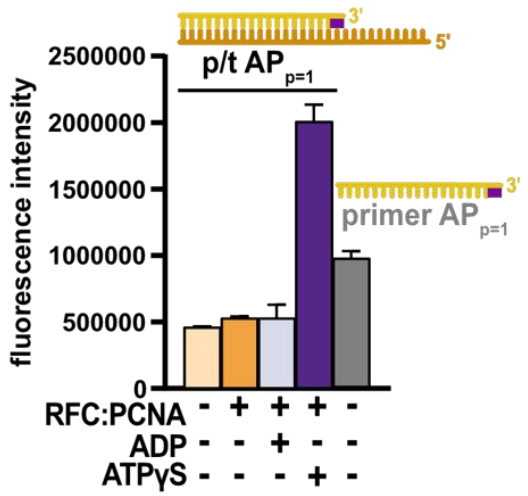

$\mathbf{F}$

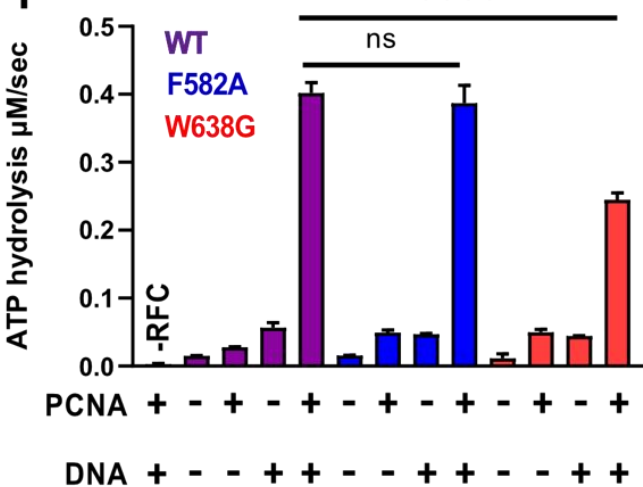

Figure 6: RFC separates the $3^{\prime}$ end of the primer strand. (A) The last nucleotide in the primer strand is separated from the duplex. (B) The collar of RFC-A contains a "separation pin" with two critical residues (Trp638 and Phe582) that stabilize the flipping of the 3 ' primer nucleotide into the pore between RFC-A and RFC-B. The cryo-EM map is shown in red mesh. (C) The primer strand of p/t-DNA contains $3^{\prime}$ nucleotide with a 2aminopurine (2AP) base, an adenine analog that reports on base-pairing and base-stacking. 2AP fluorescence increases in the presence of ATP $\mathrm{S}$ and RFC:PCNA to a higher level than in the unpaired 2-aminopurine-labeled primer strand. (D) The human RFC:PCNA complex also induces an increase in 2AP fluorescence emission, whereas the $E$. coli clamp loader, which does not flip the $3^{\prime}$ end of the primer (Simonetta et al., 05/2009), does not increase 2AP fluorescence. (E) Mutation of Phe 582 and Trp638 reduces 2-AP fluorescence in the presence of ATPYS. (F) ATPase activity of the "separation pin" mutants. The ATP hydrolysis rate of the RFC-W638G variant is significantly reduced compared to wild type in the presence of PCNA and DNA ( $p$ value from one-way ANOVA test: *** $P \leq 0.0001$ ).

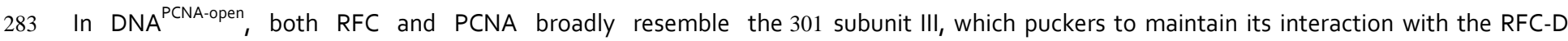
284 conformations seen in Open1 and Open2. The RFC A-gate is open, 302 subunit (Figure 5 - Supplement $1 A, B$ ). Interestingly, the interaction 285 with all 5 subunits gripping PCNA in an open lock-washer shape. 303 between DNA and PCNA becomes more extensive upon PCNA closure 286 However, both RFC and PCNA constrict relative to the Open1 and $304\left(\sim 50 \AA^{2}\right.$ vs $\left.250 \AA^{2}\right)$. Conserved basic residues lining the inner pore of 287 Open 2 structures (Figures $5 \mathrm{G}, 5 \mathrm{H}$ and Figure 5 - Supplement $1 \mathrm{~A}, \mathrm{~B}$ ). 305 PCNA also interact directly with the duplex, as has been hypothesized 288 RFC constricts modestly, pivoting the $E, D$, and C subunits around a 306 previously (Liu et al., 2017; McNally et al., 2010). We propose that 289 hinge at the B-C interface. PCNA constricts $\sim 12$ A upon DNA binding, 307 these interactions help to drive the closure of PCNA around DNA.

290 with most of this constriction occurring in subunit III of PCNA (Figure 5308 DNA ${ }^{\text {PCNA-open }}$ and DNA ${ }^{\text {PCNA-closed }}$, just like the other states described 291 - Supplement 1A). Subunit III of PCNA is held by the RFC-D and RFC-E 309 herein, are in the fully ATP-bound state: ATPYS in the active sites of 292 subunits, although RFC-E grips PCNA less tightly in DNA ${ }^{\text {PCNA-open }} 310$ the $A, B, C$, and D subunits, and ADP in the nucleotide-binding site of $293\left(\sim 3800 \AA^{2}\right.$ total RFC-PCNA interaction area for the Open1\&2 structures 311 the E subunit (Figure 5 - Supplement $1 C$ ). Therefore, these structures 294 vs $\sim 3400 \AA^{2}$ for DNA ${ }^{\text {PCNA-open }}$ ). Overall, the PCNA conformation is 312 represent reaction intermediates following DNA binding but 313 preceding ATP hydrolysis. Upon binding DNA, the AAA+ spiral 
314 constricts (Figure $5 \mathrm{H}$ ), primarily due to a hinge-like motion at the 372 particularly in the $\mathrm{F}_{5} 82 \mathrm{~A}$ variant, whose ATPase rate and apparent 315 interface between RFC-C and RFC-B. The AAA+ spiral constricts 373 affinity for DNA are similar to WT (Figures 6F and Figure 6 316 around an axis coincident with the DNA axis. Subsequent PCNA 374 Supplement $1 D, E)$. These results indicate that base flipping requires 317 closure further exaggerates the constriction of the RFC AAA+ spiral 375 the separation pin, but base flipping is not required for DNA binding or 318 (Figure 5l). Despite these movements, the position of the arginine 376 ATPase activation.

319 finger within the ATPase active site does not change substantially 377 We hypothesized that the base-flipping mechanism functions to 320 (Figure 5 - Supplement 2). Thus, DNA binding likely stimulates ATP 378 specifically recognize the $3^{\prime}$ end of the primer. By flipping the base, 321 hydrolysis through another mode of action. One such proposed mode 379 the separation pin could potentially act as a quality control mechanism 322 is repositioning a conserved arginine known as the switch residue, 380 to verify proper status of the primer end. We tested this hypothesis by 323 which in turn would activate the Walker B glutamate (Kelch et al., 381 measuring how WT-RFC and the W638G and F582A variants respond 324 2011, 2012). However, we find that this residue is not in the position 382 to various nucleic acid architectures. If our hypothesis were true, we 325 that was previously predicted to stimulate hydrolysis. Despite this, the 383 would expect that the W638G and F582A variants would lose the 326 active sites appear to be in the fully active state, with all of the 384 ability to discriminate against 'incorrect' nucleic acid substrates. We 327 catalytic machinery poised to hydrolyze ATP. We discuss the 385 tested ATPase activity against a series of nucleic acid substrates that 328 ramifications of this observation on the allosteric activation of RFC 386 include: SsDNA, 3' phosphate, 3' abasic sites, a $3^{\prime}$ ribonucleotide, an 329 below.

330 387 RNA primer, ssDNA-dsDNA junctions of opposite polarity (i.e. 388 recessed 3 ' ends, Figure 6 - Supplement 2A). We performed these 331 RFC flips the $\mathbf{3}^{\prime}$ base of the primer strand

389 assays using nucleic acid concentrations at or near the $K_{d}$ for the 332 Unexpectedly, we observe that the $3^{\prime}$ nucleotide of the primer strand 390 various forms of RFC Figure 6 - Supplement $1 \mathrm{~A}$, so that any deviations 333 is melted in both DNA-bound RFC:PCNA structures, with the base 391 in activity or binding would be observable. However, we observe 334 flipped away from the rest of the duplex (Figure 6A, 6B). The base pair 392 nearly identical ATPase activity profiles for the variants as we do for 335 is disrupted by a "separation pin" at the base of the RFC-A collar 393 WT-RFC (Figure 6 - Supplement 2B-D). Therefore, the biochemical 336 domain that wedges between the DNA strands (Figure 6B). The indole 394 characterization of variants with reduced base-flipping does not 337 ring of Trp638 replaces the flipped 3' base to maintain stacking 395 support our hypothesis that the separation pin acts to discriminate 338 interactions. The $3^{\prime}$ nucleotide is repositioned inside the pore formed 396 against incorrect substrates.

339 by the unraveling of the RFC-A Lid domain upon opening of the A- 397 To directly assess the physiological role of base-flipping in normal 340 gate; this site is closed in the Autoinhibited state (Figure 4). The 398 RFC function, we measured growth of yeast strains carrying the WT, 341 flipped base stacks against the phenyl ring of Phe 582 . These residues 399 W638G, or F582A variants as the only copy of RFC 1 (Figure 6 342 are conserved in eukaryotic clamp loaders but are absent in bacterial, 400 Supplement 3). We tested yeast growth across a wide variety of DNA 343 archaeal or phage clamp loaders (Figure 6 - Supplement $5 \mathrm{~A}$ ).

401 damaging treatments: ultraviolet radiation (UV), hydroxyurea (HU) or 344 To characterize base flipping, we measured binding of DNA 402 methylmethane sulfonate (MMS). Because base-flipping is thought to 345 substrates containing the adenine analog 2-aminopurine (2AP). 403 have a strong temperature dependence (Yin et al. 2014), we measured 346 Fluorescence of $2 \mathrm{AP}$ is dependent on base-pairing (Frey et al., $1995 ; 404$ yeast growth over a broad temperature range ( $18{ }^{\circ} \mathrm{C}$ to $37{ }^{\circ} \mathrm{C}$ ). 347 Jean and Hall, 2001): fluorescence is low when 2AP is base paired, but 405 Surprisingly, we find no obvious growth phenotype across our broad 348 high in the free state. To monitor melting, we placed 2AP either at the 406 spectrum of conditions (Figure 6 - Supplement 3 ). Thus, we currently $3493^{\prime}$ end of the primer strand $\left(\mathrm{AP}_{\mathrm{p}=1}\right)$ or at the corresponding site in the 407 find no obvious role for the separation pin, despite its conservation in 350 template strand $\left(\mathrm{AP}_{\mathrm{t}=1)}\right.$. Importantly, we find a dramatic increase in $408 \mathrm{RFC}$ complexes across all eukaryotes. Further investigation will be 351 2AP fluorescence that is dependent on addition of RFC, PCNA and 409 required to discern the functional role, if any, of the base-flipping 352 ATP analog (Figures 6C, Figure 6 - Supplement 1A-C). The increase in 410 mechanism of RFC.

353 2AP fluorescence is not observed in the presence of ADP, which does 411

354 not support DNA binding (Kelch et al., 2011; McNally et al., 2010).

355 Placement of $2 A P$ at the $p=2$ or $p=3$ position of the primer yields 412 DISCUSSION

356 diminished fluorescence, suggesting that only the $3^{\prime}$ base is flipped

357 (Figure 6 - Supplement 1B). Therefore, our 2AP experiments validate 413 Defining the clamp loading reaction in high-resolution

358 that RFC- and PCNA-dependent 3' end melting occurs in solution. The 414 We have determined a series of structures that provide a high359 human clamp loader, which has a similar separation pin as yeast RFC 415 resolution view of the clamp loading process. Our structures 360 (Gaubitz et al., 2020), greatly enhances 2AP fluorescence. However, 416 correspond to numerous reaction intermediates, allowing us to order 361 the $E$. coli clamp loader, which binds p/t-DNA but does not melt the 417 the structures into a coherent description of the clamp loading 362 primer strand (Simonetta et al., 05/2009), does not alter fluorescence 418 reaction prior to ATP hydrolysis (Figure 7 and Video 4). The 363 (Figure 6D). Thus melting of the $3^{\prime}$ nucleotide is a conserved activity 419 Autoinhibited states represent the transient encounter complex that 364 of eukaryotic clamp loaders, but is likely not used by bacterial clamp 420 forms early in the clamp loading process before ring opening. The 365 loaders.

421 Open $1 \& 2$ states represent the stable intermediate state in which 422 PCNA is opened but DNA has yet to bind. The DNA ${ }^{\text {PCNA-open }}$ structure 423 contains $p / t-D N A$ and an open clamp, which is the transient 424 intermediate following DNA binding (Liu et al., 2017; Marzahn et al., 425 2014; Sakato et al., 02/2012). Finally, the DNA ${ }^{\text {PCNA-closed }}$ structure 426 represents a possible stable intermediate that forms if ATP hydrolysis 427 were stalled for whatever reason (Marzahn et al., 2014; Sakato et al., 428 2012). Therefore, our structures delineate the conformational states 
429 that span the entire clamp opening and closing process, the central 456 clamp loaders may be free to adopt a conformation that can template 430 reaction of the clamp loading cycle.

457 the open clamp prior to clamp binding.

458 The crab-claw motion that we observe is primarily driven by a 459 hinge-like motion that pivots about the RFC-C subunit. This motion

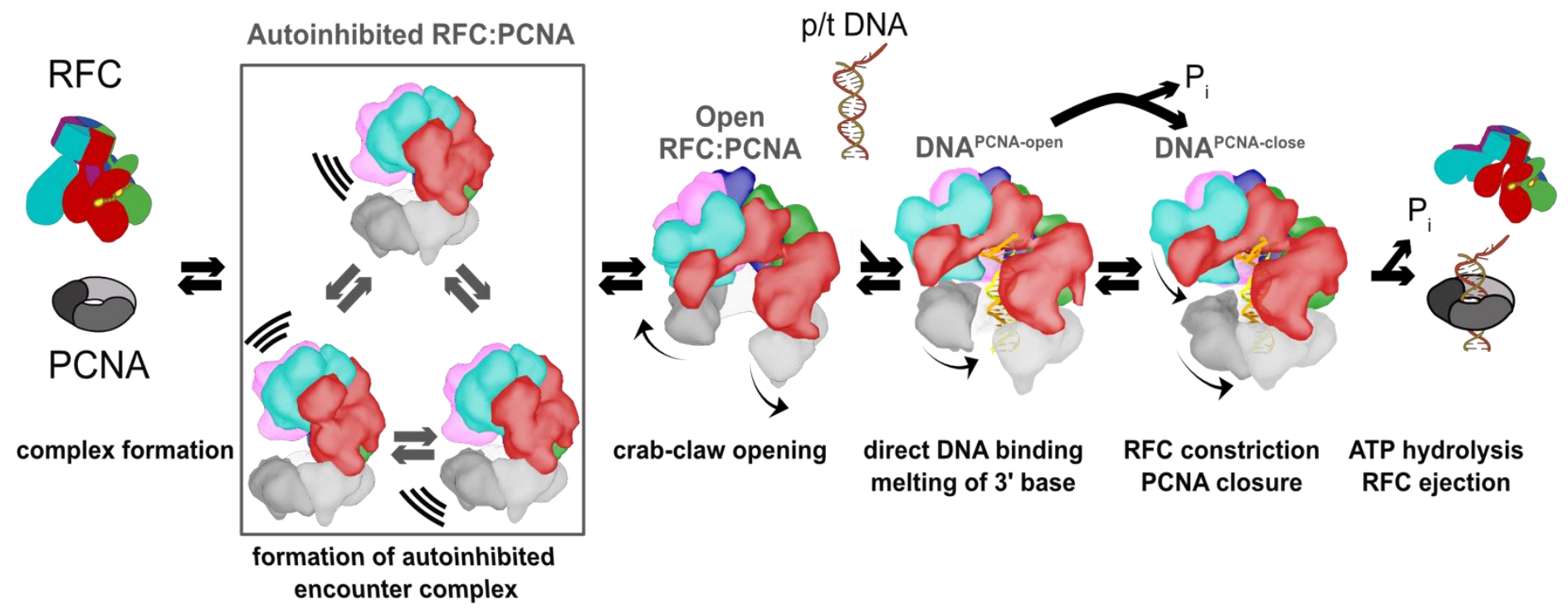

Figure 7: Clamp loading by RFC. Initial binding of RFC to PCNA places the complex in an Autoinhibited state, whereby closed PCNA and the Eplug preclude DNA binding, and an overtightened AAA+ helix inhibits ATPase activity. The Autoinhibited state is dynamic, rocking PCNA relative to RFC as captured by multibody refinement. Upon complete binding to PCNA, RFC uses the crab-claw mechanism to simultaneously open both PCNA and the A-gate, providing an entryway for p/t-DNA. p/t-DNA then binds directly through the A-gate and open PCNA, which are wide enough to accommodate dsDNA entry. The 3 ' end of the primer is flipped into the pore that is formed between RFC-A and RFC-B. PCNA closes to form additional contacts with DNA, partially detaching from RFC at the E subunit. Finally, ATPase activity and inorganic phosphate release eject RFC, leaving PCNA bound to $p / t-D N A$ in the correct orientation.

\section{A crab-claw mechanism for opening the sliding clamp}

432 Our structures show that RFC is in a constricted, auto-inhibited 433 conformation upon initial binding to PCNA. This state is highly 434 dynamic, and we captured some of the conformational heterogeneity 435 using multi-body refinement. The primary mode of motion pivots 436 PCNA relative to RFC, such that PCNA approaches the D- and E437 subunits of RFC. We speculate that this motion is on-pathway toward 438 a direct interaction between PCNA and all five RFC subunits, 439 facilitating the opening of the PCNA ring. Thus, the dynamics of the 440 Autoinhibited complex are important for the opening of PCNA. Future 441 studies will investigate this possibility.

442 To open PCNA, our structures show that RFC uses the previously 443 hypothesized "crab-claw" mechanism (Jeruzalmi et al., 2001a, 2001b; 444 O'Donnell et al.). This contradicts the previous suggestion that the $E$. 445 coli clamp loader opens the ring with limited conformational changes 446 in the clamp loader (Goedken et al., 2004; Kelch, 2016). In this "limited 447 change" model, ATP binding places the encounter complex in a 448 conformation that "templates" the open clamp. However, our 449 structures preclude this model for RFC because we observe large 450 conformational changes in the clamp loader upon opening the PCNA 451 ring. Furthermore, the Autoinhibited state of RFC cannot template an 452 open PCNA conformation. One possible reason for the discrepancy 453 between the two studies is that different model systems were used; 454 bacterial clamp loaders lack the $A^{\prime}$ domain that constricts the AAA+ 455 spiral of the yeast clamp loader. Without the $A^{\prime}$ domain, the bacterial
460 allows the $A^{\prime}$ domain and $E, D$, and $C$ subunits to grip PCNA tightly, 461 which is impossible in the Autoinhibited state. Kinetic characterization 462 of RFC variants has predicted a hinge role for this region (Sakato et al., 463 2012), highlighting this subunit's importance in clamp loading. The 464 crab-claw conformational change is remarkable because it requires a 465 fold-switching event in the Lid domain of the RFC-A subunit (Figure $4664 \mathrm{~A}, 4 \mathrm{~B})$. At a minimum, this would require that helix- 4 of the RFC-A 467 Lid to unfold and refold into a new position. The fact that clamp 468 opening is relatively fast (Liu et al., 2017) and does not require ATP 469 hydrolysis indicates that these conformational rearrangements must 470 have a relatively low energy barrier despite the large-scale motion. 471 How the RFC:PCNA complex couples these motions becomes an 472 important question for future studies.

473 Why use a "crab-claw" mechanism? We envision two non-mutually 474 exclusive hypotheses. First, we hypothesize that this mechanism 475 allows RFC to bind each of its macromolecular substrates (PCNA and $476 \mathrm{p} / \mathrm{t}-\mathrm{DNA}$ ) in the proper order to ensure efficient clamp loading and to 477 avoid futile cycles of ATP hydrolysis. For proper clamp loading, RFC 478 must bind PCNA first, because initial binding of p/t-DNA would 479 sterically hinder binding of the PCNA ring. Therefore, RFC has evolved 480 high affinity for PCNA and only binds p/t-DNA with high affinity after 481 it has bound PCNA (Cai et al., 1998; Shiomi et al., 2000). The crab-claw 482 mechanism for PCNA opening can explain this hierarchy of binding, as 483 the auto-inhibited state blocks the DNA binding site ((Gaubitz et al., 484 2020) and Figure 3E). The crab-claw mechanism ensures that RFC's 485 DNA-binding chamber only becomes accessible once the PCNA ring is 
486 open. Our second hypothesis is that the crab-claw mechanism enables 544 - Supplement 3). We still hypothesize that there is likely a role for the 487 complex modes of clamp loader regulation. Clamp loader activity 545 flipping activity, as the separation pin is conserved across RFC 488 could be inhibited by binding partners or post-translational 546 complexes from yeast to humans. Moreover, this separation pin is not 489 modifications that favor the Autoinhibited state. There are numerous 547 found in the related 9-1-1 clamp loader Rad24-RLC (Castaneda et al. 490 RFC binding partners and post-translational modifications that remain 548 2021; Zheng et al. 2021). A separation pin extension is found in the 491 unexplored, and thus are candidates for playing regulatory roles 549 related loader Ctf 18 (Figure 6 - Supplement 5 B) but the flipping amino 492 (Dephoure et al., 2008; Kim and Brill, 2001; Ochoa et al., 2020; Olsen 550 acids are not conserved. (Predictions for or against a separation pin in 493 et al., 2010; Tomida et al., 2008; Wang et al., 2012, 2013).

494

\section{RFC-A subunit drives DNA recognition}

551 the final loader subunit Elg1 are weak due to very limited sequence 552 homology between $\mathrm{RFC}_{1}$ and Elg1.) Future experiments will 553 investigate the role of base-flipping in more detail.

496 To illuminate how RFC recognizes DNA, we measured the relative 554

497 contribution of each RFC subunit to DNA binding. We find that RFC-A 555 Forces driving clamp loading

498 accounts for $\sim 64 \%$ of the buried surface area between RFC and DNA. 556 Our structures delineate a conformational pathway that illustrates 499 This contrasts with $\mathrm{T}_{4}$ and $E$. coli clamp loaders, where the A subunits 557 much of the clamp loading reaction. We reveal how: 1 ) RFC initially 500 account for $\sim 36 \%$ of the binding interface (Figure 6 - Supplement $4 \mathrm{~B}$ ). 558 binds PCNA, 2) how PCNA is opened, 3 ) how DNA is bound, and 4 ) 501 Much of this proportional increase arises from additional interactions 559 how PCNA closes around DNA. This unprecedented view into the 502 between RFC-A and DNA through the separation pin and the flipped 560 mechanism of clamp loading allows us to hypothesize on the forces $5033^{\prime}$ nucleotide. Furthermore, we find that B, C, D, and E subunits of RFC 561 that drive this reaction towards the loading of PCNA. We use the 504 interact with DNA significantly less $\left(\sim 60 \AA^{2}\right)$ than the comparable 562 interaction areas between and within PCNA, RFC, and p/t-DNA to 505 subunits of $T_{4}$ and $E$. coli $\left(\sim 1125 \AA^{2}\right)$. The decrease in DNA interaction 563 approximate these forces.

506 from the $B, C, D$, and $E$ subunits is due to the p/t-DNA duplex region 564 PCNA is opened through a large conformational change in both 507 inserting deeper into the AAA+ spiral of the $\mathrm{T}_{4}$ and $E$. coli clamp 565 PCNA and RFC. In solution the open form is the predominant state 508 loaders than in RFC (Figure 6 - Supplement $4 \mathrm{~A}$ ). Therefore, the large 566 (Zhuang et al., 2006), so it is important to understand what 509 swing in the proportional interaction area is the net result of additional 567 interactions drive this opening. Upon opening, PCNA loses the entire 510 interactions from RFC-A and less from the remaining subunits. 568 interface between subunits I and III. However, the open PCNA ring 511 This proportionally large interaction area suggests RFC-A as the 569 increases its interaction area with RFC by contacting all five subunits. 512 subunit primarily responsible for recognizing DNA. This finding 570 Moreover, the crab claw motion of RFC results in tighter association 513 provides an attractive explanation for how alternative clamp loaders 571 between adjacent AAA+ modules. Altogether, the opening of PCNA 514 specifically recognize different DNA structures. RFC-like Complexes or 572 and RFC result in an increased interaction area of $\sim 4000 \AA^{2}$ (Figure 3 F). 515 RLCs are only found in eukaryotes and share four of RFC's five 573 We propose that this is the driving force for stabilizing the open form 516 subunits (RFC-B through RFC-E); each RLC contains a unique A 574 of PCNA.

517 subunit (Majka and Burgers, 2004). We hypothesize that the 575 Once open, p/t-DNA enters the PCNA:RFC complex through the A518 diminished role of the $B, C, D$, and $E$ subunits in DNA recognition 576 gate. The A-gate is wide enough for dsDNA to directly enter into the 519 allows the A-subunit to assume the role of specifically binding unique 577 RFC:PCNA inner chamber. This finding is in direct contradiction of the 520 structures of DNA. In support of this hypothesis, bacterial and phage 578 "filter-and-slide" model for DNA binding that posited that the opening 521 clamp loaders do not have alternative forms that recognize different 579 is large enough for only ssDNA to enter such that the clamp loader 522 DNA structures, and their clamp loaders have substantially more 580 filtered out dsDNA to accelerate the search for a p/t-junction (Kelch, 523 contact between DNA and the B, C, D, and E subunits. The more 581 2016; Kelch et al., 2011, 2012). The filter-and-slide model was primarily 524 pronounced role of the $A$ subunit in eukaryotic clamp loaders allows 582 predicated on crystal structures of the T4 phage clamp loader and on 525 for dramatically more plasticity in function. Further, the diminished 583 FRET data that suggested that initial binding of DNA does not 526 role of the remaining subunits raises the question of how the pivot 584 constrict the open clamp (Kelch et al., 2011; Zhuang et al., 2006). 527 point at the $C$ subunit contributes to the activity of RLC complexes. 585 While it remains a possibility that other clamp loaders use a filter-and528 Finally, these findings raise the intriguing possibility of engineering 586 slide mechanism, our structures clearly indicate that yeast RFC uses 529 RLCs with novel specificity and activity.

587 the much more simple direct binding model.

530 Following this reasoning even further, we hypothesized that RFC 588 Once DNA is bound, PCNA must close around the ring before 531 flips the 3' nucleotide to specifically recognize the recessed 3' end of 589 ejection of the RFC complex. Rapid kinetics studies showed that ATP $532 \mathrm{p} / \mathrm{t}-\mathrm{DNA}$. We observe flipping of the $3^{\prime}$ nucleotide in both the 590 hydrolysis precedes clamp closure under normal conditions (Liu et al., 533 DNA $^{\text {PCNA-open }}$ and DNA ${ }^{\text {PCNA-closed }}$ structures, indicating that flipping can 591 2017; Marzahn et al., 2014; Sakato et al., 02/2012). Taken together, 534 occur before ring closure. This observation can explain the "DNA 592 these two points could lead to the conclusion that ATP hydrolysis 535 repositioning transition" that occurs quickly (t1/2 $35 \mathrm{~ms}$ ) after initial 593 provides the energy to actively close the clamp after loading DNA. 536 DNA binding, but before clamp closure (Liu et al., 2017). We propose 594 However, we observe this transition from our DNA ${ }^{\text {PCNA-open }}$ and 537 that this transition is the flipping of the $3^{\prime}$ nucleotide. However, the 595 DNA ${ }^{\text {PCNA-closed }}$ structures, and neither structure shows evidence of ATP 538 flipping mechanism does not appear to be used to discriminate 596 hydrolysis, suggesting that PCNA can close before ATP hydrolyzes. To 539 between different DNA architectures. The W638G and F582A variants 597 harmonize all of the available data, we must draw a new conclusion, 540 have a similar DNA discrimination profile as WT-RFC, despite having 598 which is that while ATP hydrolysis typically occurs prior to clamp 541 very different base-flipping activity (Figure 6E, Figure 6 - Supplement 599 closure, it is not strictly required, and clamp closure can precede 542 2). Moreover, the physiological role of base-flipping is unclear, as 600 hydrolysis if the hydrolysis step becomes rate-limiting, as would likely 543 yeast carrying these variants have no obvious cellular defects (Figure 6601 occur with the slowly hydrolysable ATPYS. It still remains possible that 
602 ATP hydrolysis could make clamp closure easier, by weakening 660 upon DNA binding should not be overlooked. Further studies will be 603 interactions between RFC and PCNA/DNA, but in this view clamp 661 necessary to reveal how RFC integrates binding of both PCNA and p/t604 closure is still a spontaneous process and does not require harvesting 662 DNA to achieve full activation.

605 energy from ATP hydrolysis. Therefore, it is possible that ATP 663

606 hydrolysis can proceed from either DNA ${ }^{\text {PCNA-open }}$ and DNA ${ }^{\text {PCNA-closed }} 664$ Comparison with other AAA+ machines

607 states, but most commonly from the DNA ${ }^{\text {PCNA-open }}$ state. 665 Clamp loaders have long been models for structure and mechanism 608 This raises the question as to how DNA stimulates ATP hydrolysis 666 of AAA+ proteins (Guenther et al., 1997). However, they are unusual in 609 and subsequent ejection of the clamp loader. We note that the 667 that they are pentameric protein remodeling switches instead of the 610 ATPase active sites do not change much from the Open to DNA ${ }^{\text {PCNA- }} 668$ more typical hexameric rings that act as processive motors (Hanson $611^{\text {open }}$ or DNA ${ }^{\text {PCNA-closed }}$ conformations (Figure 5 - Supplemental 2). It is 669 and Whiteheart, 2005; Kelch, 2016). We note that conformational 612 also surprising that the AAA+ modules are already in a symmetrized 670 changes that we observe here in RFC appear to be more dramatic than 613 pose prior to DNA loading, because DNA had been thought to be the 671 those typically seen during motor function. This is likely because the 614 driving force for symmetrizing the AAA+ spiral (Kelch et al., 2011; 672 constraints imposed by ring closure limits the types of motions that 615 Simonetta et al., 05/2009), and this symmetry had been thought to 673 are available. On the other hand, the open nature of the RFC complex 616 favor ATP hydrolysis. Despite this symmetry, the RFC:PCNA complex 674 is less constrained and so can adopt more dramatic conformational 617 (corresponding to the Open1 and Open2 structures) has $\sim 5$-10-fold 675 changes. We further note that these types of large conformational 618 lower ATPase activity than when both PCNA and DNA are bound 676 changes are more commonplace in other members of the 619 (Figure 6F, Chen et al., 5/2009; Gomes et al., 2001; McNally et al., 677 Initiator/Loader class of AAA+ machines. We propose that the open 620 2010; Sakato et al., 02/2012). This implies that, whereas clamp 678 nature of this class provides larger conformational variability that is 621 opening is both necessary and sufficient for symmetrizing the AAA+ 679 necessary for the regulation of these switch-like machines.

622 modules, this symmetry by itself is not sufficient to stimulate ATP 680

623 hydrolysis.

624 There remain many possible avenues for DNA to stimulate ATP 625 hydrolysis. In many AAA+ enzymes, it has been shown that certain 626 residues couple ligand binding and ATP hydrolysis by activating the 627 Walker B glutamate residue (Zhang and Wigley 2008). A set of 628 conserved arginines (termed the arginine switch residues) within the 629 core of the AAA+ module were proposed to play this role in clamp 630 loaders (Kelch et al., 2011). The arginine switch residues had been 631 hypothesized to flip outward to grip DNA, thereby releasing the 632 Walker B catalytic glutamate to activate ATP hydrolysis. However, the 633 lack of flipping of the arginine switch residues in response to DNA 634 binding in our structures argues that the proposed arginine switch 635 mechanism is not critical for sensing and responding to DNA binding. 636 Our observations are in agreement with previous studies that found 637 that the arginine switch residues of RFC do not likely play a direct role 638 in activating ATP hydrolysis, but are important for the synergistic 639 activation by both PCNA binding and DNA binding (Liu et al., 2017). 640 An alternative route, involving a different arginine residue interacting 641 with the ATPase active site, has recently been proposed for DnaC and 642 extended to RFC (Puri et al. 2021). However, we again do not see 643 structural evidence supporting this mechanism. We cannot rule out 644 these mechanisms (or a combination of the two), as these types of 645 interactions may occur just before hydrolysis and are not readily 646 apparent in stalled structures. A recent study on the T4 clamp loader 647 suggests that structural rigidity of a "central coupler" that encircles 648 DNA is important for hydrolysis (Subramanian et al. 2021). Thus, tight 649 binding of RFC to DNA could provide rigidity necessary to stimulate 650 ATP hydrolysis.

651 Lastly, we note that while DNA ${ }^{\text {PCNA-open }}$ and DNA ${ }^{\text {PCNA-closed have }}$ 652 similar overall interaction areas, PCNA interacts with DNA much more 653 intimately in the DNA ${ }^{\mathrm{PCNA} \text {-closed }}$ structure, with direct contact to several 654 conserved basic residues lining the PCNA inner pore. Lys20, Arg8o, 655 and Arg147 in particular show close interaction with the PCNA ring. 656 These residues have been independently identified as critical for 657 efficient DNA binding, ATP hydrolysis and clamp loading (McNally et 658 al., 2010; Zhou and Hingorani, 2012). Therefore, PCNA is an allosteric 659 effector in its own loading and its role in stimulating ATPase activity 
681 MATERIALS AND METHODS

682

\begin{tabular}{|c|c|c|c|c|}
\hline \multicolumn{5}{|c|}{ Key Resources Table } \\
\hline $\begin{array}{l}\text { Reagent type } \\
\text { (species) or } \\
\text { resource }\end{array}$ & Designation & Source or reference & Identifiers & Additional information \\
\hline $\begin{array}{l}\text { strain, strain } \\
\text { background } \\
\text { (Escherichia } \\
\text { coli) }\end{array}$ & $\mathrm{BL} 21\left(\mathrm{DE}_{3}\right)$ & Novagen & 69450 & Chemically competent cells \\
\hline $\begin{array}{l}\text { recombinant } \\
\text { DNA reagent }\end{array}$ & $\begin{array}{l}\operatorname{pET}(11 a)- \\
\operatorname{RFC}[2+3+4] \\
\text { (plasmid) }\end{array}$ & Finkelstein et al., 2003 & & Expression plasmid \\
\hline $\begin{array}{l}\text { recombinant } \\
\text { DNA reagent }\end{array}$ & $\begin{array}{l}\text { pLANT-2/RIL[1+5] } \\
\text { (plasmid) }\end{array}$ & Finkelstein et al., 2003 & & Expression plasmid \\
\hline $\begin{array}{l}\text { recombinant } \\
\text { DNA reagent }\end{array}$ & $\begin{array}{l}\text { pRS413-RFC1 } \\
\text { (plasmid) }\end{array}$ & This study & & $\begin{array}{l}\text { Plasmid for yeast expression of Rfc1 } \\
\text { from endogenous promotor }\end{array}$ \\
\hline $\begin{array}{l}\text { Strain, strain } \\
\text { background } \\
\text { (S. cerevisiae) }\end{array}$ & $\begin{array}{l}\mathrm{BY} 4743 \\
\text { his3 } \Delta 1 / \text { his3 } \Delta 1 \\
\text { leu2 } \Delta \text { o/leu2 } \Delta \mathrm{o} \\
\text { LYS2/lys2 } \Delta \mathrm{o} \\
\text { met15 } \Delta \text { o/MET15 } \\
\text { ura3 } \Delta \text { o/ura3 } \Delta \mathrm{o} \\
\Delta \text { rfc1::KanMX } 4 / \\
\text { RFC1 }(Y O R 217 W)\end{array}$ & Dharmacon $^{\mathrm{TM}}$ & $\begin{array}{l}\text { YSC1055 } \\
(22473)\end{array}$ & Yeast Heterozygous Collection \\
\hline $\begin{array}{l}\text { software, } \\
\text { algorithm }\end{array}$ & RELION & doi: $10.7554 /$ eLife. 42166 & Relion 3.0.2 & \\
\hline $\begin{array}{l}\text { software, } \\
\text { algorithm }\end{array}$ & cisTEM & doi: $10.7554 /$ eLife. 35383 & $\begin{array}{l}\text { cisTEM-1.0.0- } \\
\text { beta }\end{array}$ & https://cistem.org/software \\
\hline $\begin{array}{l}\text { software, } \\
\text { algorithm }\end{array}$ & Ctffind & doi: $10.1016 / j . j s b .2015 .08 .008$ & Ctffind 4.1 & \\
\hline $\begin{array}{l}\text { software, } \\
\text { algorithm }\end{array}$ & UCSF Chimera & $\begin{array}{l}\text { UCSF, } \\
\text { doi: } 10.1002 / \mathrm{jcc} .20084\end{array}$ & & http://plato.cgl.ucsf.edu/chimera/ \\
\hline $\begin{array}{l}\text { software, } \\
\text { algorithm }\end{array}$ & ChimeraX & $\begin{array}{l}\text { UCSF, } \\
\text { doi: } 10.1002 / \text { pro. } 3943\end{array}$ & $\begin{array}{l}\text { ChimeraX- } \\
1.2\end{array}$ & https://www.cgl.ucsf.edu/chimerax/ \\
\hline $\begin{array}{l}\text { software, } \\
\text { algorithm }\end{array}$ & COOT & doi:10.1107/Sog07444910007493 & Coot-0.9.4 & $\begin{array}{l}\text { http://www2.mrc- } \\
\text { Imb.cam.ac.uk/personal/pemsley/coot/ }\end{array}$ \\
\hline $\begin{array}{l}\text { software, } \\
\text { algorithm }\end{array}$ & Phenix & doi:10.1107/Sog07444909052925 & $\begin{array}{l}\text { Phenix-dev- } \\
3699\end{array}$ & https://phenix-online.org \\
\hline
\end{tabular}




\begin{tabular}{|c|c|c|c|c|}
\hline $\begin{array}{l}\text { software, } \\
\text { algorithm }\end{array}$ & PyMOL & $\begin{array}{l}\text { PyMOL Molecular Graphics System, } \\
\text { Schrodinger LLC }\end{array}$ & & https://www.pymol.org/ \\
\hline $\begin{array}{l}\text { software, } \\
\text { algorithm }\end{array}$ & GraphPad PRISM & GraphPad & $\begin{array}{l}\text { GraphPad } \\
\text { PRISM 9.2.1 }\end{array}$ & http://www.graphpad.com/ \\
\hline other & Pyruvate kinase & Calzyme & $107 \mathrm{~A} 0250$ & \\
\hline other & $\begin{array}{l}\text { Lactate } \\
\text { Dehydrogenase }\end{array}$ & $\begin{array}{l}\text { Worthington Biochemical } \\
\text { Cooperation }\end{array}$ & LSoo 2755 & \\
\hline other & $\begin{array}{l}\text { Phosphoenol- } \\
\text { pyruvic acid } \\
\text { monopotassium salt }\end{array}$ & Alfa Aesar & $\mathrm{B} 20358$ & \\
\hline
\end{tabular}


737 excised, destained, and incubated with trypsin. The digested peptides 738 were extracted and desalted as previously described (Peled et al., 739 2018) and analyzed with LC-MS coupled to a ThermoFisher Scientific 684 RFC was purified as described previously with minor modifications 740 Q Exactive Mass Spectrometer in data dependent mode selecting only 685 (Finkelstein et al., 08/2003). pET(11a)-RFC $[2+3+4]$ and pLANT-2/RIL- 741 precursors of 3. The data was searched against the UniProt database, $686 \mathrm{RFC}[1+5]$ were transformed into $\mathrm{BL21}\left(\mathrm{DE}_{3}\right)$ E. coli cells (Millipore). 742 using Byonic and XlinkX of the Proteome Discoverer 2.3 package.

687 After preculture, transformants were grown in 4 liter of prewarmed 688 terrific broth medium supplemented with $50 \mu \mathrm{g} / \mathrm{mL}$ kanamycin and 743 Electron Microscopy $689100 \mu \mathrm{g} / \mathrm{mL}$ ampicillin at $37^{\circ} \mathrm{C}$ and induced with IPTG at an optical 690 density of 0.8 . Protein expression was continued at $18^{\circ} \mathrm{C}$ for 15 hours. 744 Negative-Staining EM

691 Cells were pelleted and resuspended in $300 \mathrm{ml}$ lysis buffer (30 mM $745100 \mathrm{nM}$ of RFC:PCNA was applied on carbon-coated $400-\mathrm{mesh}$ grids. 692 Hepes- $\mathrm{NaOH}$ pH 7.5, $250 \mathrm{mM} \mathrm{NaCl}, 0.25 \mathrm{mM}$ EDTA, 5\% glycerol, 2746 Excess sample was blotted from the grid surface, the grids were $693 \mathrm{mM} \mathrm{DTT}, 2 \mu \mathrm{g} / \mathrm{mL}$ aprotinin, $0.2 \mu \mathrm{g} / \mathrm{mL}$ pepstatin, $2 \mu \mathrm{g} / \mathrm{mL}$ leupeptin, 747 washed twice with $50 \mathrm{mM}$ Hepes $\mathrm{pH} 7.5$ and stained with $1 \%$ uranyl $6941 \mathrm{mM}$ PMSF). RFC was purified by chromatography over a $10 \mathrm{~mL} \mathrm{SP}-748$ acetate. RFC:PCNA was imaged on a $120 \mathrm{kV}$ Philips CM-120 695 Sepharose column (80 $\mathrm{mL}$ gradient of $300-600 \mathrm{mM} \mathrm{NaCl}$ in BufferC) 749 microscope fitted with a Gatan Orius SC10oo detector.

696 and a $10 \mathrm{~mL}$ Q-Sepharose column (40 mL gradient of $150-500 \mathrm{mM}$

$697 \mathrm{NaCl}$ in Buffer C, GEHealthcare). Peak fractions of hRFC were pooled 750

698 and dialyzed overnight into a buffer with $30 \mathrm{mM}$ Hepes- $\mathrm{NaOH} \mathrm{pH} \mathrm{7.5,}$

$699250 \mathrm{mM} \mathrm{NaCl}, 5 \%$ glycerol, and 2 mM DTT.

751 Cryo-EM sample preparation

752 Quantifoil R $0.6 / 1$ (DNA dataset) grids were washed with ethyl 753 acetate. Quantifoil and C-flat grids (Electron Microscopy Sciences) 700 PCNA was purified as described previously with modifications 754 were glow discharged with Pelco easiGlow for $60 \mathrm{~s}$ at $25 \mathrm{~mA}$ 701 (McNally et al., 2010). BL21(DE3) E. coli cells were transformed with a 755 (negative polarity). $2.8-3 \mu \mathrm{L}$ sample was applied to grids at $10{ }^{\circ} \mathrm{C}$ and 702 pET-28 vector that encodes PCNA with a Precission ${ }^{\mathrm{TM}}$ protease $75695 \%$ humidity in a Vitrobot Mark IV (FEI). Samples were blotted with a 703 cleavable $\mathrm{N}$-terminal 6 -His tag. After transformation, preculture and 757 force of 5 for $5 \mathrm{~s}$ after a $2 \mathrm{~s}$ wait and plunged into liquid ethane.

704 induction, 1 liter of cells was grown overnight at $18^{\circ} \mathrm{C}$ in terrific broth 758

705 medium supplemented with $50 \mu \mathrm{g} / \mathrm{mL}$ kanamycin. Cells were pelleted 759 Cryo-EM data collection

706 and resuspended $30 \mathrm{mM}$ Hepes $\mathrm{pH}$ 7.6, $20 \mathrm{mM}$ imidazole, $500 \mathrm{mM} 760$ RFC:PCNA was imaged on a Titan Krios operated at $300 \mathrm{kV}$ and $707 \mathrm{NaCl}, 10 \%$ glycerol, and $5 \mathrm{mM}$ b-mercaptoethanol. The cells were 761 equipped with an GIF energy filter at $130000 \times$ magnification and a 708 lysed, centrifuged and the filtered lysate was applied to a $5 \mathrm{~mL} 762$ pixel size of $0.53 \AA$ using a K2 Summit detector in super-resolution 709 HisTrap FF column (GEHealthcare). The column was washed with a 763 counting mode. The data was collected in four sessions with a target 710 buffer at $1 \mathrm{M} \mathrm{NaCl}$, and subsequently washed with a buffer at a low 764 defocus range of -1.1 to -2.4 and a total exposure of $\sim 49-51$ e-/ $\AA^{2}$ per 711 salt concentration ( $50 \mathrm{mM} \mathrm{NaCl}$ ). PCNA was eluted with a step of $50 \% 765$ micrograph averaging 50 frames. Image shift was used to record three 712 with $500 \mathrm{mM}$ imidazole. The eluted protein was cleaved with 766 images per hole with SerialEM (Mastronarde, 2003). Defective 713 Precission $^{\mathrm{TM}}$ protease for 2 hours at room temperature and applied to 767 micrographs were discarded leaving a total of 6109 micrographs for 714 a $5 \mathrm{~mL}$ HiTrap Q HP column (GE Healthcare). Protein was eluted from 768 processing. RFC:PCNA:DNA was imaged on a Titan Krios operated at 715 the Q HP column with a $2 \mathrm{M} \mathrm{NaCl}$ buffer in a $100 \mathrm{~mL}$ gradient. Peak $769300 \mathrm{kV}$ at $81000 \times$ magnification and a pixel size of $0.53 \AA$ with a K3 716 fractions were dialyzed against buffer containing $30 \mathrm{mM}$ Tris $\mathrm{pH} 7.5,770$ detector in super-resolution mode. A total of 4499 micrographs were $717100 \mathrm{mM} \mathrm{NaCl}$, and $2 \mathrm{mM}$ DTT. Purified proteins were concentrated 771 collected in one day with a target defocus of -1.2 to -2.3 and a total 718 with an Amicon concentration device, aliquoted and frozen in liquid 772 exposure of $\sim 40$ e- $/ \AA^{2}$ per micrograph averaging 30 frames.

719 nitrogen for storage at $-80^{\circ}$.

720 Crosslinking and Mass Spectrometry

773

774 Data Processing

775 Micrograph frames were aligned in IMOD (Kremer et al., 1996) with 2X 721 RFC and PCNA were mixed in a $1 / 1$ ratio and gel filtered into $1 \mathrm{mM} 776$ binning, resulting in a pixel size of $1.06 \AA ̊$ A $/$ pixel. Initial CTF estimation 722 TCEP, $200 \mathrm{mM} \mathrm{NaCl}, 25 \mathrm{mM}$ Hepes- $\mathrm{NaOH}_{1} \mathrm{pH}$ 7.5, and $4 \mathrm{mM} \mathrm{MgCl}_{2} .777$ and particle picking was performed using cisTEM (Grant et al., 2018; 723 The protein complex was diluted to $3 \mu \mathrm{M}$ and after the addition of 1778 Rohou and Grigorieff, 2015). Following particle picking, particles were $724 \mathrm{mM}$ ATPYS and $3 \mathrm{~min}$ incubation, $1 \mathrm{mM}$ of 779 extracted with a box size of 240 pixels and subjected to $2 \mathrm{D}$ 725 Bis(sulfosuccinimidyl)suberate (BS3, Thermo Scientific Pierce) was 780 classification into 100 classes. Particles from classes with well defined 726 added for crosslinking. For crosslinking of DNA-bound RFC:PCNA, 1781 features were selected for processing in Relion (Figure 1 $727 \mathrm{mM}$ ATPYS was added to the protein complex first and incubated for 2782 Supplements 2A,B, 3A,B). Coordinates and combined micrographs $728 \mathrm{~min} .7 \mu \mathrm{M}$ primer/template DNA was added and incubated for another 783 were imported into Relion 3.0.2 (Zivanov et al., 2018), CTF parameters $7291 \mathrm{~min}$. The primer sequence was 5' -GCAGACACTACGAGTACATA-3' 784 were re-estimated with Gctf1.06 (Zhang, 2016) and particles were 730 and the template sequence was 5'-785 subjected to several rounds of 3D classification (Figure 1 731 TTTTTTTTTTTATGTACTCGTAGTGTCTGC-3'. Crosslinking was 786 Supplements 2D, 3C). For 3D classification of the RFC:PCNA dataset, 732 started with $1 \mathrm{mM} \mathrm{BS}_{3}$, incubated for $15 \mathrm{~min}$ at room temperature, 787 an ab initio model was generated with cisTEM, down-filtered to $50 \AA$ 733 and neutralized with Tris- $\mathrm{HCl}$.

788 and used as reference (Figure 1 - Supplement $2 \mathrm{C}$ ). For $3 \mathrm{D}$ classification 734 Sample without DNA was analyzed by mass spectrometry. The 789 of the RFC:PCNA:DNA dataset, class Open1 of the RFC:PCNA dataset 735 sample was reduced, alkylated, and loaded onto SDS-PAGE gel. The 790 was down-filtered to $60 \AA$ and used as reference. Selected, well $736 \mathrm{gel}$ band corresponding to the crosslinked complex >150kDa was 791 resolved 3D classes were refined with Relion. The cryo-EM density was 
792 postprocessed in Relion for estimating the resolution and density 846 performed in the presence of $375 \mathrm{nM}$ DNA, $0.5 \mu \mathrm{M}$ RFC, and $2.5 \mu \mathrm{M}$ 793 modified with PHENIX for model building and refinement (Terwilliger 847 PCNA. Experiments Figure 6D and E were performed with 150 nM 794 et al., 2020 Table 3). Model information was not used during density 848 DNA, $1 \mu M$ RFC, and $2.5 \mu M$ PCNA. 795 modification.

796

\section{Model Building and Refinement} 79 799 used for initial fitting of Autoinhibited1. All subunits were split into 853 or pRS413-RFC 1 for yeast complementation. pRS413-RFC 1 contains 800 globular domains and fitted into the cryo-EM density with UCSF 854 the entire RFC 1 sequence, where RFC 1 is expressed under the control 801 Chimera (Pettersen et al., 2004). The model was adjusted in Coot 855 of its own promotor.

802 (Emsley and Cowtan, 2004), and real-space iteratively refined with 856

803 two macrocycles in PHENIX1.17 (Liebschner et al., 2019). 857 Yeast strains and spot assay

804 Autoinhibited2,3 cryo-EM densities were rigid body fit with the refined 858 The genotype of the $S$. cerevisiae strain which was used in this study 805 model of Autoinhibited1, manually adjusted in coot and refined.

806 The refined model of Autoinhibited1 (Figure 1 - Supplement $1 \mathrm{C}$ ) was 807 fragmented into individual subunit domains and rigid body fitted into 808 the cryo-EM density of Openz. The resulting model was further 809 flexibly fitted and refined with Namdinator (Kidmose et al, 2019). The 863 For the

作 810 resulting model was adjusted in Coot, and refined in PHENIX. The 864 inoculated into $3 \mathrm{ml} \mathrm{SC-His} \mathrm{media} \mathrm{and} \mathrm{grown} \mathrm{for} 3-4$ hours to an OD of 811 model of Open2 was used for fitting the Open1 cryo-EM density. The 8650.8 . Serial 10-fold dilutions of the culture starting from OD of o.2 were 812 fitted model was manually adjusted in Coot and refined in PHENIX. 866 plated as 4 Ul drops onto YPD plates with or without chemical additives 813 The cryo-EM density of DNA ${ }^{\text {PCNA-closed }}$ (Figure 1-Supplement $3 \mathrm{C}$ ) was 867 (0.01\% methyl methanesulfonate (MMS), 100 mM hydroxyurea (HU)). 814 fitted using the Autoinhibitedı model and DNA was modelled in Coot. 868 For UV treatment, the spotted yeast was irradiated with 30 , or 100 815 The resulting model was further flexibly fitted and refined with $869 \mathrm{~J} / \mathrm{m} 2$ using a UVP UV Crosslinker. The plates were imaged after 816 Namdinator (Kidmose et al., 2019). The model was then adjusted in 870 incubating at $18^{\circ} \mathrm{C}$ for 7 days, or at $30^{\circ} \mathrm{C}, 37^{\circ} \mathrm{C}$ for 3 days.

817 Coot, and refined in PHENIX. The Namdinator output model of 871

818 DNA $^{\text {PCNA-closed }}$ was used for fitting of the DNA ${ }^{\text {PCNA-open }}$ cryo-EM

819 density. The fitted model was manually adjusted in Coot and

820 subjected to refinement in PHENIX. Interface areas were analyzed

821 with the PISA server (Krissinel and Henrick, 2007). UCSF Chimera and 822 Pymol were used for figure generation (DELANO and W. L, 2002; 823 Pettersen et al., 2004).

\section{ATPase Assays}

$8250.3 \mu \mathrm{M}$ (Figure $6 \mathrm{~F}$ ) or $0.15 \mu \mathrm{M}$ RFC (Figure S9D) was incubated with a 826 master mix (3 U/mL Pyruvate kinase, $3 \mathrm{U} / \mathrm{mL}$ Lactate dehydrogenase $8271 \mathrm{mM}$ ATP, $670 \mu \mathrm{M}$ Phosphoenol pyruvate, $170 \mu \mathrm{M}$ NADH, $50 \mathrm{mM}$ Tris $828(\mathrm{pH} 7.5), 0.5 \mathrm{mM}$ TCEP, $5 \mathrm{mM} \mathrm{MgCl} 2,200 \mathrm{mM}$ potassium glutamate, $82940 \mathrm{mM} \mathrm{NaCl}), 1 \mu \mathrm{M}$ PCNA, and annealed primer/template DNA ( $2 \mu \mathrm{M}$ 830 Figure 6F, varying amounts Figure 6 - Supplement 1D). ATPase 831 activity was measured at $25^{\circ} \mathrm{C}$ with the 2014 EnVison ${ }^{\circledR}$ Multilabel 832 Plate Reader to detect NAD+. Rates were obtained from a linear fit of 833 the slopes using GraphPad Prism. For the ATPase activity 834 measurements shown in Figure 6 - Supplement 2, $0.12 \mu \mathrm{M}$ RFC was 835 incubated with $1 \mu \mathrm{M}$ PCNA and $0.03 \mu \mathrm{M}$ different DNA constructs (as 836 described in Table 4) and the master mix and buffer described above. 837 ATPase activity was measured at room temperature. For each data 838 point three experimental replicates were performed.

\section{2-AP Fluorescence}

840 2-Aminopurine (2AP) fluorescent samples were excited at $315 \mathrm{~nm}$ (5 $841 \mathrm{~mm}$ slit width), and emission was detected at $370 \mathrm{~nm}$ (7 mm slit width) 842 with a FluoroMax 4 (Horiba Join Yvon Inc). Reactions contained 150 or $843375 \mathrm{nM}$ annealed DNA (Table 4 ) and 0.5 or $1 \mu \mathrm{M} \mathrm{RFC}$ in a buffer with 50 $844 \mathrm{mM}$ Hepes- $\mathrm{NaOH}$ pH 7.5, $200 \mathrm{mM} \mathrm{NaCl}, 4 \mathrm{mM} \mathrm{MgCl} 2,1 \mathrm{mM}$ TCEP and 845 were carried out at room temperature. Experiments Figure $6 \mathrm{C}$ were

\section{ACKNOWLEDGMENTS}

873 The authors thank Drs. C. Xu, KK Song, and K. Lee for assistance with 874 data collection, and Drs. C. Xu, and A. Jecrois for advice on data 875 processing. Additionally, we thank Dr. M. Hingorani for providing us 876 with the RFC expression plasmids. We thank J. Andrade and Dr. B. 877 Ueberheide for analyzing the crosslinked sample with mass 878 spectrometry. We thank members of the Kelch, Royer, and Schiffer 879 labs for helpful discussions. This work was funded by NIGMS (Ro1880 GM127776). C.G. was supported by an Early and Advanced Postdoc 881 Mobility (grant numbers 168972 and 177859) Fellowship of the Swiss 882 National Science Foundation. G.D. was supported by LL2008 project 883 with financial support from the MEYS CR as a part of the ERC CZ 884 program. 885

886 COMPETING INTERESTS

887 The authors declare no conflict of interest. 888

(n)
849
850 Plasmid generation
851 The separation pin variants were introduced with site-directed
852 mutagenesis in either pLANT-2/RIL-RFC $[1+5]$ for protein purification
853 or pRS $413-R_{1} C_{1}$ for yeast complementation. pRS $413-R_{1} C_{1}$ contains
854 the entire RFC 1 sequence, where RFC $C_{1}$ is expressed under the control
855 of its own promotor.

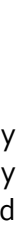
. 


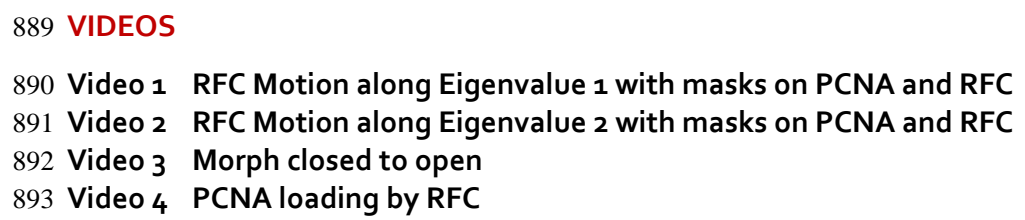

\section{SOURCE DATA}

895 Figure 1 - Source data 1

Image of full RFC and PCNA gel filtration gel.

896 Figure 6 - Source data 1

2-aminopurine fluorescence and ATPase data.

897 Figure 6 - Figure Supplement 1- Source data 1 2-aminopurine fluorescence and ATPase data.

898 Figure 6 - Figure Supplement 2- Source data 1 ATPase data.

899

900 TABLES

901 Table 1: Clamp loader structures previously obtained for the various states in the clamp loading cycle.

\begin{tabular}{|c|c|c|c|}
\hline \multicolumn{4}{|c|}{ Clamp loader prior to clamp binding } \\
\hline Species & Composition & Reference & $\begin{array}{l}\text { PDB accession } \\
\text { number }\end{array}$ \\
\hline E. coli & Clamp loader alone & Jeruzalmi et al., 2001 & $1 \mathrm{JR}_{3}$ \\
\hline E. coli & Clamp loader, ADP & Kazmirski et al., 2004 & $1 X X I$ \\
\hline E. coli & $\begin{array}{l}\text { Clamp loader, ATP } \\
\text { analog }\end{array}$ & Kazmirski et al., 2004 & $1 \mathrm{XXH}$ \\
\hline E. coli & $\begin{array}{l}\text { Clamp loader, ATP } \\
\text { analog, } \\
\text { primer/template DNA }\end{array}$ & $\begin{array}{l}\text { Simonetta et al., } \\
2009\end{array}$ & 3GLF \\
\hline \multicolumn{4}{|c|}{ Encounter complex of clamp loader bound to the closed clamp } \\
\hline H. sapiens & $\begin{array}{l}\text { Clamp loader bound } \\
\text { to the clamp, ATP } \\
\text { analog }\end{array}$ & Gaubitz et al., 2020 & $6 \mathrm{VVO}$ \\
\hline S. cerevisiae & $\begin{array}{l}\text { Clamp loader bound } \\
\text { to the closed clamp, } \\
\text { ATP analog }\end{array}$ & Bowman et al., 2004 & $1 S X J$ \\
\hline \multicolumn{4}{|c|}{ Clamp loader bound to the clamp and primer/template DNA } \\
\hline T4 phage & $\begin{array}{l}\text { Clamp loader, open } \\
\text { clamp, ATP analog, } \\
\text { DNA }\end{array}$ & Kelch et al., 2011 & $3 \cup 60$ \\
\hline T4 phage & $\begin{array}{l}\text { Clamp loader, closed } \\
\text { clamp, ATP analog, } \\
\text { DNA }\end{array}$ & Kelch et al., 2011 & $3 U_{5} Z$ \\
\hline T4 phage & $\begin{array}{l}\text { Clamp loader, closed } \\
\text { clamp, ATP analog, } \\
\text { ADP, DNA }\end{array}$ & Kelch et al., 2011 & $3 \cup 61$ \\
\hline
\end{tabular}

902

903 
904 Table 2: List of BS3 Crosslinks

\begin{tabular}{|c|c|c|c|c|c|c|c|c|}
\hline $\begin{array}{l}\text { XlinkX } \\
\text { Score }\end{array}$ & Type & $\begin{array}{l}\text { \# } \\
\text { Crosslink } \\
\text { Spectral } \\
\text { Matches }\end{array}$ & Sequence $\mathrm{A}$ & $\begin{array}{l}\text { Position } \\
\text { A }\end{array}$ & Sequence B & $\begin{array}{l}\text { Position } \\
\text { B }\end{array}$ & $\begin{array}{l}\text { Protein } \\
\text { A }\end{array}$ & $\begin{array}{l}\text { Protein } \\
\text { B }\end{array}$ \\
\hline 58,66 & Inter & 1 & [K]LHLPPGK & 100 & [K]LAATR & 274 & $\mathrm{RFC}_{4}$ & $\mathrm{RFC}_{1}$ \\
\hline 58,64 & Inter & 3 & $\begin{array}{l}\text { [K]LELNVVSSPYHLEITPSDM } \\
\text { GNNDR }\end{array}$ & 82 & $\mathrm{~S}[\mathrm{~K}] \mathrm{TLLNAGVK}$ & 385 & $\mathrm{RFC}_{5}$ & $\mathrm{RFC}_{1}$ \\
\hline 56,99 & Inter & 3 & [K]YVNTFMK & 285 & DIL[K]R & 220 & RFC2 & $\mathrm{RFC}_{5}$ \\
\hline 56,47 & Inter & 1 & NOI[K]DFASTR & 98 & [K]LAATR & 274 & $\mathrm{RFC}_{3}$ & $\mathrm{RFC}_{1}$ \\
\hline 52,59 & Inter & 2 & E[K]VKNFAR & 109 & TME[K]YSK & 160 & RFC2 & $\mathrm{RFC}_{5}$ \\
\hline 50,97 & Inter & 1 & NOI[K]DFASTR & 98 & RPDANSI[K]SR & 484 & $\mathrm{RFC}_{3}$ & $\mathrm{RFC}_{1}$ \\
\hline 48,17 & Inter & 1 & GASEALA[K]R & 182 & [K]IVKER & 269 & $\mathrm{RFC}_{1}$ & $\mathrm{RFC}_{5}$ \\
\hline 45,16 & Inter & 1 & YT[K]NTR & 139 & [K]EEER & 267 & $\mathrm{RFC}_{3}$ & $\mathrm{RFC}_{1}$ \\
\hline 41,65 & Inter & 1 & [K]LEEQHNIATK & 249 & $\mathrm{YT}[\mathrm{K}] \mathrm{NTR}$ & 139 & $\mathrm{RFC}_{1}$ & $\mathrm{RFC}_{3}$ \\
\hline 91,6 & Intra & 3 & [K]LEEQHNIATK & 249 & RPDANSI[K]SR & 484 & $\mathrm{RFC}_{1}$ & $\mathrm{RFC}_{1}$ \\
\hline 72,73 & Intra & 4 & EAELLV[K]KEEER & 266 & [K]LAATR & 274 & $\mathrm{RFC}_{1}$ & $\mathrm{RFC}_{1}$ \\
\hline 71,87 & Intra & 12 & $\begin{array}{l}\text { OLIAGMPAEGGDGEAAE[K] } \\
\text { AR }\end{array}$ & 245 & R[K]LEEOHNIATK & 249 & $\mathrm{RFC}_{1}$ & $\mathrm{RFC}_{1}$ \\
\hline 71,27 & Intra & 2 & E[K]FKLDPNVIDR & 495 & [K]LAATR & 274 & $\mathrm{RFC}_{1}$ & $\mathrm{RFC}_{1}$ \\
\hline 71,03 & Intra & 1 & F[K]LDPNVIDR & 497 & [K]LAATR & 274 & $\mathrm{RFC}_{1}$ & $\mathrm{RFC}_{1}$ \\
\hline 71,03 & Intra & 9 & [K]TSTPLILICNER & 446 & S[K]TLLNAGVK & 385 & $\mathrm{RFC}_{1}$ & $\mathrm{RFC}_{1}$ \\
\hline 64 & Intra & 1 & EAELLV[K]KEEER & 266 & S[K]KLAATR & 273 & $\mathrm{RFC}_{1}$ & $\mathrm{RFC}_{1}$ \\
\hline 62,71 & Intra & 1 & RPDANSI[K]SR & 484 & SA[K]YYR & 678 & $\mathrm{RFC}_{1}$ & $\mathrm{RFC}_{1}$ \\
\hline 62,2 & Intra & 2 & YAPTNLOOVCGN[K]GSVMK & 314 & L[K]NWLANWENSKK & 321 & $\mathrm{RFC}_{1}$ & $\mathrm{RFC}_{1}$ \\
\hline 61,3 & Intra & 4 & EAELLVK[K]EEERSK & 267 & [K]LAATR & 274 & $\mathrm{RFC}_{1}$ & $\mathrm{RFC}_{1}$ \\
\hline 60,15 & Intra & 1 & FAFACNOSN[K]IIEPLOSR & 149 & VT[K]NLAOVK & 275 & $\mathrm{RFC}_{4}$ & $\mathrm{RFC}_{4}$ \\
\hline 60,15 & Intra & 3 & YS[K]LSDEDVLKR & 165 & VT[K]NLAQVK & 275 & $\mathrm{RFC}_{4}$ & $\mathrm{RFC}_{4}$ \\
\hline 58,98 & Intra & 1 & IPATV[K]SGFTR & 767 & HAG[K]DGSGVFR & 340 & $\mathrm{RFC}_{1}$ & $\mathrm{RFC}_{1}$ \\
\hline 58,55 & Intra & 4 & GASEALA[K]R & 182 & VT[K]SISSK & 190 & $\mathrm{RFC}_{1}$ & $\mathrm{RFC}_{1}$ \\
\hline 57,1 & Intra & 3 & RPDANSI[K]SR & 484 & [K]EEER & 267 & $\mathrm{RFC}_{1}$ & $\mathrm{RFC}_{1}$ \\
\hline 56,99 & Intra & 1 & KLEEOHNIAT[K]EAELLVK & 259 & [K]EEER & 267 & $\mathrm{RFC}_{1}$ & RFC1 \\
\hline 56,99 & Intra & 1 & DNVVREED[K]LWTVK & 296 & [K]EEER & 267 & $\mathrm{RFC}_{1}$ & $\mathrm{RFC}_{1}$ \\
\hline 56,41 & Intra & 1 & [K]YNSMTHPVAIYR & 773 & LGTSTD[K]IGLR & 698 & $\mathrm{RFC}_{1}$ & $\mathrm{RFC}_{1}$ \\
\hline 53,33 & Intra & 1 & Y[K]CVIINEANSLTK & 136 & L[K]IDVR & 69 & $\mathrm{RFC}_{5}$ & $\mathrm{RFC}_{5}$ \\
\hline 52,59 & Intra & 2 & [K]ASSPTVKPASSK & 77 & [K]TKPSSK & 90 & $\mathrm{RFC}_{1}$ & $\mathrm{RFC}_{1}$ \\
\hline 52,59 & Intra & 2 & HAG[K]DGSGVFR & 340 & GSVM[K]LK & 319 & $\mathrm{RFC}_{1}$ & $\mathrm{RFC}_{1}$ \\
\hline 52,59 & Intra & 2 & ASSPTV[K]PASSK & 84 & [K]TKPSSK & 90 & $\mathrm{RFC}_{1}$ & $\mathrm{RFC}_{1}$ \\
\hline 51,79 & Intra & 2 & [K]LEEOHNIATK & 249 & [K]LAATR & 274 & $\mathrm{RFC}_{1}$ & $\mathrm{RFC}_{1}$ \\
\hline 50,97 & Intra & 1 & [K]TATSKPGGSK & 845 & S[K]TLLNAGVK & 385 & $\mathrm{RFC}_{1}$ & $\mathrm{RFC}_{1}$ \\
\hline 50,34 & Intra & 1 & KMPVSNVIDVSETPEGE[K]K & 68 & LPLPA[K]R & 75 & $\mathrm{RFC}_{1}$ & $\mathrm{RFC}_{1}$ \\
\hline 49,59 & Intra & 4 & EKF[K]LDPNVIDR & 497 & RPDANSI[K]SR & 484 & $\mathrm{RFC}_{1}$ & $\mathrm{RFC}_{1}$ \\
\hline 47,92 & Intra & 1 & LGTSTD[K]IGLR & 698 & [K]LAATR & 274 & $\mathrm{RFC}_{1}$ & $\mathrm{RFC}_{1}$ \\
\hline 47,92 & Intra & 1 & $\mathrm{~S}[\mathrm{~K}] \mathrm{TLLNAGVK}$ & 385 & [K]LAATR & 274 & $\mathrm{RFC}_{1}$ & $\mathrm{RFC}_{1}$ \\
\hline
\end{tabular}




\begin{tabular}{|c|c|c|c|c|c|c|c|c|}
\hline 47,92 & Intra & 1 & GASEALA[K]R & 182 & [K]LAATR & 274 & $\mathrm{RFC}_{1}$ & $\mathrm{RFC}_{1}$ \\
\hline 47,85 & Intra & 2 & SISS[K]TSVVVLGDEAGPK & 195 & [K]LEEQHNIATK & 249 & $\mathrm{RFC}_{1}$ & $\mathrm{RFC}_{1}$ \\
\hline 47,85 & Intra & 1 & [K]YNSMTHPVAIYR & 773 & [K]TATSKPGGSK & 845 & $\mathrm{RFC}_{1}$ & $\mathrm{RFC}_{1}$ \\
\hline 46,57 & Intra & 4 & R[K]LEEQHNIATK & 249 & GASEALA[K]R & 182 & $\mathrm{RFC}_{1}$ & $\mathrm{RFC}_{1}$ \\
\hline 46,35 & Intra & 1 & [K]ASSPTVKPASSK & 77 & VT[K]SISSK & 190 & $\mathrm{RFC}_{1}$ & $\mathrm{RFC}_{1}$ \\
\hline 45,16 & Intra & 1 & YAPTNLOOVCGN[K]GSVMK & 314 & [K]EEER & 267 & $\mathrm{RFC}_{1}$ & $\mathrm{RFC}_{1}$ \\
\hline 45,16 & Intra & 1 & E[K]FKLDPNVIDR & 495 & [K]EEER & 267 & $\mathrm{RFC}_{1}$ & $\mathrm{RFC}_{1}$ \\
\hline 45,16 & Intra & 2 & [K]LEEOHNIATK & 249 & [K]EEER & 267 & $\mathrm{RFC}_{1}$ & $\mathrm{RFC}_{1}$ \\
\hline 44,72 & Intra & 1 & E[K]FKLDPNVIDR & 495 & RPDANSI[K]SR & 484 & $\mathrm{RFC}_{1}$ & $\mathrm{RFC}_{1}$ \\
\hline 44,45 & Intra & 1 & YAPTNLOOVCGN[K]GSVMK & 314 & [K]LEEOHNIATK & 249 & $\mathrm{RFC}_{1}$ & $\mathrm{RFC}_{1}$ \\
\hline 44,14 & Intra & 2 & NLP[K]MRPFDR & 462 & S[K]TLLNAGVK & 385 & $\mathrm{RFC}_{1}$ & $\mathrm{RFC}_{1}$ \\
\hline 44,14 & Intra & 1 & RPDANSI[K]SR & 484 & GASEALA[K]R & 182 & $\mathrm{RFC}_{1}$ & $\mathrm{RFC}_{1}$ \\
\hline 44,12 & Intra & 1 & [K]LEEOHNIATK & 249 & [K]TKPSSK & 90 & $\mathrm{RFC}_{1}$ & $\mathrm{RFC}_{1}$ \\
\hline 43,7 & Intra & 1 & NLP[K]MRPFDR & 462 & LGTSTD[K]IGLR & 698 & $\mathrm{RFC}_{1}$ & $\mathrm{RFC}_{1}$ \\
\hline 43,7 & Intra & 1 & [K]YNSMTHPVAIYR & 773 & TATS[K]PGGSK & 850 & $\mathrm{RFC}_{1}$ & $\mathrm{RFC}_{1}$ \\
\hline 41,98 & Intra & 2 & LGTSTD[K]IGLR & 698 & RPDANSI[K]SR & 484 & $\mathrm{RFC}_{1}$ & $\mathrm{RFC}_{1}$ \\
\hline 41,98 & Intra & 1 & [K]LEEOHNIATK & 249 & F[K]LDPNVIDR & 497 & $\mathrm{RFC}_{1}$ & $\mathrm{RFC}_{1}$ \\
\hline 41,98 & Intra & 1 & HAG[K]DGSGVFR & 340 & VT[K]SISSK & 190 & $\mathrm{RFC}_{1}$ & $\mathrm{RFC}_{1}$ \\
\hline 41,94 & Intra & 1 & NQI[K]DFASTR & 98 & YT[K]NTR & 139 & $\mathrm{RFC}_{3}$ & $\mathrm{RFC}_{3}$ \\
\hline 40,95 & Intra & 1 & NLAOV[K]ESVR & 281 & IHKLNN[K]A & 322 & $\mathrm{RFC}_{4}$ & $\mathrm{RFC}_{4}$ \\
\hline 40,92 & Intra & 1 & KLPLPA[K]R & 75 & [K]EEER & 267 & $\mathrm{RFC}_{1}$ & $\mathrm{RFC}_{1}$ \\
\hline
\end{tabular}


906 Table 3: Cryo-EM data collection, processing, and model statistics

\begin{tabular}{|c|c|c|c|c|c|c|c|}
\hline Dataset & \multicolumn{4}{|c|}{ NO DNA } & \multicolumn{3}{|c|}{ DNA } \\
\hline Magnification & \multicolumn{4}{|c|}{130,000} & \multicolumn{3}{|c|}{81,000} \\
\hline Voltage (keV) & \multicolumn{4}{|c|}{300} & \multicolumn{3}{|c|}{300} \\
\hline $\begin{array}{l}\text { Cumulative exposure } \\
\left(\mathrm{e}-/ \AA \AA_{2} 2\right)\end{array}$ & \multicolumn{4}{|c|}{$49-51$} & \multicolumn{3}{|c|}{40} \\
\hline Detector & \multicolumn{4}{|c|}{ K2 Summit } & \multicolumn{3}{|c|}{$\mathrm{K}_{3}{ }^{\mathrm{TM}}$} \\
\hline Pixel size $(\AA ̊)$ & \multicolumn{4}{|c|}{1.059} & \multicolumn{3}{|c|}{1.06} \\
\hline Defocus range $(\mu \mathrm{m})$ & \multicolumn{4}{|c|}{-1.1 to -2.4} & \multicolumn{3}{|c|}{-1.2 to -2.3} \\
\hline Micrographs used (no.) & \multicolumn{4}{|c|}{6109} & \multicolumn{3}{|c|}{4499} \\
\hline Initial particle images (no.) & \multicolumn{4}{|c|}{954,291} & \multicolumn{3}{|c|}{$1,331,440$} \\
\hline Symmetry & \multicolumn{7}{|c|}{$\mathrm{C}_{1}$} \\
\hline Class Name & $\begin{array}{l}\text { Auto- } \\
\text { inhibited1 }\end{array}$ & $\begin{array}{l}\text { Auto- } \\
\text { inhibited2 }\end{array}$ & $\begin{array}{l}\text { Auto- } \\
\text { inhibited3 }\end{array}$ & Open1 & Open2 & DNA-open & DNA-closed \\
\hline $\begin{array}{l}\text { Final Refined particles } \\
\text { (no.) }\end{array}$ & 55,308 & 68,227 & 60,036 & 46,069 & 63,752 & 46300 & 76270 \\
\hline Applied B factor $\left(\AA^{2}\right)$ & -100 & $-159 \cdot 352$ & -163.938 & -100 & -106.457 & -105.857 & $-105 \cdot 313$ \\
\hline $\begin{array}{l}\text { Map resolution } \\
(\AA \AA \text { FSC } 0.143)\end{array}$ & 3.8 & $3 \cdot 9$ & 4.0 & 4.0 & $3 \cdot 5$ & $3 \cdot 4$ & $3 \cdot 3$ \\
\hline Model-Map CC_mask & 0.78 & 0.77 & 0.77 & 0.76 & 0.78 & 0.79 & 0.77 \\
\hline $\begin{array}{l}\text { Bond lengths }(\AA), \\
\text { angles }\left({ }^{\circ}\right)\end{array}$ & $\begin{array}{l}0.002, \\
0.585\end{array}$ & $\begin{array}{l}0.002, \\
0.561\end{array}$ & $\begin{array}{l}0.002 \\
0.558\end{array}$ & $\begin{array}{l}0.002 \\
0.574\end{array}$ & $\begin{array}{l}0.002 \\
0.542\end{array}$ & $\begin{array}{l}0.002 \\
0.518\end{array}$ & $\begin{array}{l}0.002, \\
0.523\end{array}$ \\
\hline $\begin{array}{l}\text { Ramachandran Outliers, } \\
\text { Allowed, Favored }\end{array}$ & $\begin{array}{l}0.00, \\
3.16,96.84\end{array}$ & $\begin{array}{l}0.00, \\
3.11,96.89\end{array}$ & $\begin{array}{l}0.00, \\
2.89,97.11\end{array}$ & $\begin{array}{l}0.00, \\
3.08,96.92\end{array}$ & $\begin{array}{l}0.00, \\
3.38,96.62\end{array}$ & $\begin{array}{l}0.00, \\
2.23,97.77\end{array}$ & $\begin{array}{l}0.00, \\
2.16,97.84\end{array}$ \\
\hline $\begin{array}{l}\text { Poor rotamers (\%), } \\
\text { MolProbity score, } \\
\text { Clashscore (all atoms) }\end{array}$ & $\begin{array}{l}0.00 \\
1.68 \\
9.05\end{array}$ & $\begin{array}{l}0.00, \\
1.68 \\
9.42\end{array}$ & $\begin{array}{l}0.00 \\
1.68 \\
9.95\end{array}$ & $\begin{array}{l}0.00, \\
1.67, \\
9.26\end{array}$ & $\begin{array}{l}2.01 \\
1.91 \\
8.67\end{array}$ & $\begin{array}{l}1.09, \\
1.54, \\
8.44\end{array}$ & $\begin{array}{l}1.09, \\
1.55, \\
9.18\end{array}$ \\
\hline $\begin{array}{l}\text { Accession number, } \\
\text { EMDB, PDB }\end{array}$ & $\begin{array}{l}25568 \\
7 \mathrm{THJ}\end{array}$ & $\begin{array}{l}25569, \\
7 \mathrm{TIC}\end{array}$ & $\begin{array}{l}25614, \\
7 \mathrm{THV}\end{array}$ & $\begin{array}{l}25615, \\
7 T K U\end{array}$ & $\begin{array}{l}25753 \\
7 \mathrm{~T} 18\end{array}$ & $\begin{array}{l}25616 \\
7 \text { TIB }\end{array}$ & 25617, 7TID \\
\hline
\end{tabular}


908 Table 4: DNA sequences

\begin{tabular}{|c|c|c|c|c|}
\hline $\begin{array}{l}\text { Template } \\
\text { name }\end{array}$ & sequence & Primer name & sequence & $\begin{array}{l}\text { Name used in } \\
\text { assay }\end{array}$ \\
\hline \multirow[t]{7}{*}{$\begin{array}{l}\text { Template3o- } \\
\text { 20-A }\end{array}$} & $\begin{array}{l}\text { TTTTTTTTTTAATGTACT } \\
\text { CGTAGTGTCTGC }\end{array}$ & Primer20-3'abasic & $\begin{array}{l}\text { GCAGACACTACGAGTACAT/3dS } \\
\mathrm{p} /\end{array}$ & p/t-DNA 3'-abasic \\
\hline & & $\begin{array}{l}\text { Primer20-3'-T- } \\
\text { phosphate }\end{array}$ & $\begin{array}{l}\text { GCAGACACTACGAGTACATT/3P } \\
\text { hos/ }\end{array}$ & $\mathrm{p} / \mathrm{t}-\mathrm{DNA} 3^{\prime} \mathrm{PO}_{4}$ \\
\hline & & $\begin{array}{l}\text { Primer20-3'-T- } \\
\text { RNA }\end{array}$ & $\begin{array}{l}\text { rGrCrArGrArCrArCrUrArCrGrArG } \\
\text { rUrArCrArUrU }\end{array}$ & $\begin{array}{l}\text { RNA primer/DNA } \\
\text { template }\end{array}$ \\
\hline & & Primer2o-3'-riboT & GCAGACACTACGAGTACATrU & p/t-DNA 3' ribo \\
\hline & & Primer20-3'-T & GCAGACACTACGAGTACATT & $\mathrm{p} / \mathrm{t}-\mathrm{DNA}$ \\
\hline & & Primer2o-2AP-o & $\begin{array}{l}\text { GCAGACACTACGAGTACAT/32A } \\
\mathrm{mPu} /\end{array}$ & $p / t-A P, p=1$ \\
\hline & & Primer20-2AP-2 & $\begin{array}{l}\text { GCAGACACTACGAGTAC/i2AmP } \\
\text { r/TA }\end{array}$ & $p / t-A P, p=3$ \\
\hline $\begin{array}{l}\text { Template3o- } \\
\text { T-1 }\end{array}$ & $\begin{array}{l}\text { TTTTTTTTTTTTTTGTACT } \\
\text { CGTAGTGTCTGC-3' }\end{array}$ & Primer20-2AP-1 & $\begin{array}{l}\text { GCAGACACTACGAGTACA/i2Am } \\
\text { Pr/A }\end{array}$ & $p / t-A P, p=2$ \\
\hline $\begin{array}{l}\text { Template3o- } \\
\text { 20-2AP }\end{array}$ & $\begin{array}{l}\text { TTTTTTTTTT/i2AmPr/AT } \\
\text { GTACTCGTAGTGTCTGC } \\
-3^{\prime}\end{array}$ & Primer20-3'-T & GCAGACACTACGAGTACATT & $p / t-A P, t=1$ \\
\hline \multirow[t]{2}{*}{$\begin{array}{l}\text { Template20- } \\
5^{\prime}-\mathrm{A}\end{array}$} & $\begin{array}{l}\text { AATGTACTCGTAGTGTC } \\
\text { TGC }\end{array}$ & Primer20-3'-T & GCAGACACTACGAGTACATT & Blunt DNA \\
\hline & & $\begin{array}{l}\text { Primer 20-3'-T- } \\
\text { 10ext }\end{array}$ & $\begin{array}{l}\text { GCAGACACTACGAGTACATTTT } \\
\text { TTTTTTTT }\end{array}$ & 3' overhang DNA \\
\hline \multirow[t]{2}{*}{$\begin{array}{l}\text { Template3o- } \\
\text { 20-A-3'T }\end{array}$} & $\begin{array}{l}\text { AATGTACTCGTAGTGTC } \\
\text { TGCTTTTTTTTTT }\end{array}$ & $\begin{array}{l}\text { Primer 20-3'-T- } \\
\text { 10ext }\end{array}$ & $\begin{array}{l}\text { GCAGACACTACGAGTACATTTT } \\
\text { TTTTTTTT }\end{array}$ & $\begin{array}{l}\text { 3' overhang } \\
\text { dumbbell DNA }\end{array}$ \\
\hline & & polyT 20 & TTTTTTTTTTTTTTTTTTTT & ssDNA (poly T) \\
\hline
\end{tabular}

909 


\section{SUPPLEMENTAL FIGURE LEGENDS}

912 Figure 1 - Supplement 1. Characterization and cryo-EM of full-length RFC:PCNA . (A) SDS-PAGE gel of purified RFC and PCNA 913 after gel filtration. A fraction with stoichiometric amounts of RFC and PCNA was used for grid preparation. (B) Crosslinking of the 914 RFC:PCNA at a concentration of $1 \mathrm{mM}$ Bissulfosuccinimidyl suberate (BS3) led to the identification of intermolecular and intramolecular 915 crosslinks in RFC, and are shown in schematic representation. 88\% of the crosslinks mapped to RFC-A and no crosslinks in PCNA 916 were detected, although PCNA was detected in the sample. (C) Local resolution of reconstructions (center) and a representative 917 section of each complex subunit for each reconstruction. (D) Fourier shell correlation (FSC) curves for the two halves of the 918 reconstructions as well as model vs map curves.

919

920 Figure 1 - Supplement 2. Schematic of yRFC:PCNA cryo-EM processing. (A) A down-filtered micrograph taken on a Thermo 921 Fisher Scientific Titan Krios with a Gatan K2 detector is displayed. (B) 2D class averages show different side views. (C) The 3D 922 reference for refinement was generated ab initio with cisTEM (Grant et al., 2018). (D) The ab initio model was downfiltered to $50 \AA$ and 923 used as reference for 3D classification. The first round of classification was performed with the $2 x$ binned particle stack. Further rounds 924 of classification with the unbinned stack improved the resolution. 3D classification with local angular search further helped to improve 925 the resolution of the reconstructions representing complexes with closed PCNA (blue).

926

927 Figure 1 - Supplement 3. Schematic of yRFC:PCNA:DNA cryo-EM processing. (A) A downfiltered micrograph taken on a Thermo 928 Fisher Scientific Titan Krios with a Gatan K3 detector is displayed. (B) 2D class averages show different side views. (C) Class Open1 of 929 the dataset without DNA was downfiltered to $60 \AA$ and used as reference for 3D classification. The first round of classification was 930 performed with the $4 x$ binned particle stack and the second round of classification with the $2 x$ binned stack. Further classification with 931 the unbinned stack with resolution limit and without alignment helped to separate different conformational states and improved the 932 resolution.

933

934 Figure 2 - Supplement 1. RFC:PCNA complexes in autoinhibited conformations. (A) Side views of the atomic models of 935 Autoinhibited1, the RFC:PCNA crystal structure (Bowman et al., 2004), and of the human RFC:PCNA complex show similarity. (B) 936 Close-up of the nucleotide binding sites. The cryo-EM map is shown in yellow overlaying the atomic model. The catalytically important 937 Walker A lysine, Walker B glutamates, and trans-acting arginine fingers are shown. The arginine fingers are distant within the active 938 sites of RFC-B,C,D in Autoinhibited1\&2 and in RFC-B,D of Autoinhibited3, rendering these active sites inactive. For comparison, the 939 nucleotide binding sites in the atomic model of the RFC:PCNA crystal structure (PDB 1SXJ) are shown. Here, the SRC motif arginine 940 fingers were mutated to glutamines. RFC-E is not catalytically competent and has ADP-bound. The A' domain does not donate trans941 acting arginine fingers. (C) Top views on the AAA+ spiral of the T4 clamp loader, RFC:PCNA crystal structure and Autoinihibited1-3. 942 The T4 clamp loader, which has DNA bound, is in an active conformation. Here, the rotation axes that relate the subunits are coincident 943 with each other and the central axis of DNA. In contrast, the symmetry of the AAA+ spiral of RFC in the autoinhibited conformation is 944 distorted, and the axes are skewed in all these structures.

945

946 Figure 2 - Supplement 2. Multibody analyses with all 183,571 particles combined from the three Autoinhibited states to 947 investigate the dynamic initial complex of RFC with PCNA. (A) Superpositions of Autoinhibited 1\&2 and 1\&3 highlight differences in 948 the orientation of PCNA towards RFC as well as the opening of the A-gate. (B) The two masks used for the first multibody refinement 949 define PCNA and RFC as separate rigid bodies. (C) Principal Component (PC) analysis revealed the two most dominant motions with 950 RFC and PCNA. (D) Amplitude histogram of PC2 is unimodal. (E) PC2 reveals a swiveling motion. The $\mathrm{C}_{\alpha}$ displacement is indicated by 951 modevector generated arrows, scaled down by a factor of 2. (F) The two masks used for the second multibody refinement were chosen 952 to match domain boundaries determined with the ENM DynOmics server (Li et al., 2017) and to capture motion between the A' and the 953 AAA + module of the A-gate. (G) PC analysis revealed two dominant motions. (H) Amplitude histogram of PC1 is unimodal. (I) Multibody 954 refinement 2 also revealed rocking and swiveling as dominant motions.

955

956 Figure 3 - Supplement 1. Comparison of RFC bound to open PCNA from different datasets. (A) Top and side view of the cryo957 EM map of RFC bound to open PCNA, which was obtained from the dataset without DNA. (B) Top and side view of the cryo-EM map of 958 RFC bound to open PCNA obtained from the dataset with DNA. (C) Overlay of the two models for Open1 and Open2 shows that the 959 two models strongly resemble each other. (D) Open1 superposed to Open2. Open2 is colored by RMSD. (E) Close-up of the nucleotide 960 binding sites in Open1 and in Open2. The cryo-EM map is shown in yellow overlaying the atomic model. Critical catalytic residues are 961 shown as sticks. All active sites are occupied with ATPYS. (F) PCNA intrasubunit distortions that occur for opening. The Ca 962 displacement is indicated by modevector-generated arrows, scaled up by a factor of four.

963

964 
965 Figure 3 - Supplement 2. RFC interacts with all five subunits to hold PCNA open. (A) Overview of interaction sites of RFC with 966 PCNA in the autoinhibited conformation. The three PCNA subunits and RFC's AAA+ module are shown in a cartoon flattened onto the 967 page. RFC-D and RFC-E are not in contact with PCNA. (B) Cartoon overview of interaction sites of RFC with PCNA in the open 968 conformation. RFC-D and RFC-E now contact PCNA. (C) Close up views of the RFC-PCNA interaction sites in Autoinhibited1 are 969 shown, the rest is omitted for clarity. The contact between PCNA and RFC-A is mediated by a short helix and adjacent hydrophobic and 970 aromatic residues that insert into PCNA's hydrophobic pockets. This conformation is commonly seen in binding partners which contain 971 a PCNA-interacting protein (PIP) motif or derived motifs. (D) Contacts of RFC-A and RFC-B with PCNA do not change significantly 972 upon PCNA opening. The interaction of PCNA with RFC-C becomes more extensive, and RFC-D and RFC-E establish new contacts to 973 PCNA. RFC-C and RFC-E insert into PCNA's hydrophobic pocket but do not employ a PIP motif. The E-plug and A' domain reinforce 974 the interaction with PCNA.

975

976 Figure 5 - Supplement 1. (A) PCNA constriction in DNA ${ }^{\text {PCNA-open }}$ and DNA ${ }^{\text {PCNA-closed }}$. Displacement vectors between Open2 and 977 DNA ${ }^{\text {PCNA-open }}$ are shown as green arrows, scaled by a factor of four (left). Displacement vectors between DNA ${ }^{\text {PCNA-open }}$ and DNA ${ }^{\text {PCNA- }}$ $978{ }^{\text {closed }}$ are shown as green arrows, scaled by a factor of four (right). Upon DNA binding, the PCNA lock-washer constricts in DNA ${ }^{P C N A-o p e n}$, 979 due to a motion at the NTD of PCNA-III. PCNA is closed in a puckered conformation in DNA ${ }^{\text {PCNA-closed }}$ through constricting motions of 980 PCNA-I and PCNA-III. (B) The overlay of the rotation axes in the open conformation of RFC is indicative for spiral symmetry. The tilt 981 angles show that in the DNA-bound structures (DNA ${ }^{\text {PCNA-open }}$ and DNA ${ }^{\text {PCNA-closed }}$, the rotation axes become more tilted upon PCNA 982 closure, indicating that DNA binding and PCNA closure slightly disrupt the symmetric arrangement of the AAA+ spiral. (C) Close-up of 983 the nucleotide binding sites in DNA ${ }^{\text {PCNA-open }}$ and DNA ${ }^{\text {PCNA-closed }}$. The cryo-EM map is shown in yellow overlaying the atomic model. 984 Critical catalytic residues are shown as sticks. All active sites are occupied with ATPYS.

985

986 Figure 5 - Supplement 2. Superposition of the ATPase active sites across conformations. In all cases, the active sites were 987 aligned about their Walker A and Walker B motifs. (A) Comparing the active sites of Closed1 to Open2. (B) Comparing the active sites 988 of Open2 to DNAPCNA-open. (C) Comparing the active sites of DNA ${ }^{\text {PCNA-open }}$ to DNA ${ }^{\text {PCNA-closed }}$. The most substantial change occurs 989 upon clamp opening (A), which brings the arginine fingers in the RFC B-D active sites close to the $Y$-phosphate. This change does not 990 occur in RFC-A, whose hydrolysis is dispensable for clamp loading. After opening, DNA binding (B) and then clamp closure (C) do not 991 change the active sites much, indicating that DNA binding does not stimulate hydrolysis by reorganizing the ATPase binding interface.

992

993 Figure 6 - Supplement 1. The separation wedge has two critical residues. (A) Fluorescence intensity traces for $375 \mathrm{nM}$ of $\mathrm{p} / \mathrm{t} \mathrm{AP} \mathrm{p}_{\mathrm{p}}$ 994 in the presence of RFC:PCNA with and without nucleotide or primer $A P_{p=1}$. (B) Placement of $2 A P$ at different positions. The 995 fluorescence with $\mathrm{p} / \mathrm{t} A \mathrm{P}_{\mathrm{p}=1}$ in the presence of ATPYS and RFC:PCNA increases $\sim 4$-fold in relation to the sample without ATPYS, 996 whereas placement of the oligo further away from the 3'-OH end reduces the fluorescence increase to $\sim 2$-fold. (C) Results from (Figure 9976 B) could be recapitulated using p/t-DNA with 2-AP in the template strand $(t=1)$. The $E$. coli clamp loader, which does not have a 998 separation pin, does not change fluorescence in the presence of ATPyS. (D) ATPase activity of the 'separation pin' mutants. DNA 999 binding affinity and maximum ATP hydrolysis rate is reduced in RFC ${ }^{\text {W638G }}$. (E) The steady-state ATP hydrolysis rate of the RFC-W638G 1000 variant is significantly reduced compared to wild type ( $p$ value $=0.0005$ ). The RFC-F582A variant binds DNA with similar affinity than 1001 wild type ( $p$ value $=0.0288$ ). DNA binding affinity for RFC-W638G is slightly reduced ( $p$ value $<0.0001$ ). Error bars reflect the standard 1002 deviation from three replicates. The number above the error bar indicates the mean. The asterisks correspond to $p$-values from one1003 way ANOVA tests comparing variants to wild type, 'ns' = not significant.

1004

1005 Figure 6 - Supplement 2. Discrimination of different primer template junctions by RFC. (A) Cartoon depiction of different DNA 1006 substrates that were used to probe if the separation pin acts to discriminate different moieties at the primer template junction. (B-D) 1007 Similar ATPase activity profiles of the wild type and the two separation pin variants indicate that the separation pin is not critical to 1008 discriminate between these DNA substrates. Error bars on these bar graphs reflect the standard deviation from three replicates. The 1009 number above the error bar indicates the mean. The asterisks on these graphs correspond to $p$-values from one-way ANOVA tests 1010 comparing different DNA substrates with an unmodified primer template junction ( $p / t$ DNA): 'ns' - not significant $P>0.05$, ${ }^{*} P \leq 0.05$, ${ }^{* *} P$ $1011 \leq 0.01,{ }^{* * *} \mathrm{P} \leq 0.001,{ }^{* * *} \mathrm{P} \leq 0.0001$.

1012 
1013 Figure 6 - Supplement 3. Functional characterization of separation pin mutants in S. cerevisiae. To directly assess the 1014 physiological role of the separation pin using yeast with, we performed spot assays with strains that express either wild type RFC1 or 1015 the F582A or the W638G variant. The two variants and the wild type display similar colony sizes across a variety of conditions, 1016 including varying temperatures, UV radiation, and treatment with hydroxyurea (HU) or methyl Methanesulfonate (MMS), indicating that 1017 there is no striking phenotype with the tested conditions.

1018

1019 Figure 6 - Supplement 4. Differences in how duplex p/t-DNA is held in the central chamber of clamp loaders. (A) In the T4 and 1020 E. coli clamp loaders, the duplex p/t-DNA extends farther into the central chamber, enabling more substantial contacts with the B-E 1021 subunits compared to RFC. (B) Contribution of RFC subunits to DNA binding. RFC-A dominates contact with p/t-DNA when compared 1022 to other clamp loaders.

1023

1024 Figure 6 - Supplement 5 . Conservation of the separation pin. (A) The separation pin is conserved in RFC1 across eukaryotes. 1025 Sequence alignment shows the conservation of the 'separation pin' among 5 eukaryotic species. The conserved sequences are marked 1026 by blue boxes. The fully conserved residues are in white with a red background, the highly conserved residues are in red, and the less 1027 conserved ones are in black. F582 and W638 are pointed out by the blue arrow. (B) A potential separation pin in the Ctf18 clamp 1028 loader. The structure of yeast Ctf18 (blue) predicted by AlphaFold (Jumper et al., 2021, Varadi et al., 2021) is superposed onto collar 1029 domain of the DNA ${ }^{\text {PCNA-open }}$ structure of yeast RFC (RFC1 in red, primer strand in yellow, and template strand in orange). Key residues 1030 of the RFC1 separation pin are highlighted (Phe 582, Gln 636, \& Trp 638), as well as their predicted counterparts in Ctf18 (Glu427, 1031 Asn477, \& Leu481). While the separation pin helical hairpin is likely conserved, the key residues that mediate base-flipping in RFC1 are 1032 not conserved.

1033

1034

1035 Supplemental References:

1036 Li, H., Chang, Y.-Y., Lee, J.Y., Bahar, I., and Yang, L.-W. (2017). DynOmics: dynamics of structural proteome and beyond. Nucleic 1037 Acids Research 45, W374-W380.

1038

1039 Jumper, J et al. Highly accurate protein structure prediction with AlphaFold. Nature (2021).

1040

1041 Varadi, M et al. AlphaFold Protein Structure Database: massively expanding the structural coverage of protein-sequence space with 1042 high-accuracy models. Nucleic Acids Research (2021).

1043 
1044

\section{REFERENCES}

1046 Bowman, G.D., O'Donnell, M., and Kuriyan, J. (2004). Structural 1047 analysis of a eukaryotic sliding DNA clamp-clamp loader complex. 1048 Nature 429, 724-730.

1049 Castaneda, Juan C., Marina Schrecker, Dirk Remus, and Richard K. 1050 Hite. 2021. "Mechanisms of Loading and Release of the 9-1-1 1051 Checkpoint Clamp." BioRxiv.

1052 https://doi.org/10.1101/2021.09.13.460164.

1053 Cai, J., Yao, N., Gibbs, E., Finkelstein, J., Phillips, B., O’Donnell, M., 1054 and Hurwitz, J. (1998). ATP hydrolysis catalyzed by human replication 1097 Guenther, B., Onrust, R., Sali, A., O’Donnell, M., and Kuriyan, J. (1997). 1055 factor $C$ requires participation of multiple subunits. Proceedings of the 1098 Crystal structure of the delta' subunit of the clamp-loader complex of 1056 National Academy of Sciences 95, 11607-11612.

1057 Chen, S., Levin, M.K., Sakato, M., Zhou, Y., and Hingorani, M.M. 1058 (5/2009). Mechanism of ATP-Driven PCNA Clamp Loading by S. 1059 cerevisiae RFC. J. Mol. Biol. 388, 431-442.

1060 DELANO, and W. L (2002). The PyMOL Molecular Graphics System. $1061 \mathrm{Http}: / /$ www.pymol.org.

1062 Dephoure, N., Zhou, C., Villén, J., Beausoleil, S.A., Bakalarski, C.E., 1063 Elledge, S.J., and Gygi, S.P. (2008). A quantitative atlas of mitotic 1064 phosphorylation. Proc. Natl. Acad. Sci. U. S. A. 105, 10762-10767.

1065 Emsley, P., and Cowtan, K. (2004). Coot: model-building tools for 1066 molecular graphics. Acta Crystallogr. D Biol. Crystallogr. 6o, 212610672132.

1068 Erzberger, J.P., and Berger, J.M. (2006). Evolutionary relationships 1069 and structural mechanisms of AAA+ proteins. Annu. Rev. Biophys. 1070 Biomol. Struct. 35, 93-114.

1071 Finkelstein, J., Antony, E., Hingorani, M.M., and O'Donnell, M. 1072 (08/2003). Overproduction and analysis of eukaryotic multiprotein 1073 complexes in Escherichia coli using a dual-vector strategy. Anal. 1074 Biochem. 319, 78-87.

1075 Frey, M.W., Sowers, L.C., Millar, D.P., and Benkovic, S.J. (1995). The 1076 nucleotide analog 2-aminopurine as a spectroscopic probe of 1077 nucleotide incorporation by the Klenow fragment of Escherichia coli 1078 polymerase I and bacteriophage T4 DNA polymerase. Biochemistry 1079 34, 9185-9192.

1080 Gaubitz, C., Liu, X., Magrino, J., Stone, N.P., Landeck, J., Hedglin, M., 1123 1675-1680.

1081 and Kelch, B.A. (2020b). Structure of the human clamp loader reveals 1082 an autoinhibited conformation of a substrate-bound AAA switch. 1083 Proceedings of the National Academy of Sciences 117, 23571-23580.

1084 Gerlach, P., Schuller, J.M., Bonneau, F., Basquin, J., Reichelt, P., Falk, 1085 S., and Conti, E. (2018). Distinct and evolutionary conserved structural 1086 features of the human nuclear exosome complex. Elife 7.

1087 Goedken, E.R., Levitus, M., Johnson, A., Bustamante, C., O’Donnell,
1088 M., and Kuriyan, J. (2004). Fluorescence measurements on the E.coli 1089 DNA polymerase clamp loader: implications for conformational 1090 changes during ATP and clamp binding. J. Mol. Biol. 336, 1047-1059.

1091 Gomes, X.V., Schmidt, S.L., and Burgers, P.M. (2001). ATP utilization 1092 by yeast replication factor C. II. Multiple stepwise ATP binding events 1093 are required to load proliferating cell nuclear antigen onto primed 1094 DNA. J. Biol. Chem. 276, 34776-34783.

1095 Grant, T., Rohou, A., and Grigorieff, N. (2018). cisTEM, user-friendly 1096 software for single-particle image processing. Elife 7.

1099 E. coli DNA polymerase III. Cell 91, 335-345

1100 Hanson, P.I., and Whiteheart, S.W. (2005). AAA+ proteins: have 1101 engine, will work. Nat. Rev. Mol. Cell Biol. 6, 519-529.

1102 Jean, J.M., and Hall, K.B. (2001). 2-Aminopurine fluorescence 1103 quenching and lifetimes: role of base stacking. Proc. Natl. Acad. Sci. U. 1104 S. A. 98, 37-41.

1105 Jeruzalmi, D., O’Donnell, M., and Kuriyan, J. (2001a). Crystal structure 1106 of the processivity clamp loader gamma (gamma) complex of E. coli

1107 DNA polymerase III. Cell 106, 429-441.

1108 Jeruzalmi, D., Yurieva, O., Zhao, Y., Young, M., Stewart, J., Hingorani, 1109 M., O'Donnell, M., and Kuriyan, J. (2001b). Mechanism of processivity 1110 clamp opening by the delta subunit wrench of the clamp loader 1111 complex of E. coli DNA polymerase III. Cell 106, 417-428.

1112 Jessop, M., Felix, J., and Gutsche, I. (2021). AAA+ ATPases: structural 1113 insertions under the magnifying glass. Curr. Opin. Struct. Biol. 66, 1114 119-128.

1115 Johnson, A., Yao, N.Y., Bowman, G.D., Kuriyan, J., and O’Donnell, M. 1116 (2006). The Replication Factor C Clamp Loader Requires Arginine 1117 Finger Sensors to Drive DNA Binding and Proliferating Cell Nuclear 1118 Antigen Loading. J. Biol. Chem. 281, 35531-35543.

1119 Kelch, B.A. (2016). Review: The lord of the rings: Structure and 1120 mechanism of the sliding clamp loader. Biopolymers 105, 532-546.

1121 Kelch, B.A., Makino, D.L., O'Donnell, M., and Kuriyan, J. (2011). How a 1122 DNA polymerase clamp loader opens a sliding clamp. Science 334,

1124 Kelch, B.A., Makino, D.L., O'Donnell, M., and Kuriyan, J. (2012). Clamp 1125 loader ATPases and the evolution of DNA replication machinery. BMC 1126 Biol. 10, 34-48.
1127 Kidmose, R.T., Juhl, J., Nissen, P., Boesen, T., Karlsen, J.L., and 1128 Pedersen, B.P. (2019). Namdinator - automatic molecular dynamics 1129 flexible fitting of structural models into cryo-EM and crystallography 1130 experimental maps. IUCrJ 6, 526-531. 
1131 Kim, H.S., and Brill, S.J. (2001). Rfc4 interacts with Rpa1 and is 1132 required for both DNA replication and DNA damage checkpoints in 1133 Saccharomyces cerevisiae. Mol. Cell. Biol. 21, 3725-3737.

\section{Kremer, J.R., Mastronarde, D.N., and McIntosh, J.R. (1996). Computer} 1135 visualization of three-dimensional image data using IMOD. J. Struct. 1136 Biol. 116, 71-76.

1137 Krissinel, E., and Henrick, K. (2007). Inference of Macromolecular 1138 Assemblies from Crystalline State. Journal of Molecular Biology 372, $1139774-797$.

1140 Liebschner, D., Afonine, P.V., Baker, M.L., Bunkóczi, G., Chen, V.B., 1141 Croll, T.I., Hintze, B., Hung, L.W., Jain, S., McCoy, A.J., et al. (2019). 1142 Macromolecular structure determination using $X$-rays, neutrons and 1143 electrons: recent developments in Phenix. Acta Crystallogr D Struct 1144 Biol 75, 861-877.

1145 Liu, J., Zhou, Y., and Hingorani, M.M. (2017). Linchpin DNA-binding 1146 residues serve as go/no-go controls in the replication factor C1147 catalyzed clamp loading mechanism. J. Biol. Chem. jbc.M117.798702.

1148 Majka, J., and Burgers, P.M.J. (2004). The PCNA-RFC families of DNA 1149 clamps and clamp loaders. Prog. Nucleic Acid Res. Mol. Biol. 78, 2271150260.

1151 Marzahn, M.R., Hayner, J.N., Meyer, J.A., and Bloom, L.B. (2014). 1152 Kinetic analysis of PCNA clamp binding and release in the clamp 1153 loading reaction catalyzed by Saccharomyces cerevisiae replication 1154 factor C. Biochim. Biophys. Acta 1854, 31-38.

1155 Mastronarde, D.N. (2003). SerialEM: A Program for Automated Tilt 1156 Series Acquisition on Tecnai Microscopes Using Prediction of 1157 Specimen Position. Microsc. Microanal. 9, 1182-1183.

1158 McNally, R., Bowman, G.D., Goedken, E.R., O’Donnell, M., and 1159 Kuriyan, J. (2010). Analysis of the role of PCNA-DNA contacts during 1160 clamp loading. BMC Struct. Biol. 10, 3.

1161 Moldovan, G.-L., Pfander, B., and Jentsch, S. (2007). PCNA, the 1162 maestro of the replication fork. Cell 129, 665-679.

1163 Nakane, T., Kimanius, D., Lindahl, E., and Scheres, S.H.W. (2018). 1164 Characterisation of molecular motions in cryo-EM single-particle data 1165 by multi-body refinement in RELION. Elife 7 .

1166 Ochoa, D., Jarnuczak, A.F., Viéitez, C., Gehre, M., Soucheray, M., 1167 Mateus, A., Kleefeldt, A.A., Hill, A., Garcia-Alonso, L., Stein, F., et al. 1168 (2020). The functional landscape of the human phosphoproteome. 1169 Nat. Biotechnol. 38, 365-373.

1170 O'Donnell, M., Jeruzalmi, D., and Kuriyan, J. Clamp loader structure 1171 predicts the architecture of DNA polymerase III holoenzyme and RFC. 1172 Curr. Biol. 11, R935-R946.

1173 Olsen, J.V., Vermeulen, M., Santamaria, A., Kumar, C., Miller, M.L., 1174 Jensen, L.J., Gnad, F., Cox, J., Jensen, T.S., Nigg, E.A., et al. (2010).
1175 Quantitative phosphoproteomics reveals widespread full

1176 phosphorylation site occupancy during mitosis. Sci. Signal. 3, ra3.

1177 Peled, M., Tocheva, A.S., Sandigursky, S., Nayak, S., Philips, E.A., 1178 Nichols, K.E., Strazza, M., Azoulay-Alfaguter, I., Askenazi, M., Neel, 1179 B.G., et al. (2018). Affinity purification mass spectrometry analysis of 1180 PD-1 uncovers SAP as a new checkpoint inhibitor. Proc. Natl. Acad. 1181 Sci. U. S. A. 115, E468-E477.

1182 Pettersen, E.F., Goddard, T.D., Huang, C.C., Couch, G.S., Greenblatt, 1183 D.M., Meng, E.C., and Ferrin, T.E. (2004). UCSF Chimera--a 1184 visualization system for exploratory research and analysis. J. Comput. 1185 Chem. 25, 1605-1612.

1186 Puri, Neha, Amy J. Fernandez, Valerie L. O’Shea Murray, Sarah 1187 McMillan, James L. Keck, and James M. Berger. 2021. "The Molecular 1188 Coupling between Substrate Recognition and ATP Turnover in a AAA+ 1189 Hexameric Helicase Loader." ELife 10 (May).

1190 https://doi.org/10.7554/eLife.64232.

1191 Rohou, A., and Grigorieff, N. (2015). CTFFIND4: Fast and accurate 1192 defocus estimation from electron micrographs. J. Struct. Biol. 192,

1193 216-221.

1194 Sakato, M., Zhou, Y., and Hingorani, M.M. (02/2012). ATP Binding and 1195 Hydrolysis-Driven Rate-Determining Events in the RFC-Catalyzed 1196 PCNA Clamp Loading Reaction. J. Mol. Biol. 416, 176-191.

1197 Sakato, M., O’Donnell, M., and Hingorani, M.M. (2012). A central 1198 swivel point in the RFC clamp loader controls PCNA opening and 1199 loading on DNA. J. Mol. Biol. 416, 163-175.

1200 Shiomi, Y., Usukura, J., Masamura, Y., Takeyasu, K., Nakayama, Y., 1201 Obuse, C., Yoshikawa, H., and Tsurimoto, T. (2000). ATP-dependent 1202 structural change of the eukaryotic clamp-loader protein, replication 1203 factor C. Proc. Natl. Acad. Sci. U. S. A. 97, 14127-14132.

1204 Simonetta, K.R., Kazmirski, S.L., Goedken, E.R., Cantor, A.J., Kelch, 1205 B.A., McNally, R., Seyedin, S.N., Makino, D.L., O'Donnell, M., and 1206 Kuriyan, J. (05/2009). The Mechanism of ATP-Dependent Primer1207 Template Recognition by a Clamp Loader Complex. Cell 137, 659-671.

1208 Subramanian, Subu, Kent Gorday, Kendra Marcus, Matthew R. 1209 Orellana, Peter Ren, Xiao Ran Luo, Michael E. O'Donnell, and John 1210 Kuriyan. 2021. "Allosteric Communication in DNA Polymerase Clamp 1211 Loaders Relies on a Critical Hydrogen-Bonded Junction." ELife 10 1212 (April). https://doi.org/10.7554/eLife.66181.

1213

1214 Terwilliger, T.C., Ludtke, S.J., Read, R.J., Adams, P.D., and Afonine, 1215 P.V. (2020). Improvement of cryo-EM maps by density modification. 1216 Nat. Methods 17, 923-927.

1217 Thompson, J.A., Marzahn, M.R., O’Donnell, M., and Bloom, L.B. 1218 (2012). Replication Factor C Is a More Effective Proliferating Cell 1219 Nuclear Antigen (PCNA) Opener than the Checkpoint Clamp Loader, 
1221 Tomida, J., Masuda, Y., Hiroaki, H., Ishikawa, T., Song, I., Tsurimoto, 1222 T., Tateishi, S., Shiomi, T., Kamei, Y., Kim, J., et al. (2008). DNA 1244 Zhang, Xiaodong, and Dale B. Wigley. 2008. "The 'glutamate Switch' 1223 damage-induced ubiquitylation of RFC2 subunit of replication factor C1245 Provides a Link between ATPase Activity and Ligand Binding in AAA+ 1224 complex. J. Biol. Chem. 283, 9071-9079.

1246 Proteins." Nature Structural \& Molecular Biology 15 (11): 1223-27.

1225 Wang, X., Li, J., Schowalter, R.M., Jiao, J., Buck, C.B., and You, J. 1226 (2012). Bromodomain protein Brd 4 plays a key role in Merkel cell 1227 polyomavirus DNA replication. PLoS Pathog. 8, e1003021.
1247 Zhang, K. (2016). Gctf: Real-time CTF determination and correction. J. 1248 Struct. Biol. 193, 1-12.

1249 Zheng, Fengwei, Roxana E. Georgescu, Nina Y. Yao, Michael E. 1228 Wang, X., Helfer, C.M., Pancholi, N., Bradner, J.E., and You, J. (2013). 1250 O'Donnell, and Huilin Li. 2021. "Rad24-RFC Loads the 9-1-1 Clamp by 1229 Recruitment of Brd4 to the human papillomavirus type 16 DNA 1251 Inserting DNA from the Top of a Wide-Open Ring, Opposite the 1230 replication complex is essential for replication of viral DNA. J. Virol. 87,1252 Mechanism of RFC/PCNA." BioRxiv.

$12313871-3884$.

1253 https://doi.org/10.1101/2021.10.01.462756.

1232 Xavier V. Gomes, Sonja L. Gary, Peter M.J. Burgers, (2000).

1254 Zhou, Y., and Hingorani, M.M. (2012). Impact of Individual 1233 Overproduction in Escherichia coli and Characterization of Yeast 1234 Replication Factor C Lacking the Ligase Homology Domain, JBC, 275 1235 (19), 14541-14549

1236 Yoo, J., Wu, M., Yin, Y., Herzik, M.A., Lander, G.C., and Lee, S.-Y. 1237 (2018). Cryo-EM structure of a mitochondrial calcium uniporter. 1238 Science eaar4056.

1239 Yin, Yandong, Lijiang Yang, Guanqun Zheng, Chan Gu, Chengqi Yi, 1240 Chuan He, Yi Qin Gao, and Xin Sheng Zhao. 2014. "Dynamics of 1241 Spontaneous Flipping of a Mismatched Base in DNA Duplex."
1255 Proliferating Cell Nuclear Antigen-DNA Contacts on Clamp Loading 1256 and Function on DNA. J. Biol. Chem. 287, 35370-35381.

1257 Zhuang, Z., Yoder, B.L., Burgers, P.M.J., and Benkovic, S.J. (2006). 1258 The structure of a ring-opened proliferating cell nuclear antigen1259 replication factor $C$ complex revealed by fluorescence energy transfer. 1260 Proc. Natl. Acad. Sci. U. S. A. 103, 2546-2551.

1261 Zivanov, J., Nakane, T., Forsberg, B.O., Kimanius, D., Hagen, W.J., 1262 Lindahl, E., and Scheres, S.H.W. (2018). New tools for automated 1263 high-resolution cryo-EM structure determination in RELION-3. Elife 7. 
$5 \quad$ Superose 6 elution

$\underline{12} 13141516171819202122 \quad 23$ Fraction

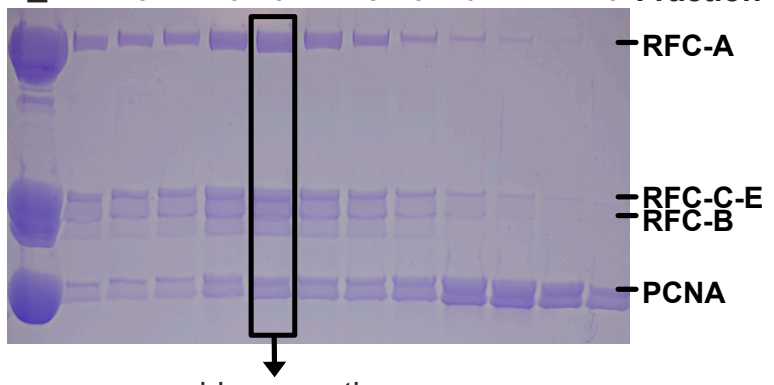

grid preparation

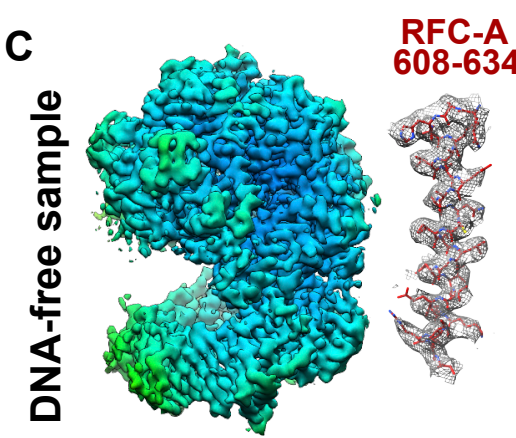

Autoinhibited1
RFC-A

608-634

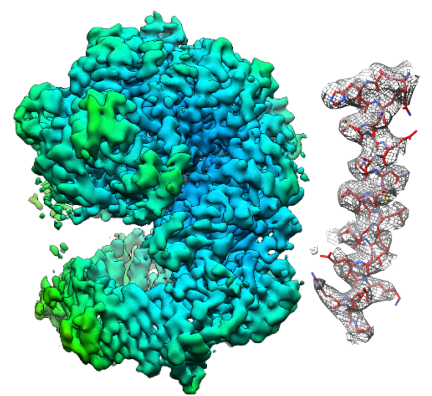

Autoinhibited2

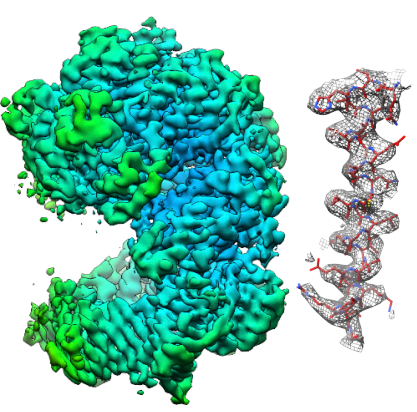

Autoinhibited3

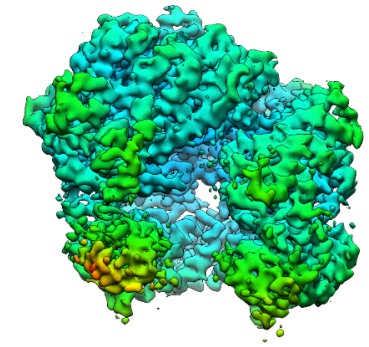

Open1

心
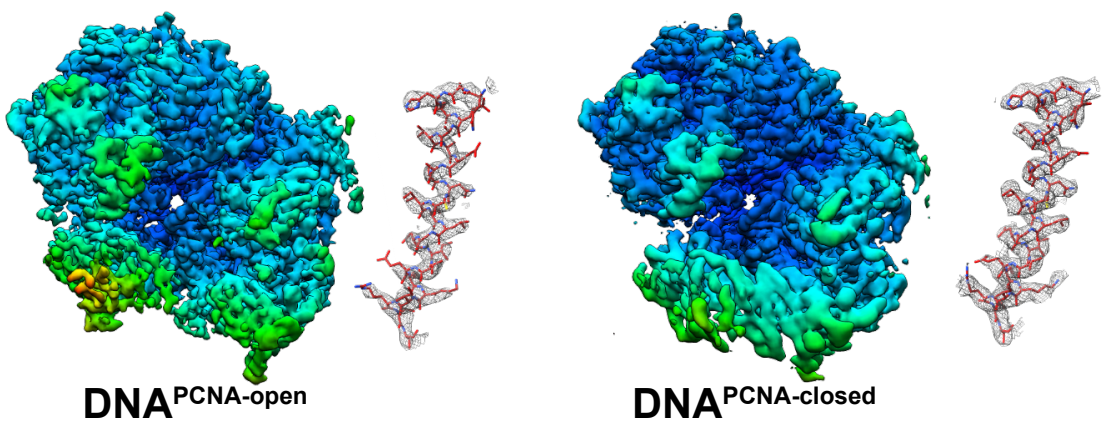

3.0

3.5

4.0
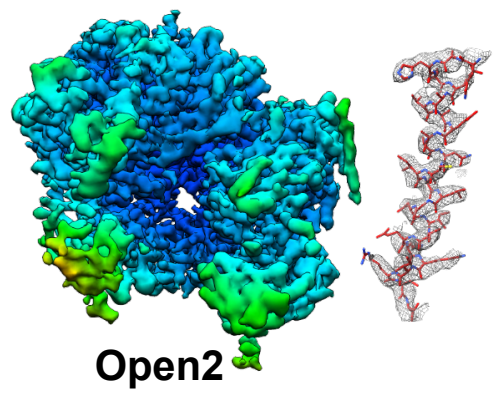

DNA

4.5

5.0

5.5

6.0

6.5

7.0

7.5
D

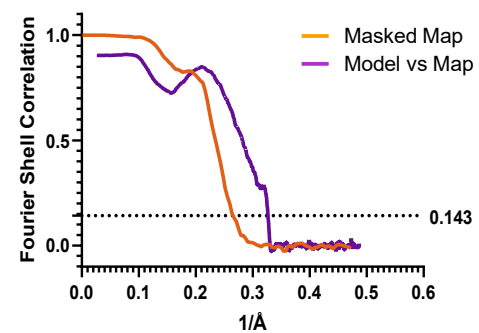

Autoinhibited2

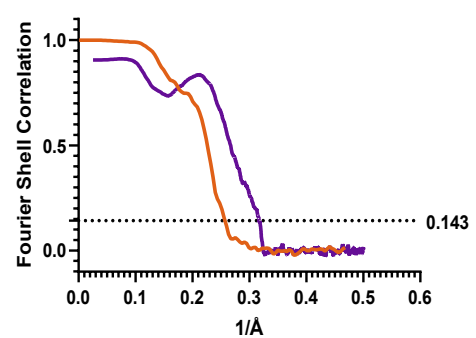

Autoinhibited3

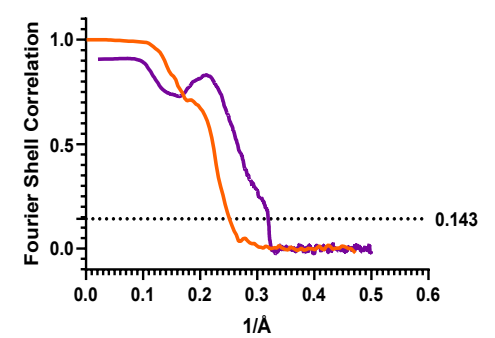

Open1

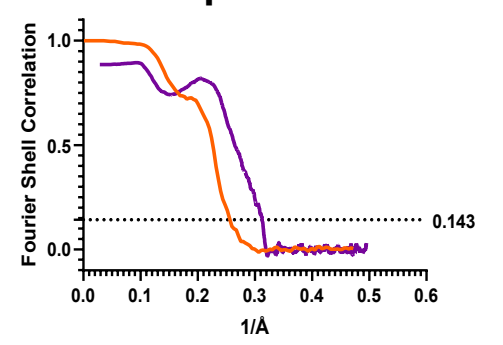

Open2

DNA PCNA-open

DNAPCNA-closed
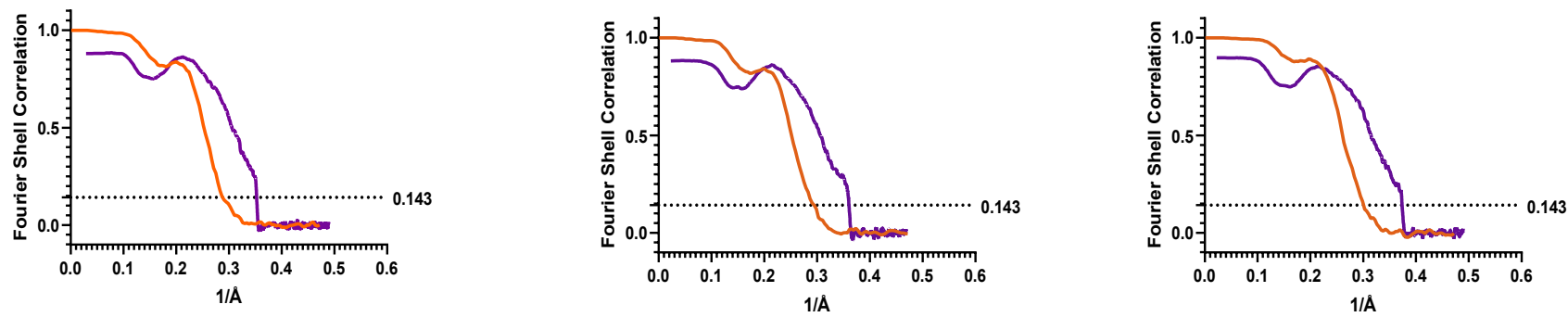

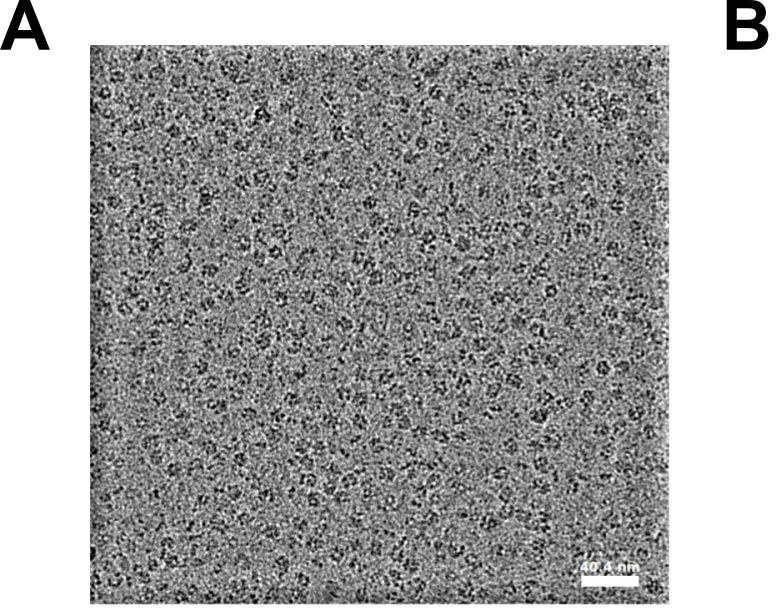

\section{D class averages}

6109 micrographs

$\downarrow$ picking

954291 particles

$\downarrow$

2D classification

834099 particles
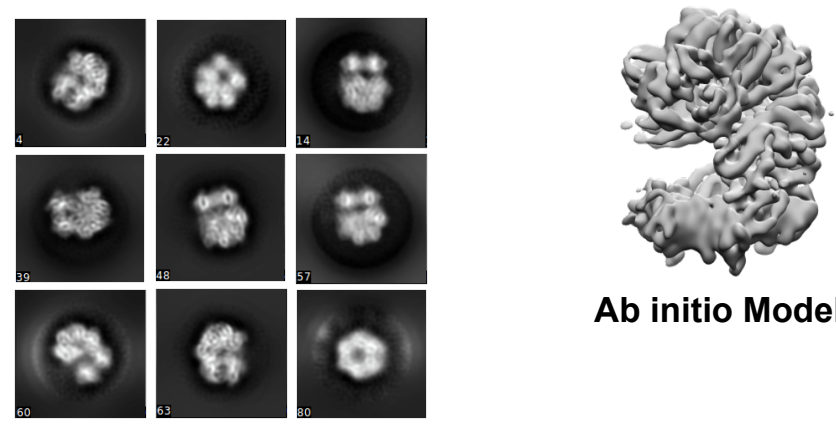

Ab initio Model

3D classification

834099 particles, $4.24 \AA /$ pixel
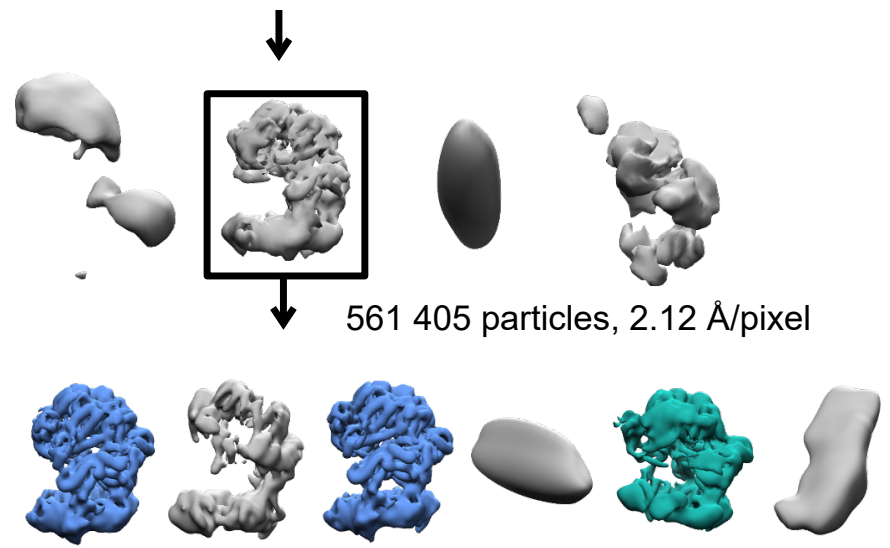

336272 particles, $1.06 \AA$ Apixel $\downarrow$

$\downarrow 123200$ particles, $1.06 \AA$ Åpixel
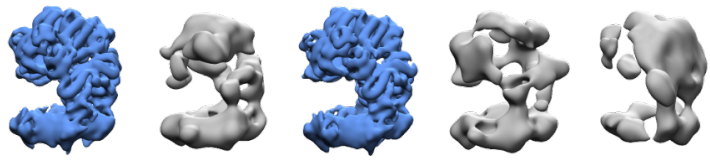

$\downarrow 297797$ particles
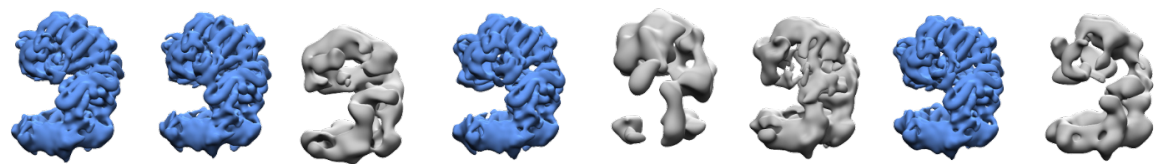

local angular search $\downarrow 241793$ particles
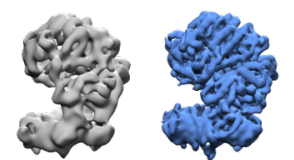

$\downarrow$

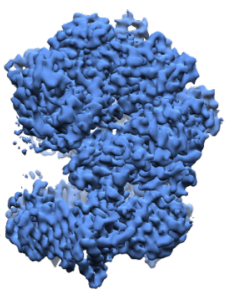

Autoinhibited2

68227 particles

$3.9 \AA$
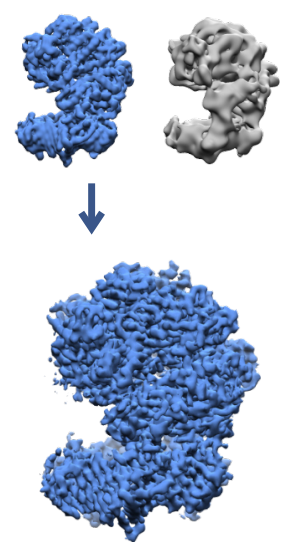

Autoinhibited1

55308 particles

$3.8 \AA$
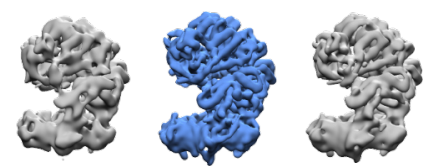

refinement

map sharpening

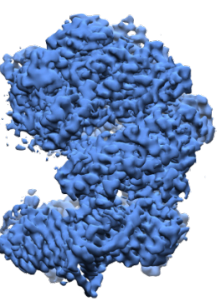

Autoinhibited3

60036 particles $4.0 \AA$
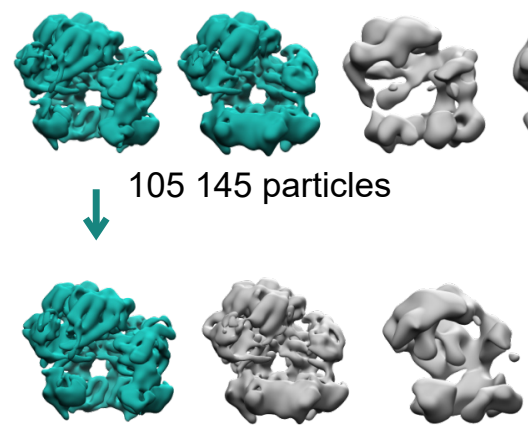

refinement $\checkmark$ map sharpening

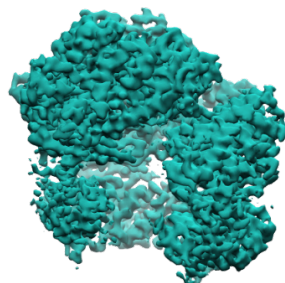

Open1

46069 particles

$4.0 \AA$ 


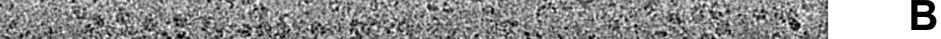

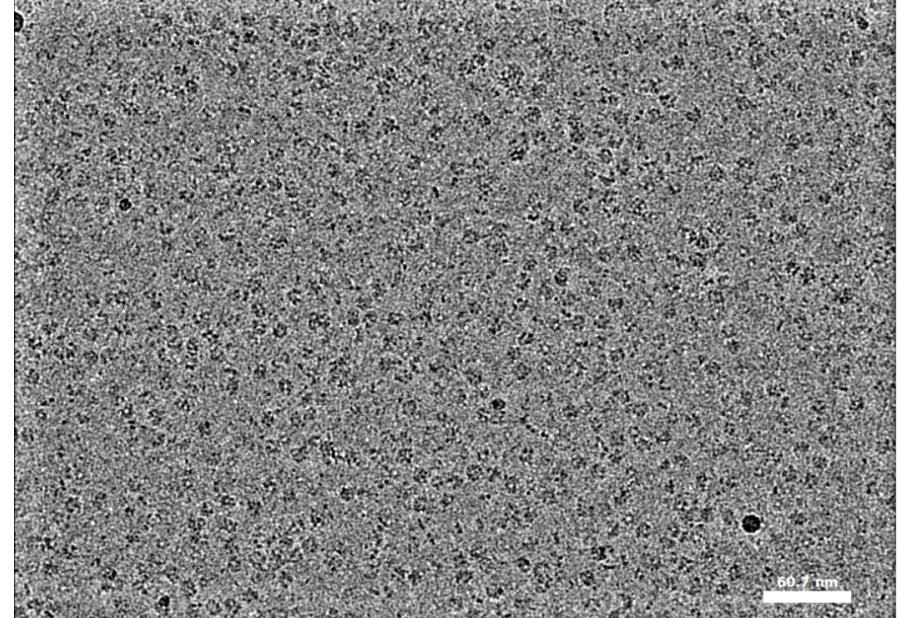

4499 micrographs automatic
picking

1331440 particles

$\downarrow$

2D classification

851158 particles

3D classification

C

843621 particles, $4.24 \AA /$ pixel
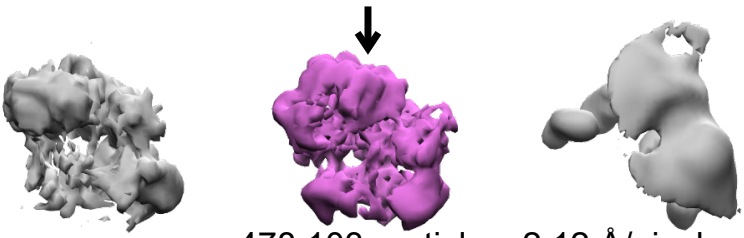

478103 particles, $2.12 \AA /$ pixel
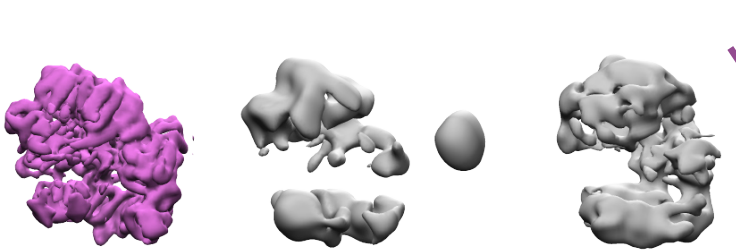

$\checkmark$

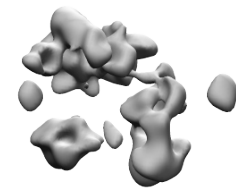

$\downarrow$

288196 particles, $1.06 \AA \AA$ /pixel
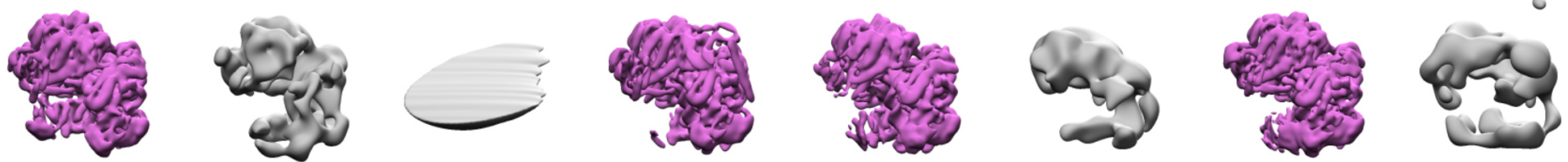

refinement of 272010 particles,

$\downarrow$ classification without alignment

$\downarrow$ (20 A resolution limit)
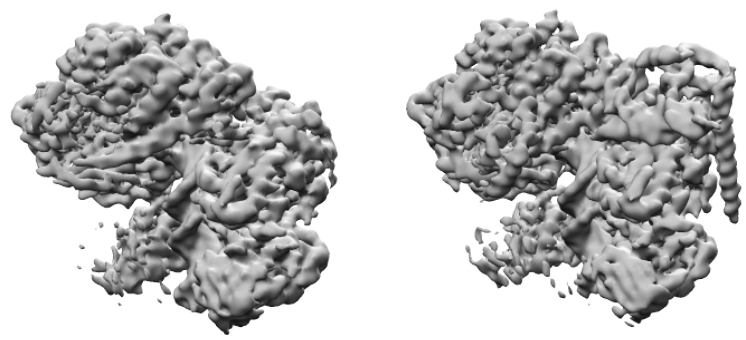
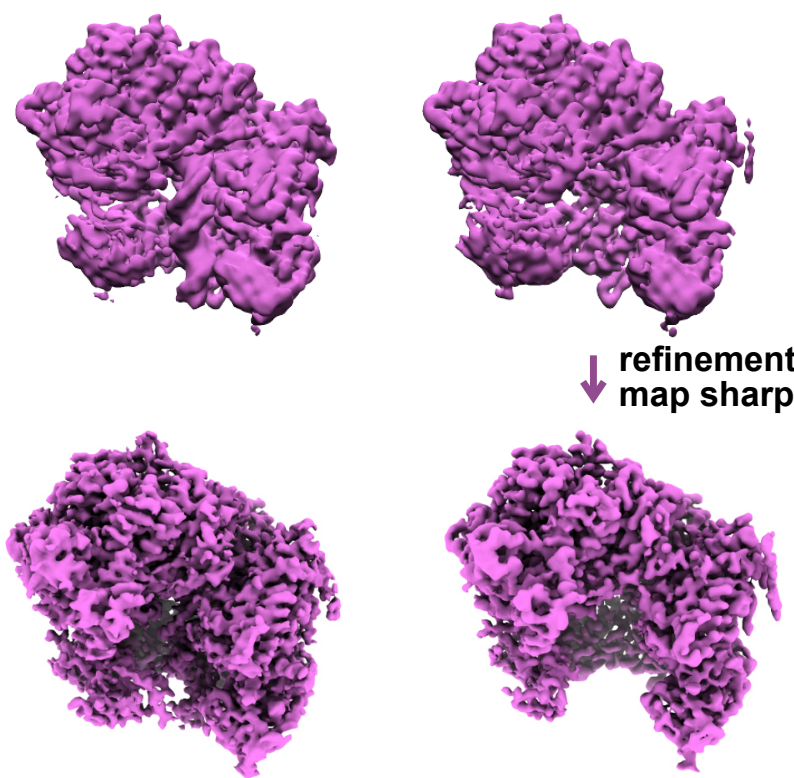

Open2

DNA ${ }^{\text {PCNA-open }}$

46300 particles

$3.4 \AA$
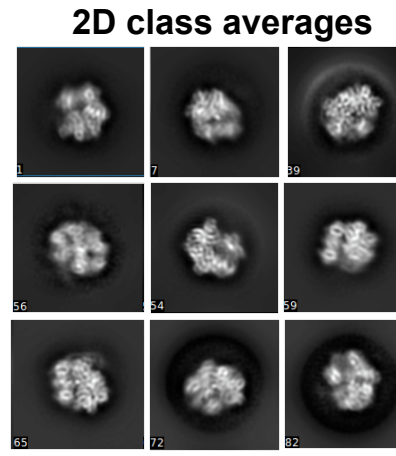

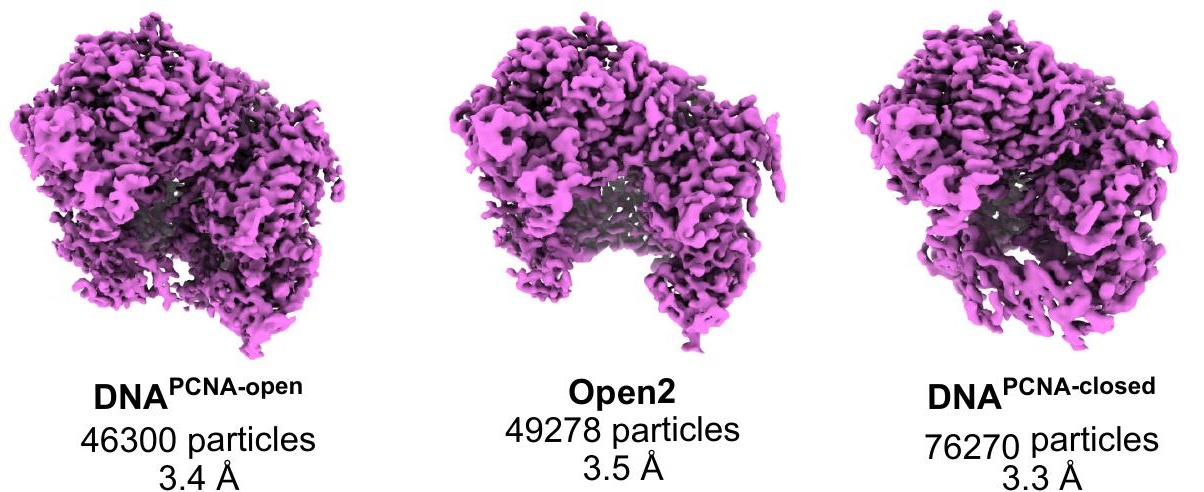



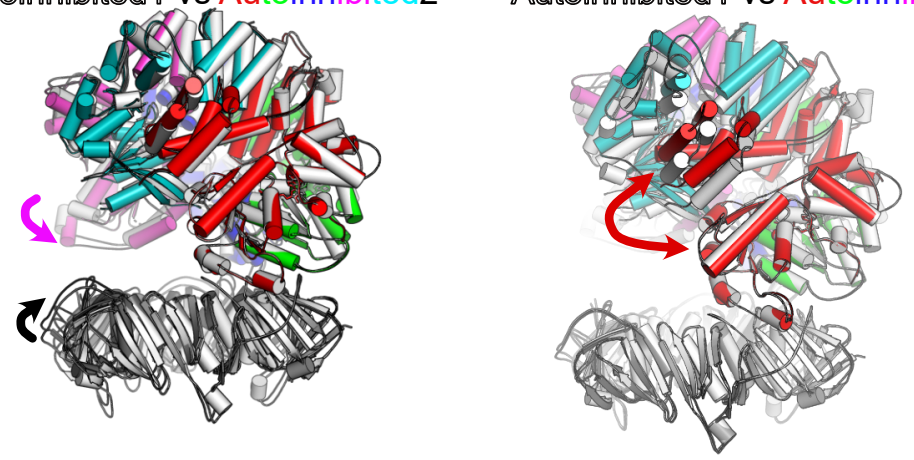

C

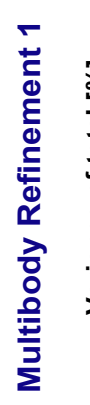

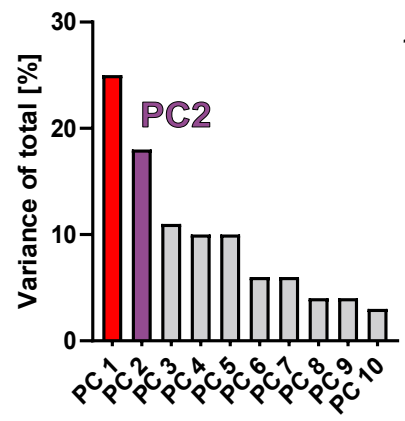

D

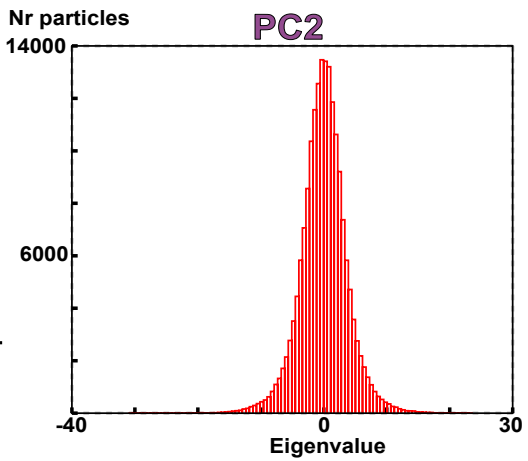

E

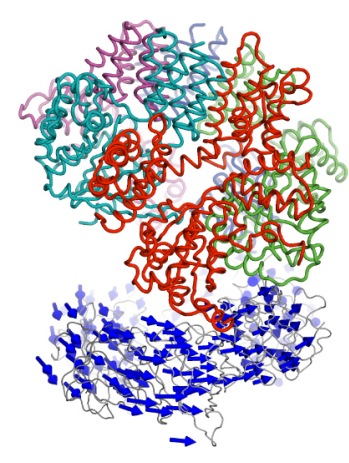

PC2
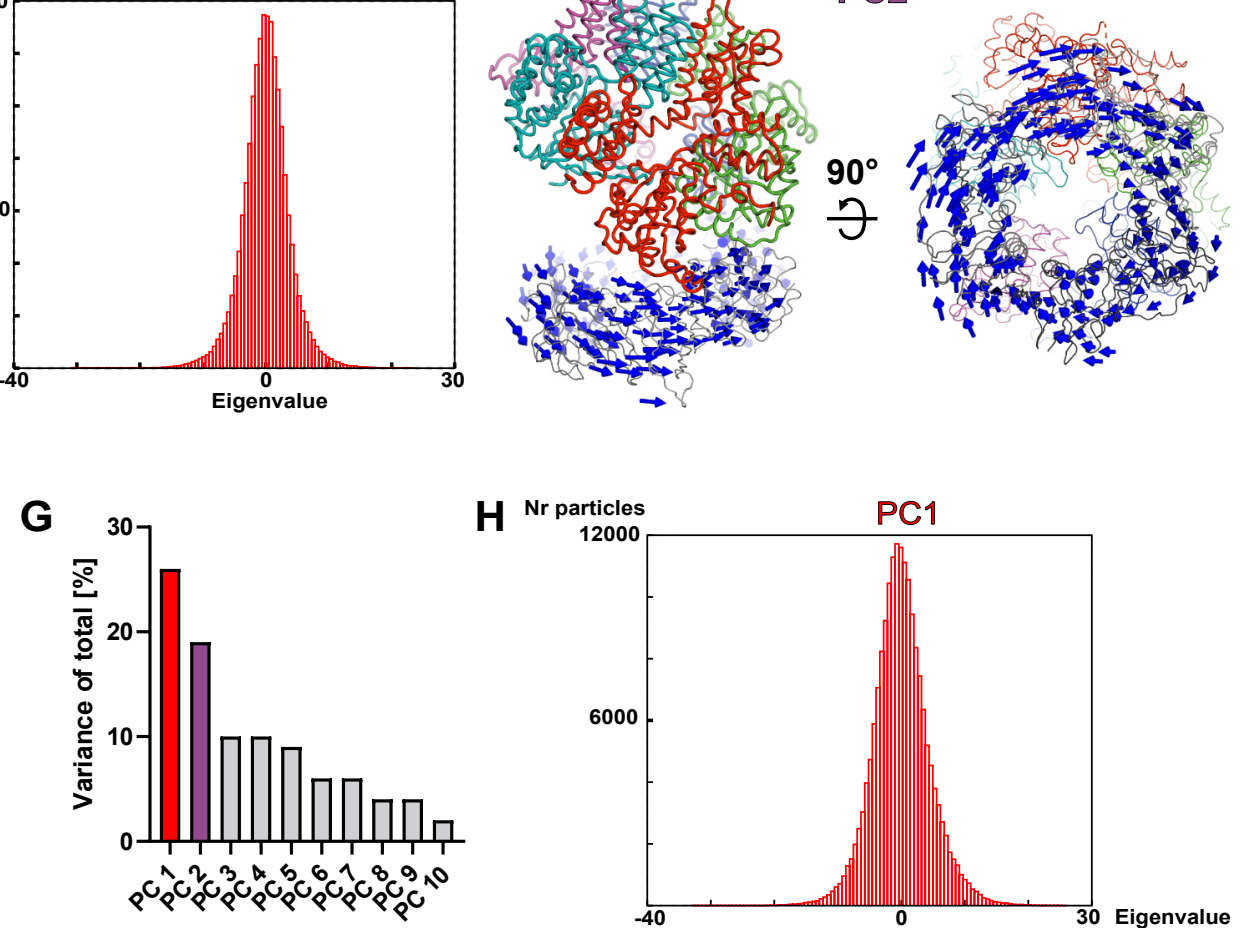
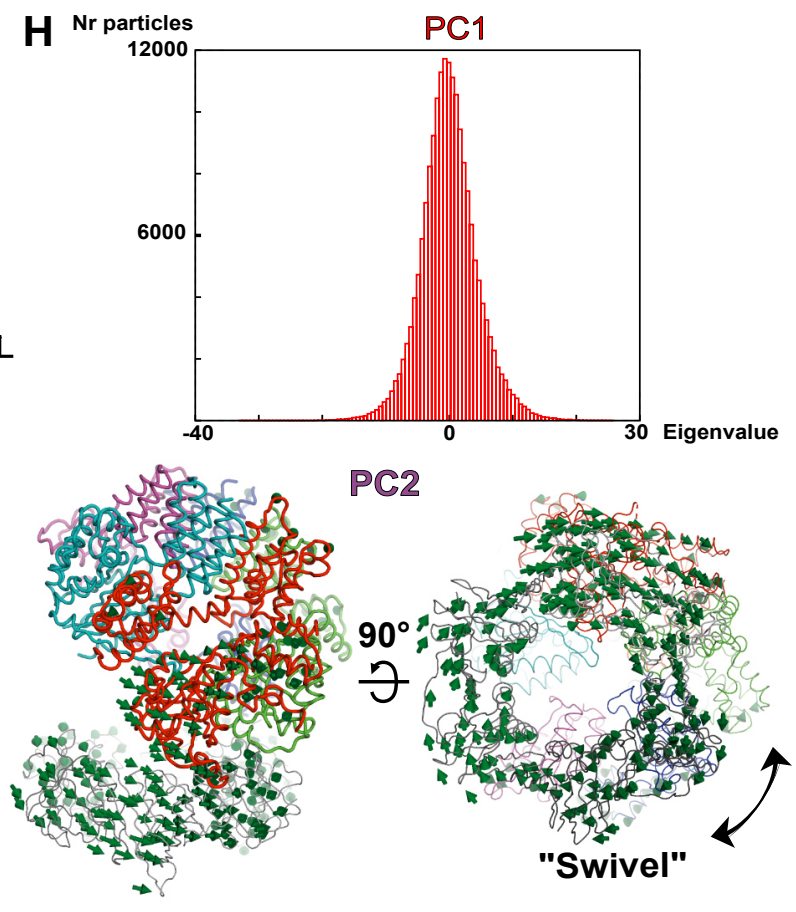

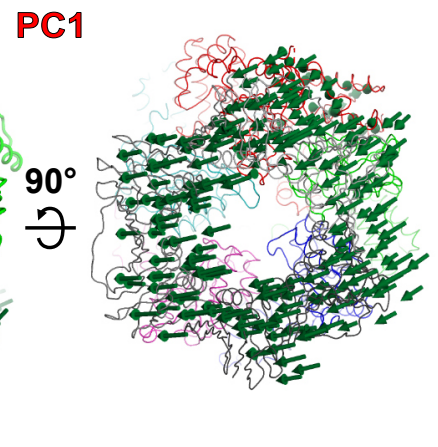


A $\quad$ Open1

from the dataset without DNA
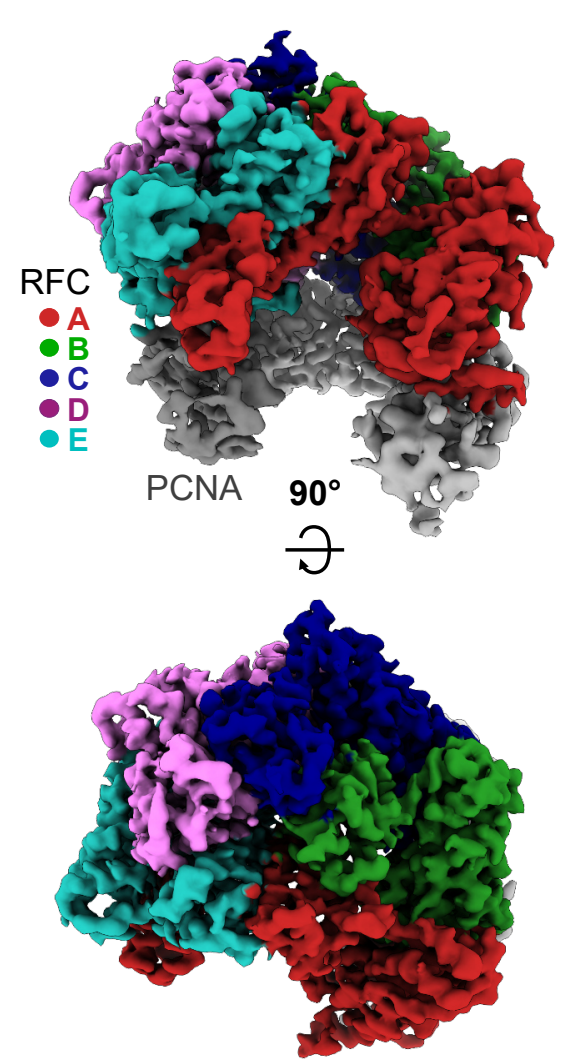

B Open2

C

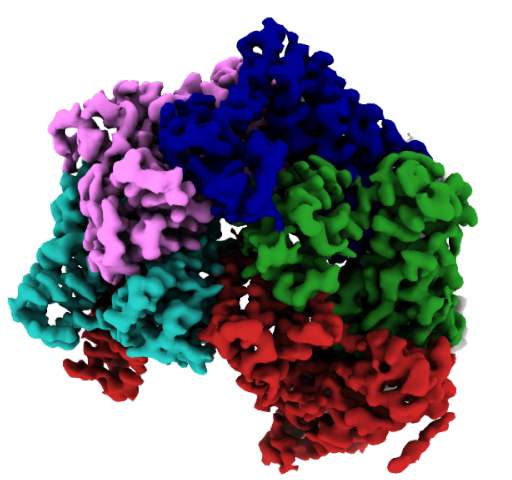

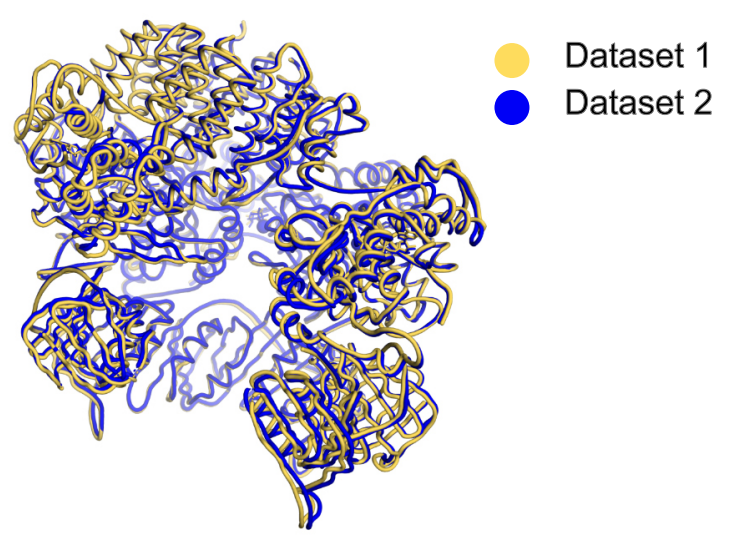

RFC:PCNA ${ }^{\text {open }}$ from dataset 2

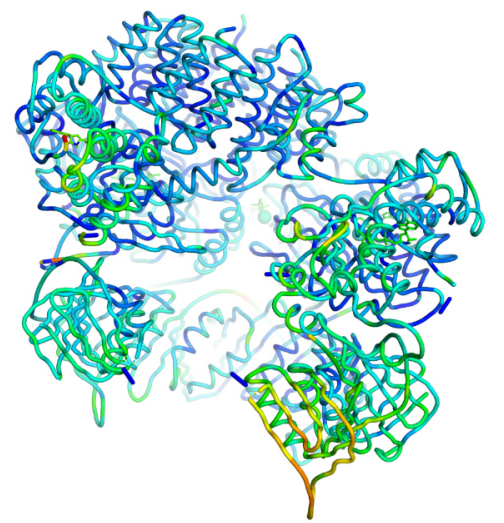

$0.00 \AA$

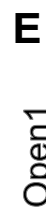

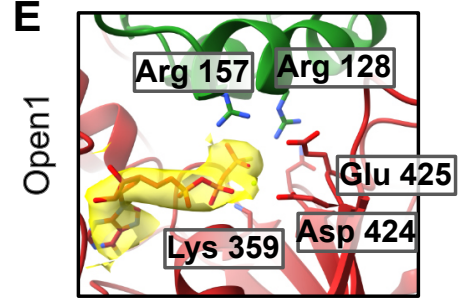

N
ঠั
O̊

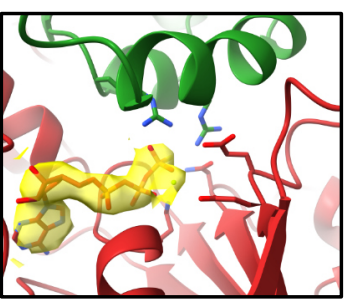

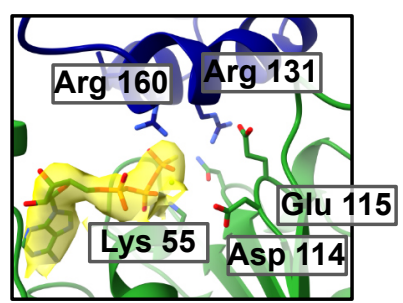

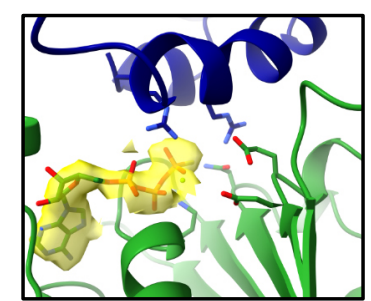

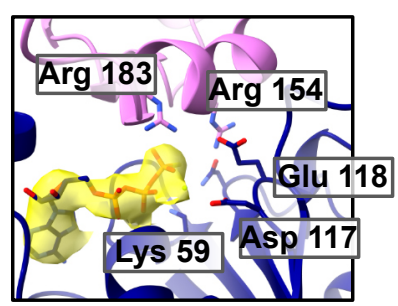

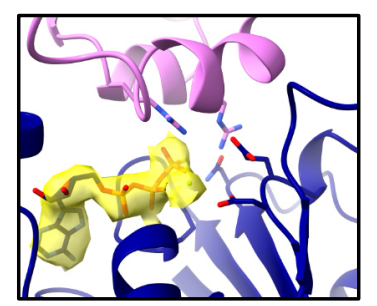

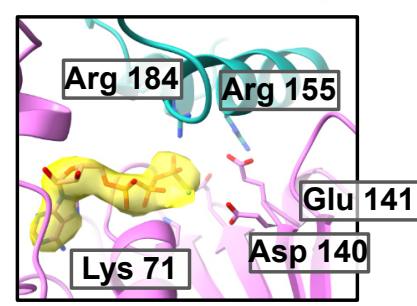
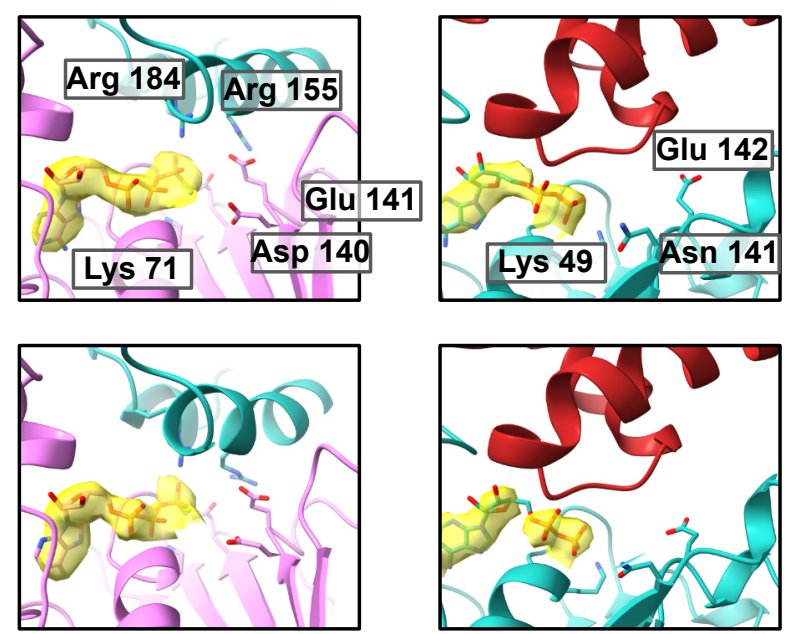

$\mathbf{F}$

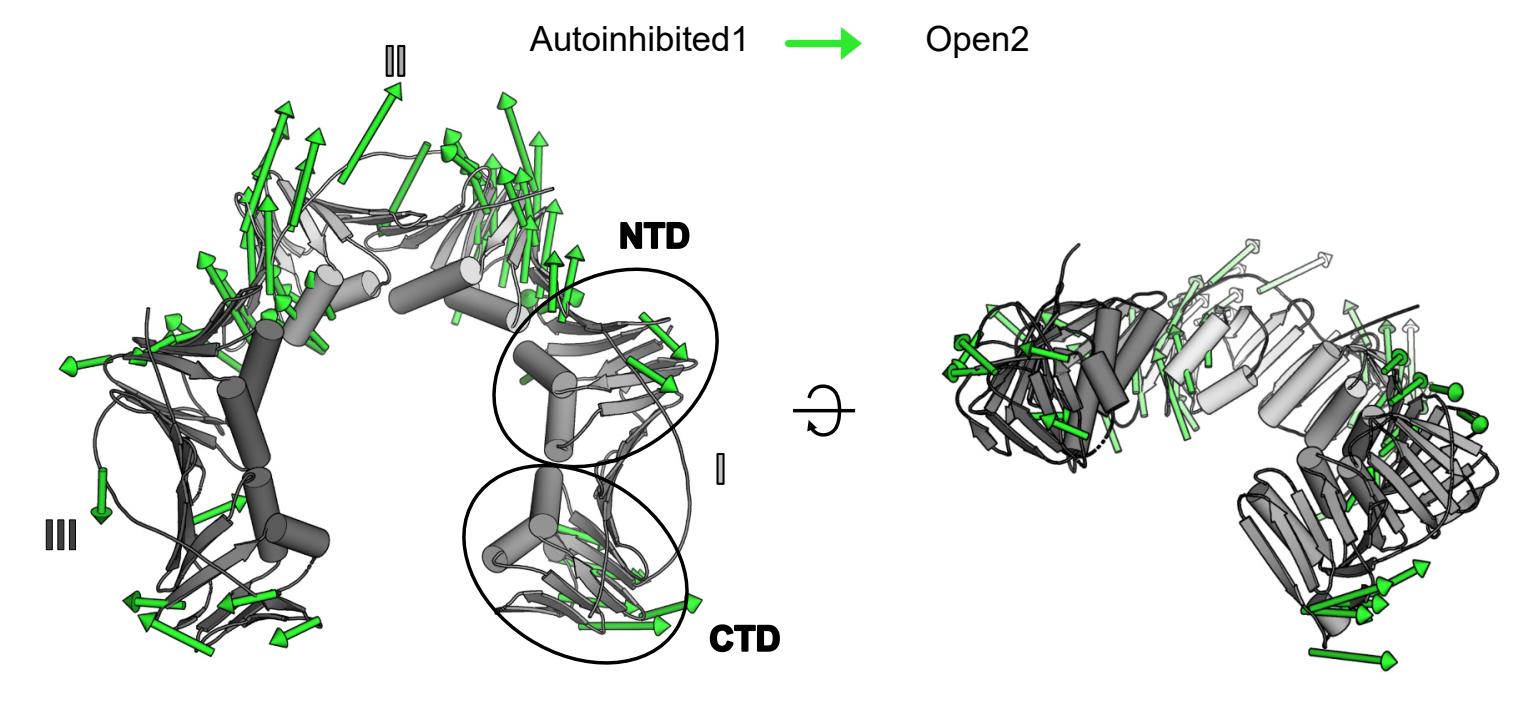

$3.23 \AA$

(Ca)

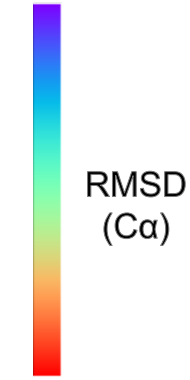


A

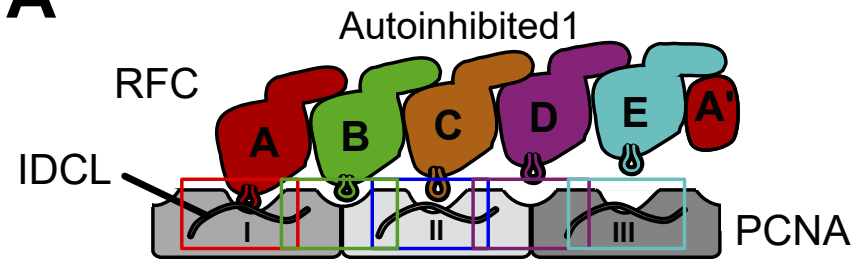

C
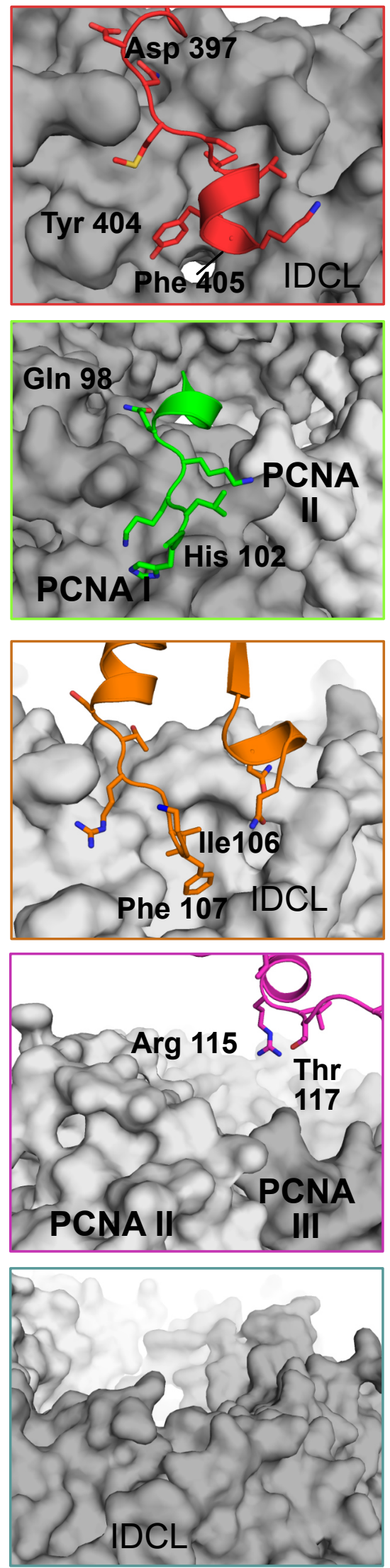

B

Open 2

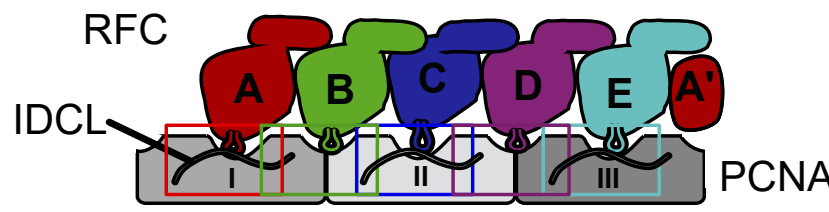

D

RFC-A PIP motif

RFC-A 397 DNMSVVGYF 405

Consensus $\times Q \times x \Psi \times x \Omega \Omega$

$\Psi=\mathrm{M}, \mathrm{I}, \mathrm{L}, \mathrm{V}$

$\Omega=F, Y$
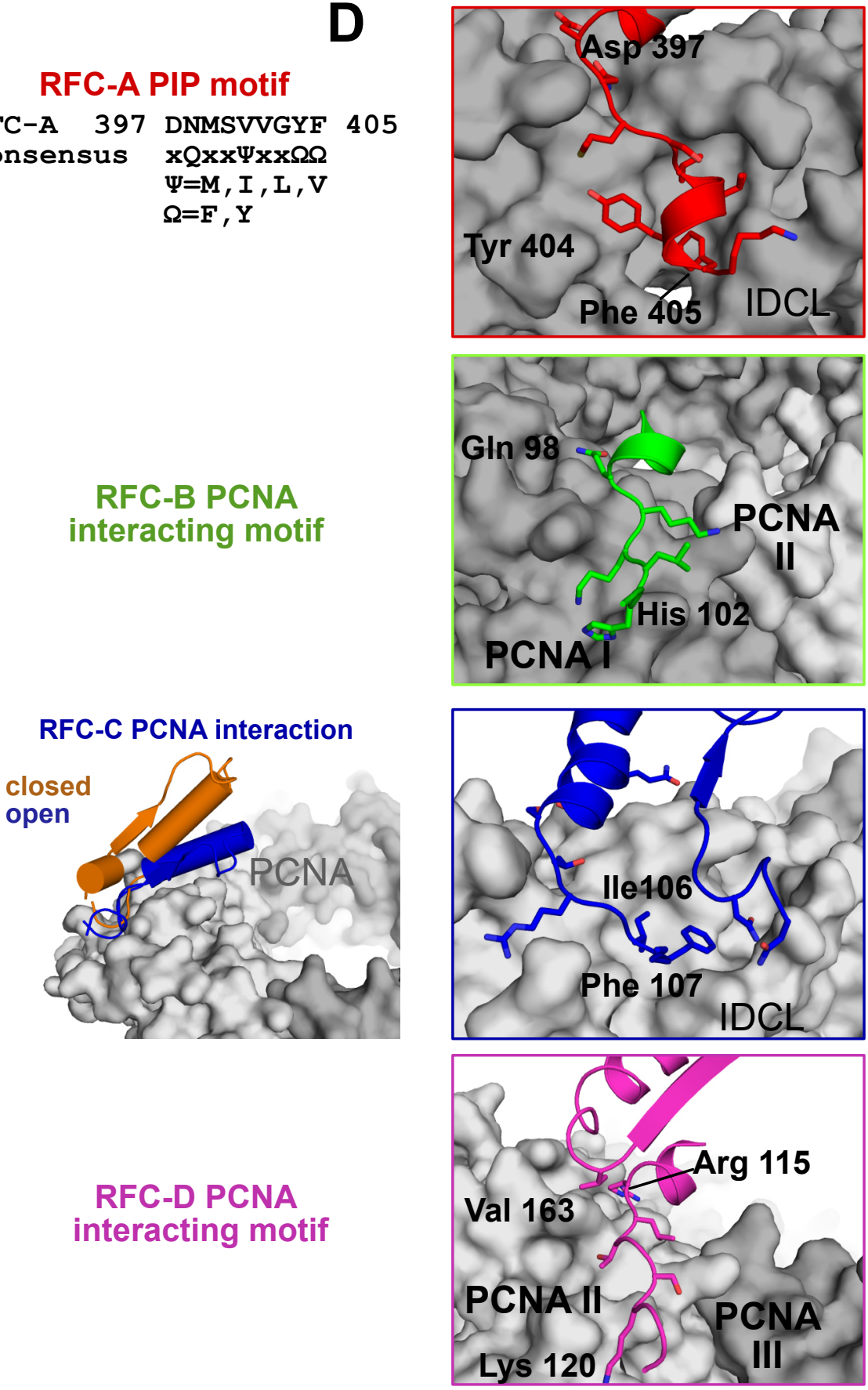

RFC-D PCNA

interacting motif

RFC-E PCNA interacting motif

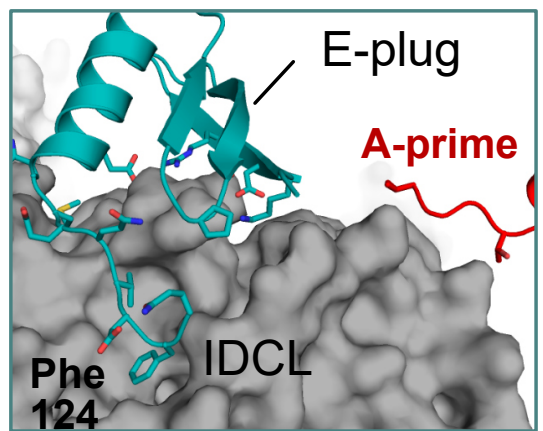




\section{A}
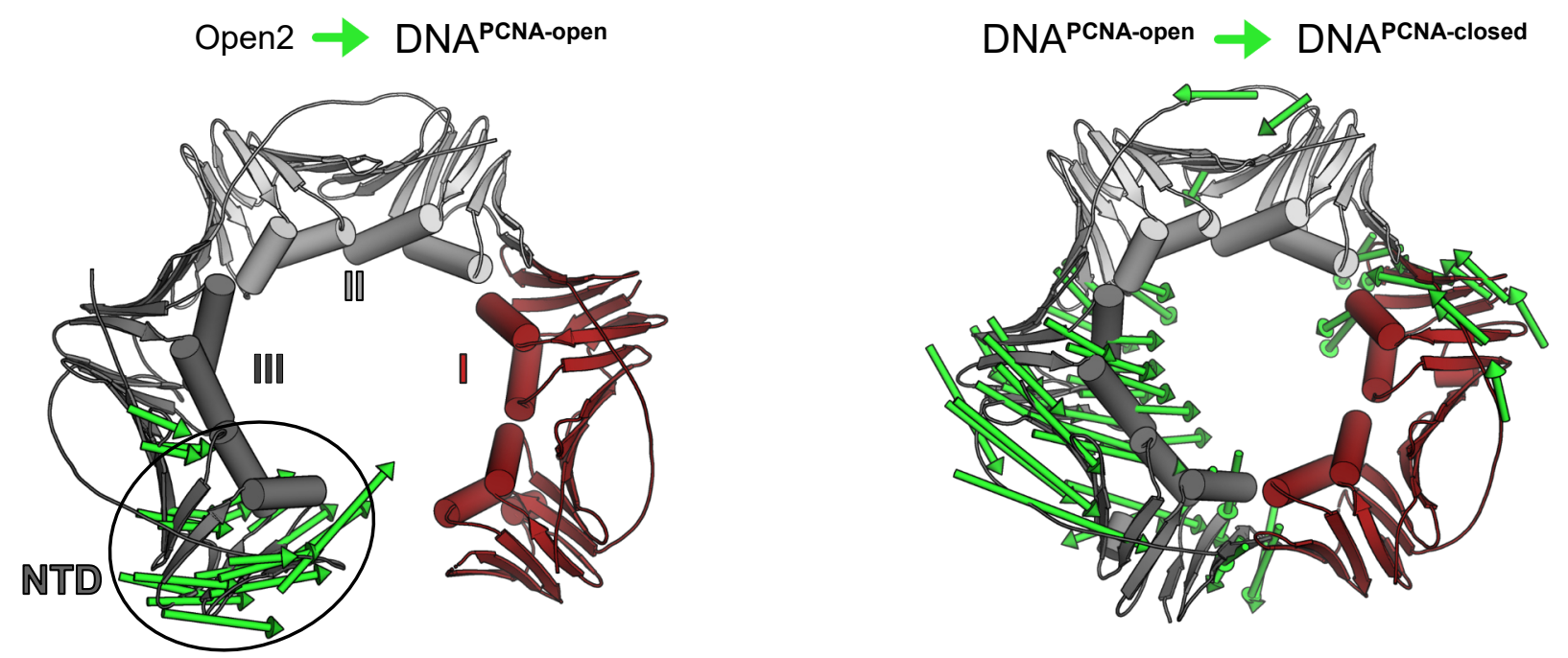

B

rotation
$A / B$
$B / C$
$C / D$
$D / E$

O B/C - C/D: $1.5^{\circ}$

त C/D - D/E: $5.6^{\circ}$

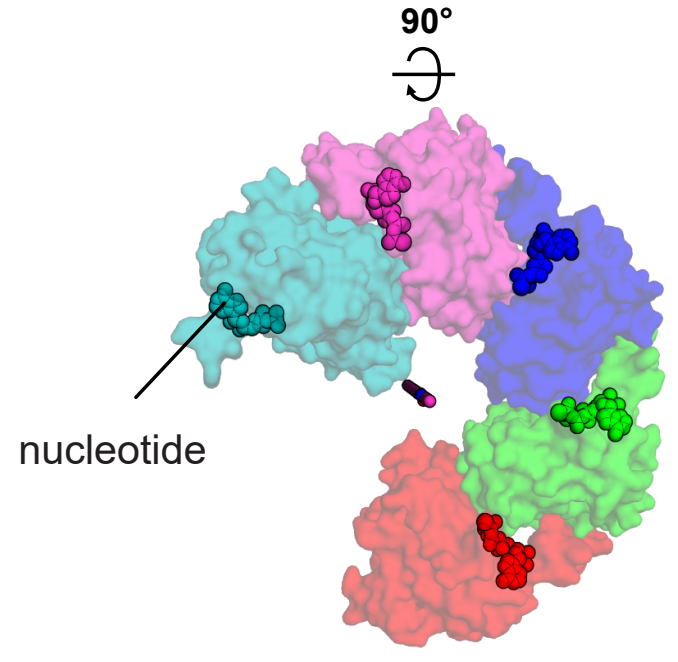

C Nucleotide

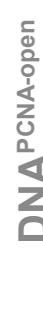

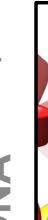

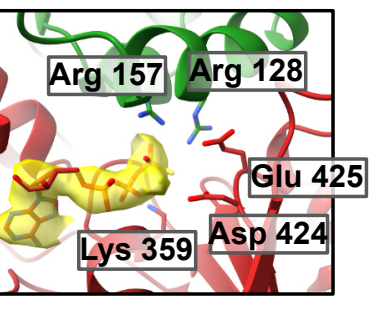

\& A/B - B/C: $2.1^{\circ}$
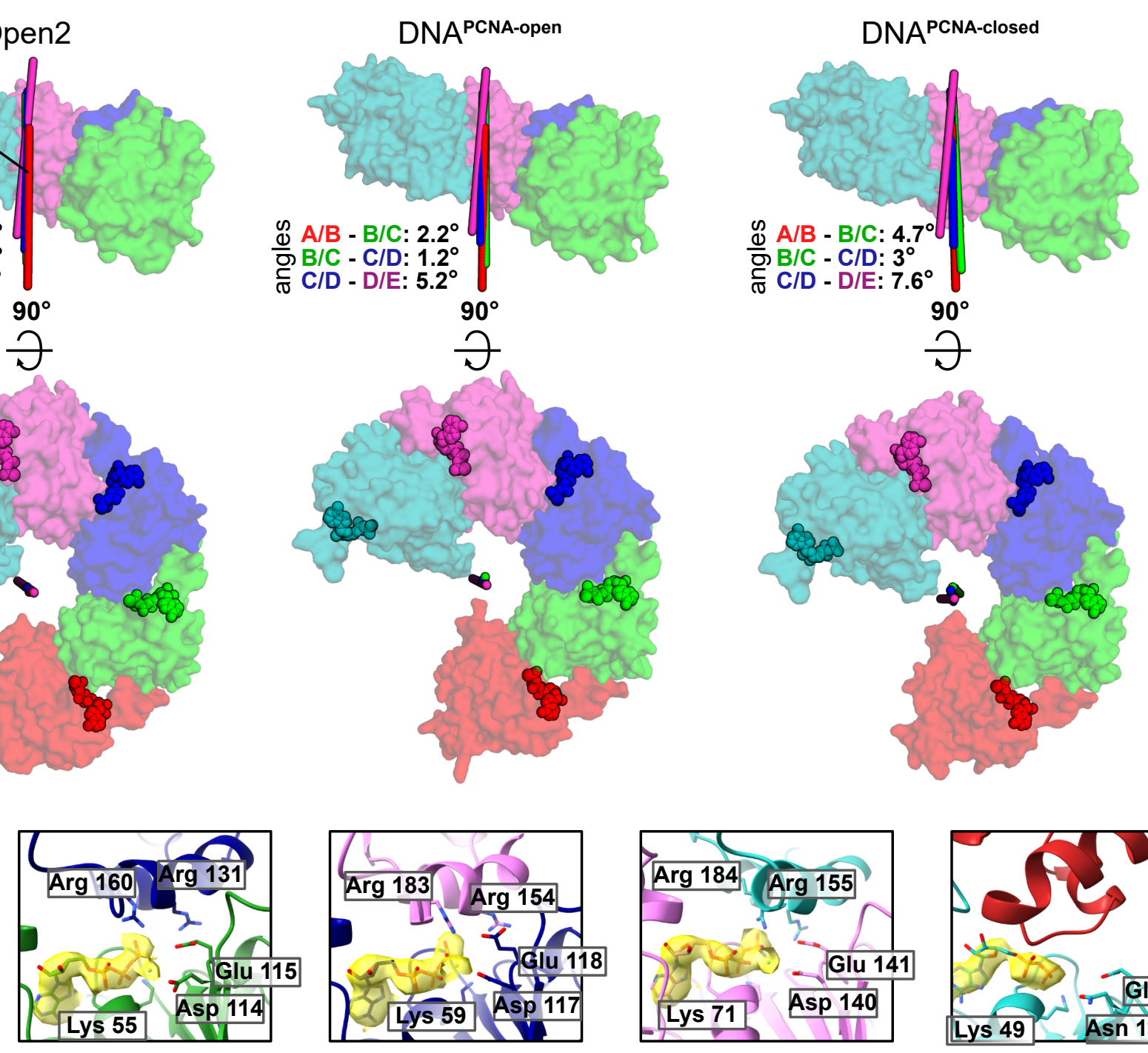
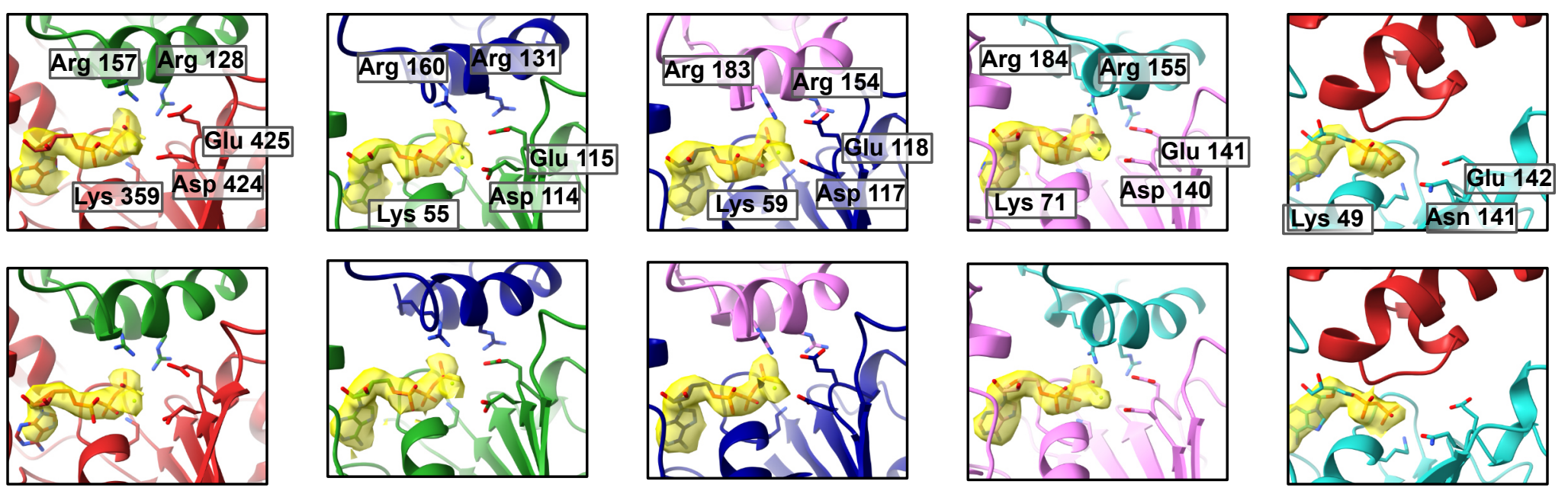
RFC

A

$B$

- C

D

E

A Closed1 (color) to Open2
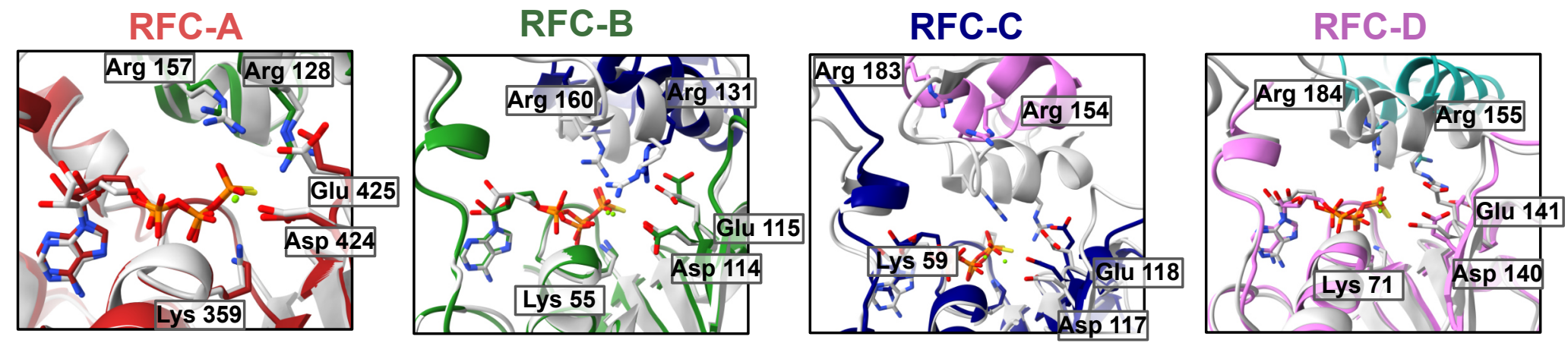

B Open2 (color) to DNA ${ }^{\text {PCNA-open }}$
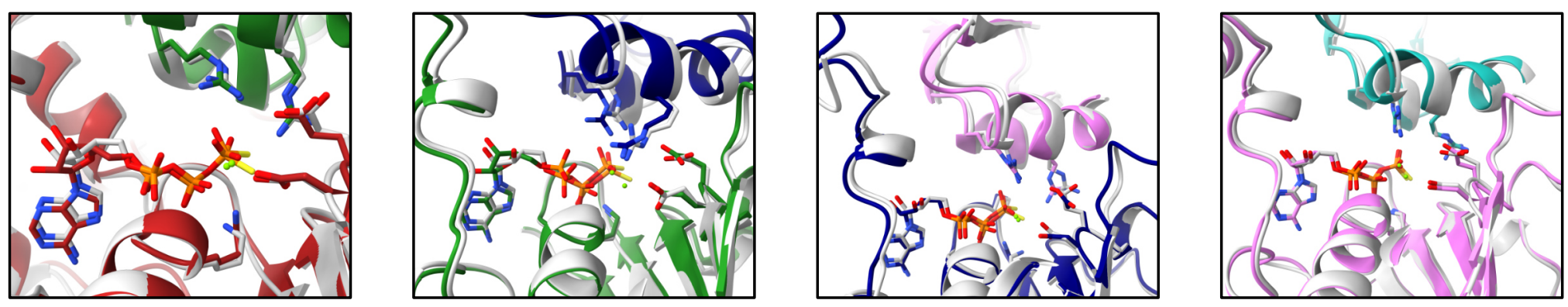

C DNA ${ }^{\text {PCNA-open }}$ (color) to DNA ${ }^{\text {PCNA-closed }}$
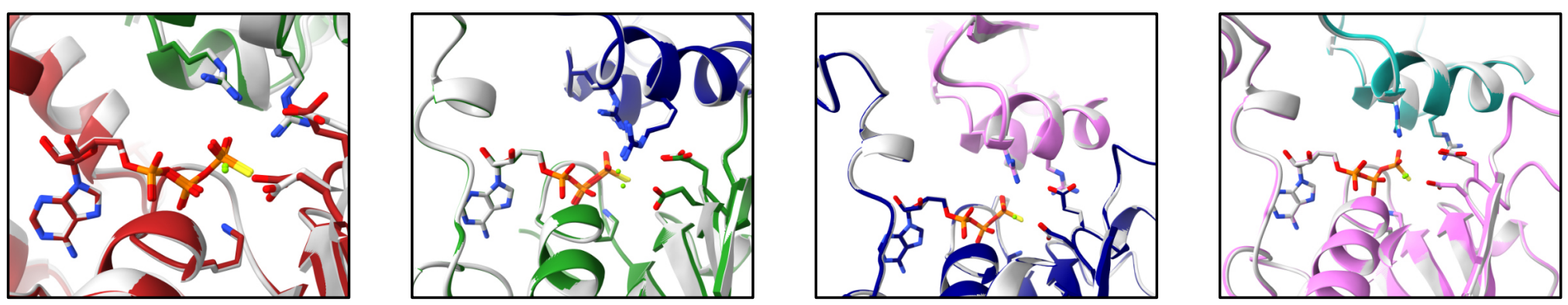
A

B

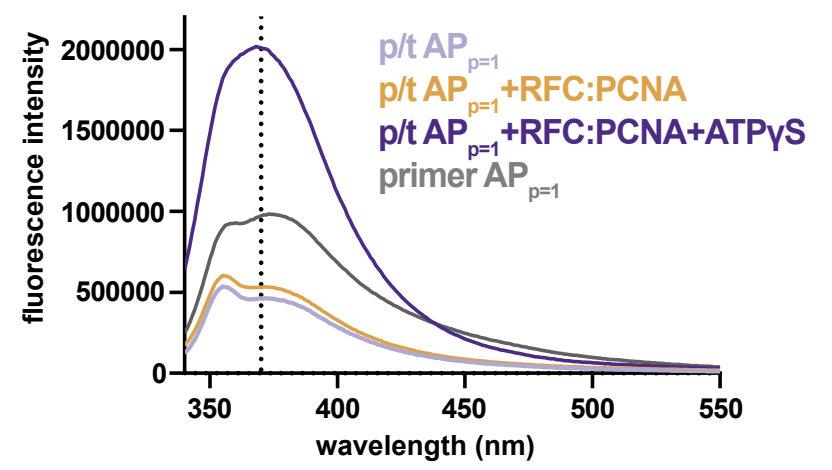

C

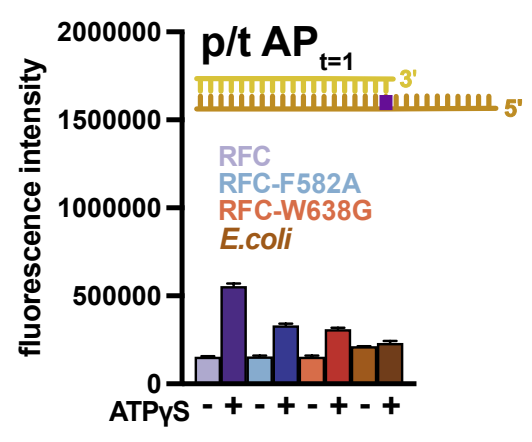

E
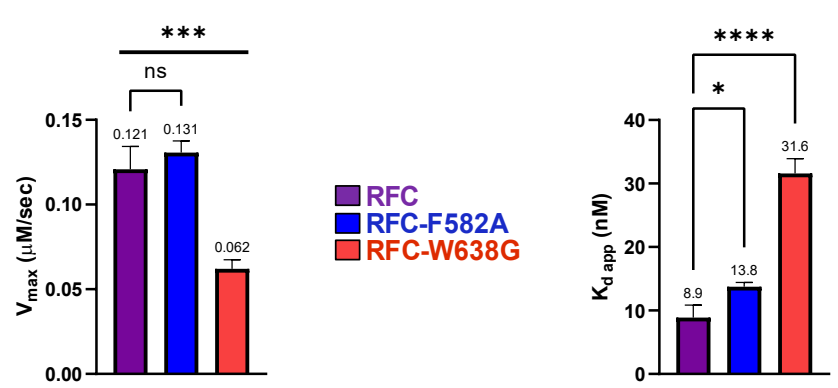

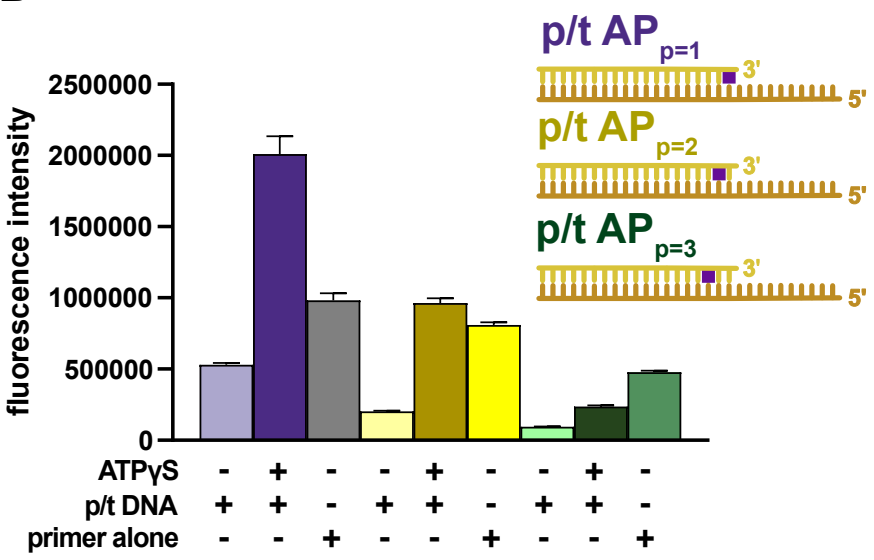

D

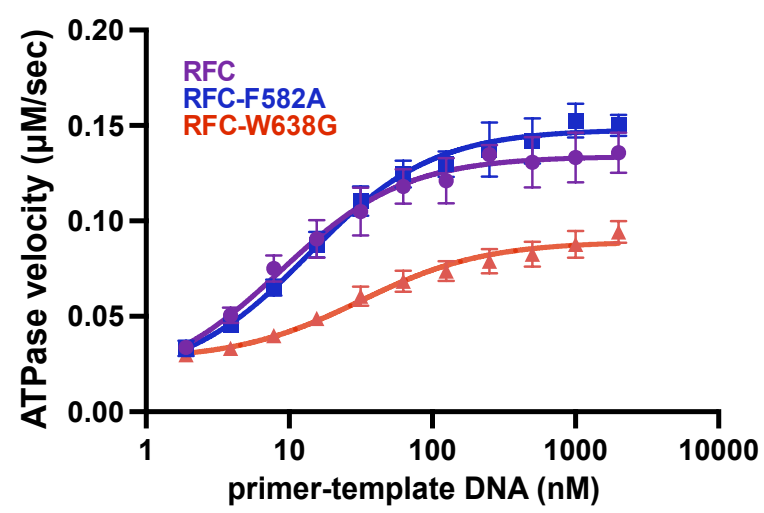

$p / t P_{p=1}$

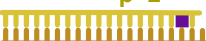
$p / t P_{p=3}$ p/t AP

\begin{tabular}{|l|l|l|}
\hline & $\mathrm{V}_{\max }(\mu \mathrm{M} / \mathrm{s})$ & $\mathrm{K}_{\mathrm{d} \text { app }}(\mathrm{nM})$ \\
\hline WT & $0.121 \pm 0.014$ & $8.9 \pm 2.0$ \\
\hline F582A & $0.131 \pm 0.007$ & $13.8 \pm 0.7$ \\
\hline W638G & $0.062 \pm 0.005$ & $31.6 \pm 2.4$ \\
\hline
\end{tabular}



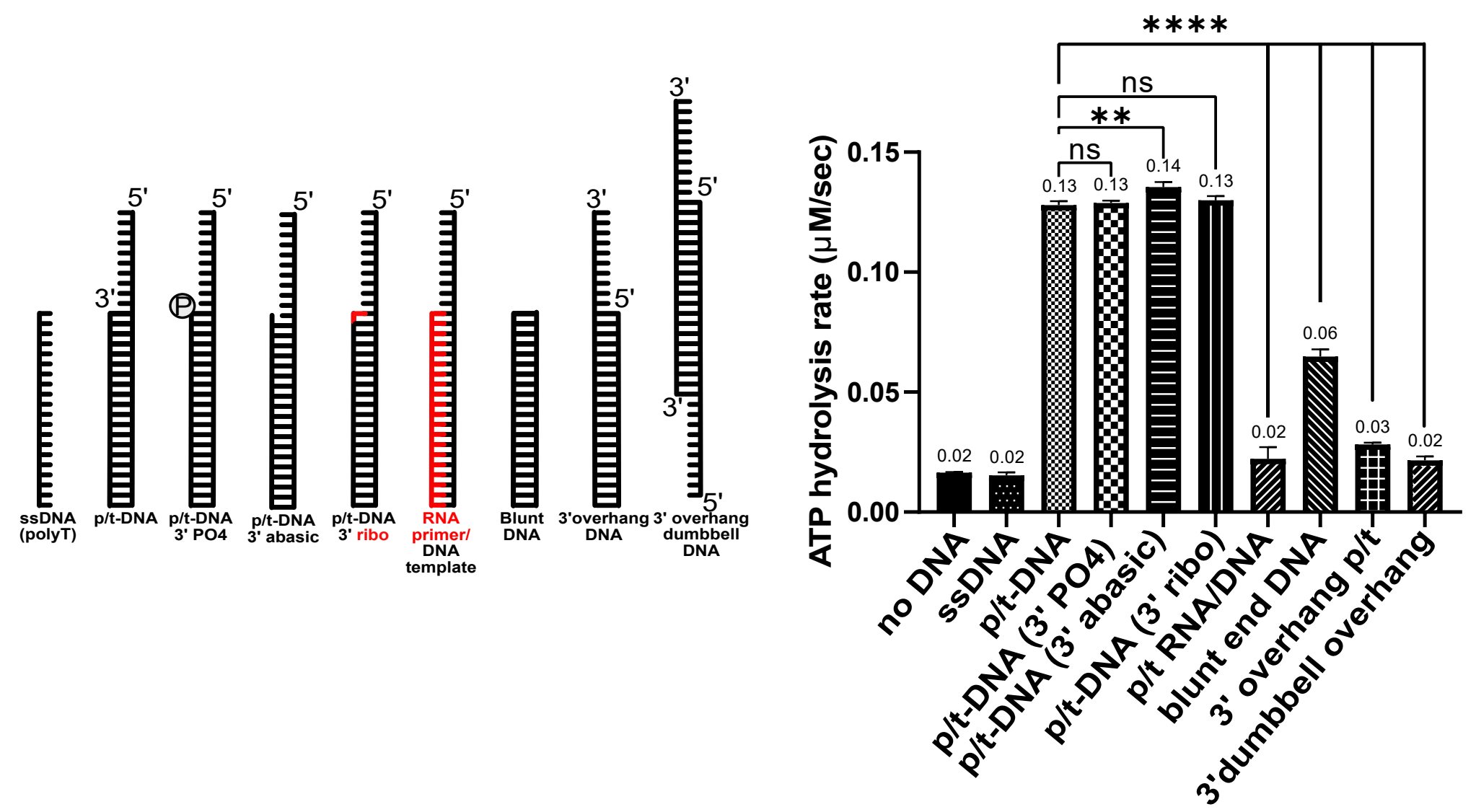

C

\section{$\mathrm{F} 582 \mathrm{~A}$}
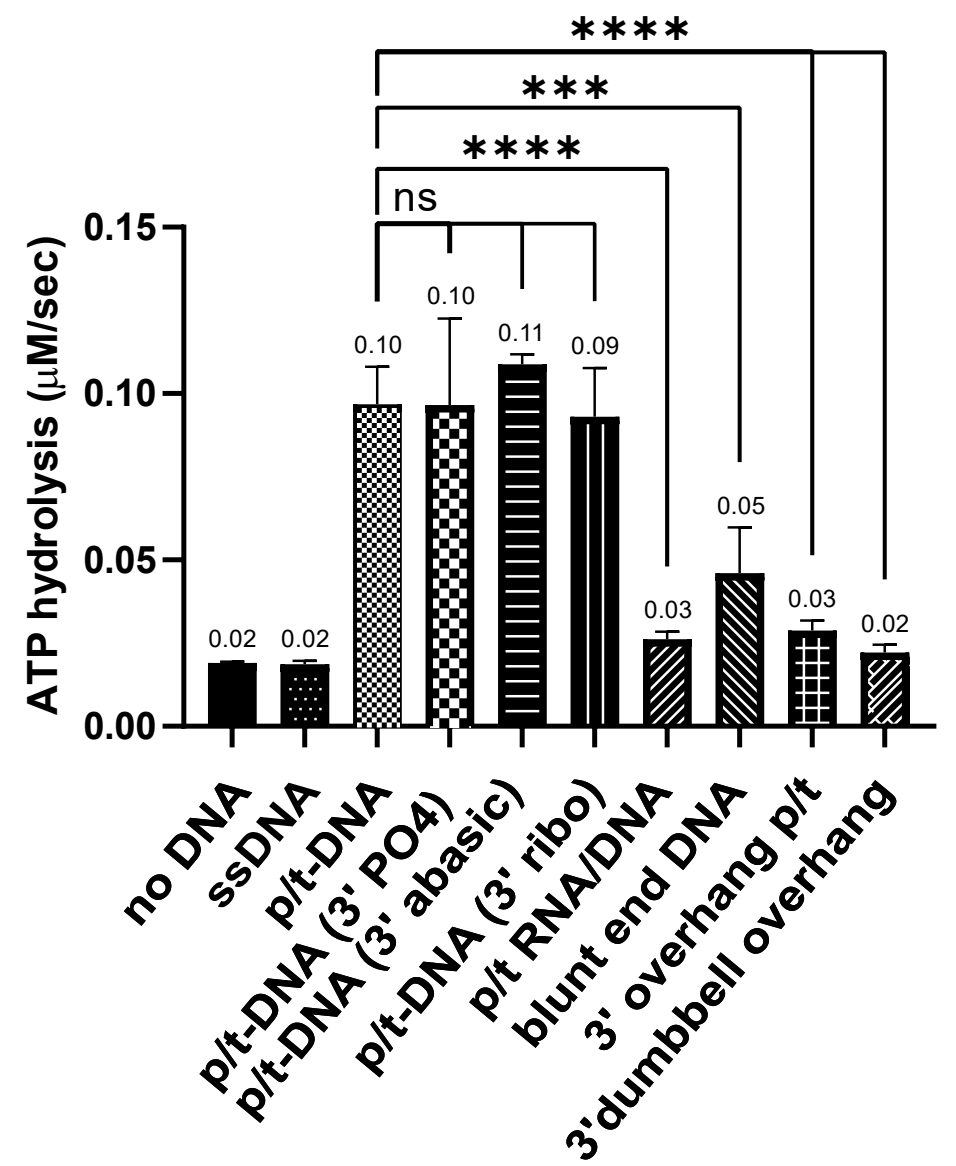

\section{W638G}

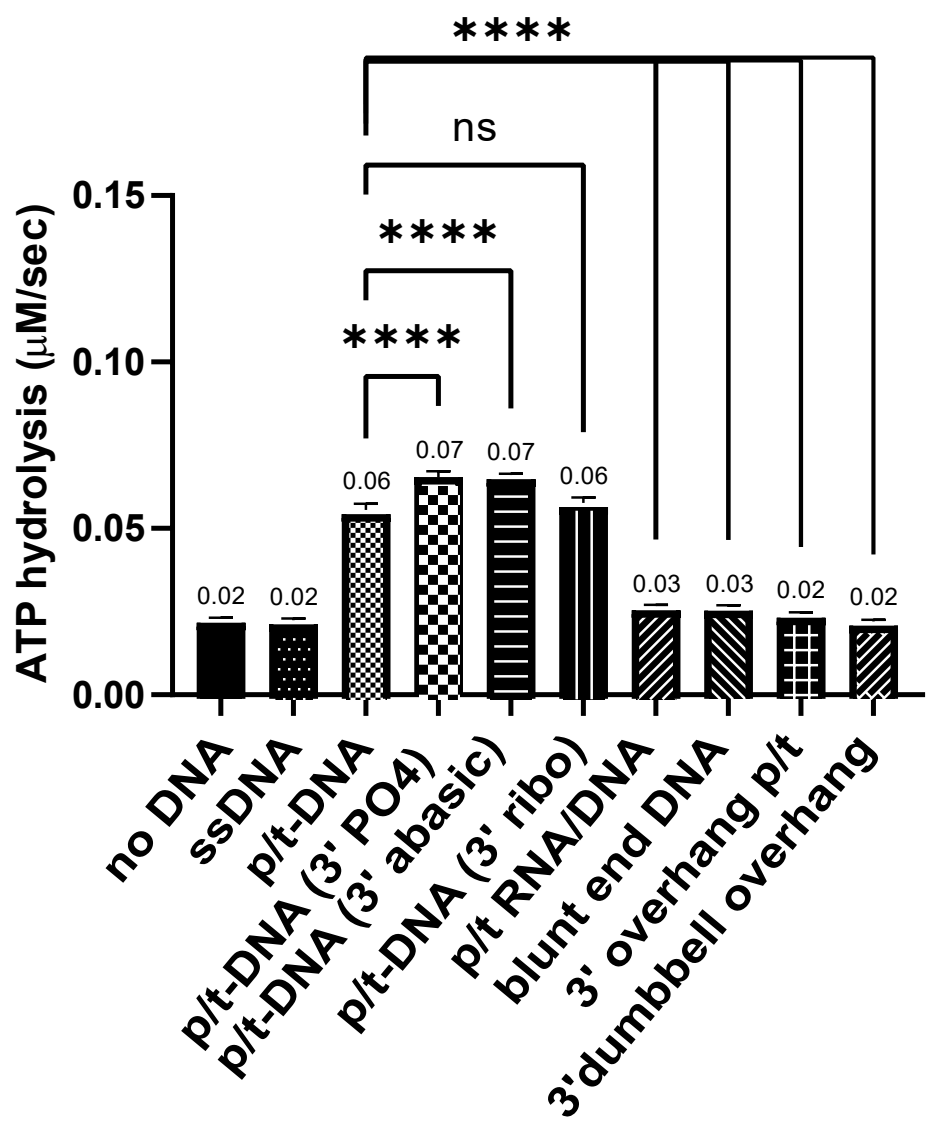


A

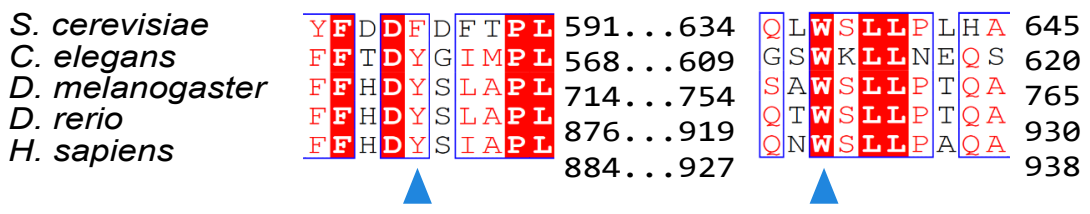

B

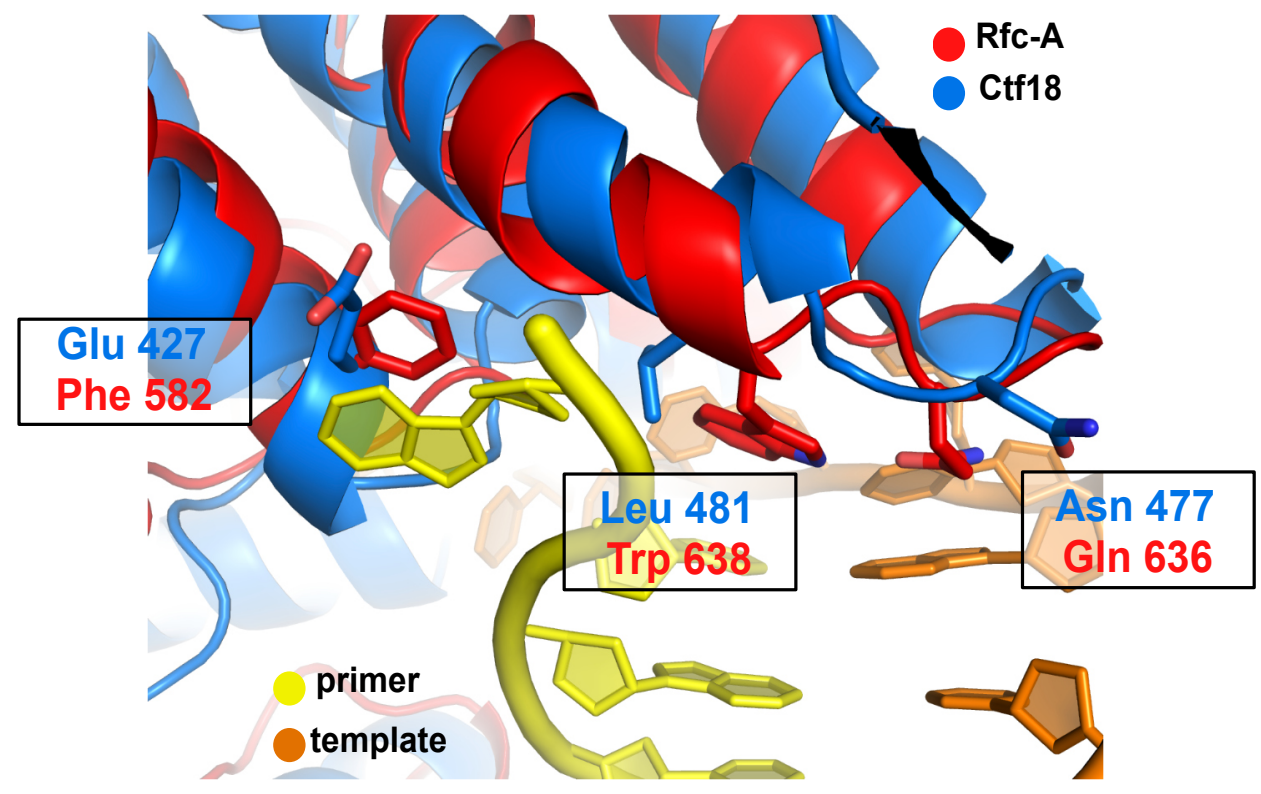

